\title{
Discrimination Against the Unhealthy in Health Insurance
}

\author{
Mary Crossley*
}

\section{INTRODUCTION}

What ends do we expect health insurance to serve in our society? This unresolved question, which one scholar aptly terms "the struggle for the soul of health insurance" arises today in many settings. This struggle pits a "social solidarity" vision of health coverage (by which insurance permits the risk of medical costs to be spread broadly across society, so that healthy persons subsidize the care received by unhealthy persons) against an individualistic vision of health coverage (by which insurance enables each person to pay an amount that reflects as closely as possible his own anticipated cost of care). ${ }^{2}$ The tension between these two views may emerge, for example, in debates over proposals to require community rating of insurance premiums or to mandate that insurers cover particular services. ${ }^{3}$

Laws that prohibit discrimination in health insurance also highlight this tension. These laws - whether they apply directly to insurance issuers or to employers providing health insurance coverage as an employment benefit - seem to embody the social solidarity view that persons with particular traits should neither be denied a place in the insurance pool nor be subjected to inferior coverage. The application of these antidiscrimination laws to health insurance occupies center stage in controversies over whether employers are required to provide prescription contraceptive coverage for their employees ${ }^{4}$ and whether

* Dean and Professor of Law, University of Pittsburgh School of Law.

1. Deborah A. Stone, The Struggle for the Soul of Health Insurance, 18 J. Health Pol., POL'Y \& L. 287, 287 (1993).

2. See id. (discussing the pitfalls of an individualistic vision).

3. Cf. Metro. Life Ins. Co. v. Massachusetts, 471 U.S. 724, 731 (1985) (noting that mandated coverage of mental health benefits responded to adverse selection in voluntary mental health insurance market).

4. See, e.g., Dan Margolies, Area Women Sue AT\&T over Contraceptive Coverage, KAN. CITY STAR, Jan. 21, 2003, at D17 (reporting on a case against the plaintiffs' employer for discrimination, alleging the company insurance plan covered sex-related drugs for men, but not contraceptives for women). 
employers can terminate retiree health benefits for Medicare-eligible retirees. $^{5}$ Existing laws address discrimination based on a variety of traits including race, sex, age, disability, genetic makeup, and the need for mental health treatment. ${ }^{6}$

Yet while these antidiscrimination laws at first glance seem to share a common vision of insurance inclusiveness, inconsistencies quickly surface when one examines the particular terms of these laws and courts' interpretations of them. To date, courts interpreting laws prohibiting health-insurance discrimination have failed to articulate any consistentmuch less overarching-vision either of the scope of the protection against discrimination or of the justification for that protection. Consequently, in the course of a single opinion, a court may apply one standard for assessing claims of sex discrimination in health insurance and another for claims of disability discrimination. ${ }^{7}$ Meanwhile, state legislatures have supplied still another standard in passing laws prohibiting genetic discrimination. ${ }^{8}$ So we are left wondering what sense to make of existing legal approaches to health-insurance discrimination.

We might also wonder about absences from the foregoing list of traits protected under federal and state antidiscrimination laws. One notable absence is health status. This absence, however, is not the result of legislative oversight or lack of need. Discrimination against unhealthy persons is deeply ingrained in the health insurance industry and traditionally has been generally accepted as a legitimate application of underwriting and risk-classification principles. These principles are consonant with the individualistic view of health coverage, where individuals' costs of coverage should vary with their predicted consumption of medical care. Indeed, some argue that state unfair trade practice laws regulating insurers mandate health-status discrimination.

5. See, e.g., T. Shawn Taylor, EEOC Defends Letting Firms Drop Retiree Health Benefit, CHI. TRIB., May 18, 2004, § 3, at 5 (discussing a new policy adopted by the Equal Employment Opportunity Commission).

6. See infra Part III.

7. See Saks v. Franklin Covey Co., 316 F.3d 337, 344 (2d Cir. 2003) (finding that equal access to benefits is the proper inquiry for ADA claims, while Title VII sex discrimination claims require assessment of the relative comprehensiveness of coverage).

8. See infra Part III.B.5. 
While lawmakers have not recognized "the unhealthy" as a group meriting protection under a civil-rights-informed antidiscrimination law, both state and federal law provide unhealthy people with limited protection against adverse differential treatment. ${ }^{10}$ For example, the handful of states that mandate community rating of health insurance protect persons with health problems from being charged higher premiums than their healthier peers. More broadly, in passing the Health Insurance Portability and Accountability Act (HIPAA) in 1996, Congress prohibited group health plans from excluding individuals from a group or charging them higher premiums based on their health status. ${ }^{11}$

Ironically, though, HIPAA's prohibitions of overt discrimination based on health status may have helped stimulate the development of forms of employer-provided coverage that discriminate more subtly against unhealthy persons. The recent emergence of novel types of health coverage typically is attributed to consumer backlash against managed care cost-containment methodologies and managed care's resulting inability to continue its downward pressure on health-care inflation. $^{12}$ Also worth noting, however, is that, as employers' health costs escalated, HIPAA limited employers' ability either to keep unhealthy and expensive employees out of their groups or to make those employees pay more. As a result, employers have increasingly turned to other avenues-from simply increasing enrollees' copayments to adopting so-called consumer-driven health plans - to constrain their health benefits costs. ${ }^{13}$ The common thread uniting recent trends in employer-provided coverage is the shifting of insurance risk (i.e., the risk

9. Who are "the unhealthy" to whom this Article frequently refers? The term admittedly suffers from substantial imprecision, but I use it in this Article to refer broadly to those persons whose health status renders them heavy users of (and thus heavy spenders on) health-care services. Thus, while the chronically "sick" would certainly fall into this group, so too could individuals who require expensive screening and preventative services on a regular basis to keep them from becoming sick, as could an individual who simply suffers an accident or acute illness requiring hospitalization. A person who has been diagnosed with one or more chronic conditions requiring ongoing medical care and pharmaceutical intervention is the exemplar of a member of this group.

10. See infra Parts III.B-IV.

11. See infra Part IV.C.

12. See James C. Robinson, Reinvention of Health Insurance in the Consumer Era, 291 JAMA 1880,1881 (2004) (describing the changes in managed care).

13. While employers concerned with profitability obviously care about rising health-care costs, the recent escalation in employers' health costs has generated broader societal concern. According to recent accounts, rapidly rising health costs have played a role in producing a "jobless" recovery, see Eduardo Porter, Costs of Benefits Cited as Factor in Slump in Jobs, N.Y. TIMES, Aug. 19, 2004, at D1, and are negatively affecting the international competitiveness of American business, see John Flesher, Health-care Costs Imperil U.S. Competitiveness, GM Chief Says, CHI. TRIB., June 7, 2004, $\S 4$, at 4 . 
of incurring medical expenses) away from the insurance company or self-insured employer and onto the shoulders of employees.

Logic and emerging evidence confirm what health insurers have long known: bearing insurance risk for unhealthy persons costs more than bearing insurance risk for healthy persons. Accordingly, it stands to reason that as employers adopt health coverage vehicles that shift insurance risk from the insurer to individual insureds, the burden falling on unhealthy enrollees generally will be heavier than any burden on healthy enrollees. In this disparity of costs shifted we can discern discrimination against the unhealthy. Although employers adopting these new coverage vehicles in all likelihood treat their employees identically in providing health benefits, the coverage provided imposes a heavier burden on employees with health problems. Adoption of facially neutral policies that disproportionately burden a particular group is, of course, the core definition of disparate-impact discrimination. ${ }^{14}$

The observation that increased copayment requirements and consumer-driven vehicles such as health savings accounts may disproportionately burden the unhealthy is not novel. Indeed, concerns about the inequity of this burden have been voiced at least since the policy debates over including a medical savings accounts demonstration project in HIPAA. This Article reviews the policy arguments for and against the shifting of insurance risk to individual health-care consumers, but then moves beyond partisan debate to examine emerging research on the impacts of risk shifting. This research suggests that the repercussions do not simply impose heavier financial costs onto unhealthy individuals; they also affect health-care consumption and, ultimately, health status. In sum, newer forms of coverage may leave unhealthy individuals underinsured and thereby exposed to many of the same harms that uninsured persons face.

In the end, this Article briefly suggests reasons for objecting to and seeking to curb the trend toward the shifting of risk to individual insureds. First, we might find the disproportionate burden visited upon the unhealthy troubling because of a sense that this disparate impact is somehow associated with social inequality and violates their civil rights.

14. See 42 U.S.C. $\$ 2000 \mathrm{e}-2$ (2000). For disparate-impact discrimination to be deemed a violation of laws prohibiting employment discrimination based on race or sex, the disproportionate adverse impact must be unjustified by the employer's "business necessity." See id. The interpretation of the business-necessity standard remains a bone of contention in employment discrimination law. As will be discussed infra notes 173-80 and accompanying text, any legal prohibition against health-insurance discrimination against the unhealthy, to the extent it incorporated disparate-impact theory, would likely similarly incorporate some type of necessity justification. 
Alternatively, we might understand the inequality of burdens as indicating an unjust distribution of consumerism's benefits and burdens.

This Article proceeds as follows: Part II describes the struggle for the soul of health insurance and suggests how it is implicated in legislation regarding health coverage. Part III reports on the federal and state laws that already prohibit discrimination on a variety of bases and attempts to discern any logic underlying inconsistencies in the coverage of and justifications for these laws. Part IV examines laws that address the legality of health-status discrimination in health insurance. The advent of a "consumerist" movement in health coverage is presented in Part V, along with an articulation of the policy perspectives that favor and disfavor the movement. Part $\mathrm{V}$ also presents evidence regarding the financial and health effects of the consumerist movement on unhealthy individuals. Part VI builds on the preceding parts to sketch rationales for policy responses designed to discourage or redirect the current trends in health coverage.

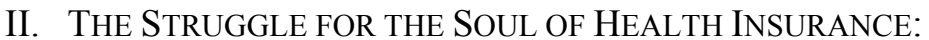 ENCAPSULATING THE DEBATE}

The following discussion of health-insurance discrimination and the unhealthy will be aided by fleshing out the idea of a "struggle for the soul of health insurance." 15 The phrase comes from the title of Deborah Stone's insightful and provocative article, which examines the competing concepts of solidarity and actuarial fairness in the context of health insurance coverage and pricing decisions. ${ }^{16}$ Stone describes the logic of solidarity as understanding health insurance as a form of mutual aid, in which community members pool their risks of incurring medical care expenses and share those expenses when they occur. ${ }^{17}$ Under such a system of mutual aid, the majority of members who are fortunate enough to remain healthy subsidize the care of those members who become sick or suffer injuries; the mutual aid system thus explicitly contemplates and accepts redistribution from the healthy to the sick. ${ }^{18}$ By contrast, the principle of actuarial fairness, in its purest form, ${ }^{19}$ cannot abide cross

15. Stone, supra note 1 , at 287.

16. Id. at $290-94$.

17. Id. at $290-91$.

18. Id.

19. According to Deborah Hellman, in an actuarially fair insurance pricing scheme, "each insured pays a price for coverage that is equivalent to the risk she poses of drawing from the insurance pool, given available information." Deborah S. Hellman, Is Actuarially Fair Insurance Pricing Actually Fair?: A Case Study in Insuring Battered Women, 32 HARV. C.R.-C.L. L. REV. 355, 
subsidies among insurance purchasers. Instead, the principle of actuarial fairness dictates that each individual should bear financial responsibility for his own risk of incurring medical expenses, and that each person's insurance premium should reflect that person's actuarially determined risk - no more and no less. ${ }^{20}$ Thus, a health insurance market that follows the principle of actuarial fairness in making coverage and pricing decisions will segment its insureds into ever-more-finely defined pools, each of which contains policyholders whose risks are as homogeneous as possible. $^{21}$ In that way, no one whose health prospects are bright will be called upon to subsidize the medical needs for those with gloomy medical outlooks. ${ }^{22}$

Stone views this tension between the competing principles of solidarity and actuarial fairness as reflecting more than a simple choice about how to structure and price health insurance. ${ }^{23}$ Instead, she asserts that the underlying question posed is "whether medical care will be distributed as a right of citizenship or as a market commodity." 24 Thus, the struggle for the soul of health insurance takes on a moral tenor-the combatants invoke political philosophy and neoclassical economics in the struggle.

On the ground, however, it is the extreme skewing of medical spending across the population that makes this struggle unavoidable. Although most people are generally healthy and usually do not experience large health-care costs in any given year, a relatively small number of people suffer illnesses or accidents that result in massive medical spending. ${ }^{25}$ Because the risk of illness or accident remains at some level unpredictable, purchasing health insurance is a rational way

358 (1997). As a practical matter, insurers are unlikely to implement pure actuarial fairness because the costs of predicting each insured's risk as precisely as possible would outweigh the competitive risk selection benefits that an insurer would reap from such prediction. Consequently, Hellman sees a more moderated approach to actuarial fairness as more plausible. Id. at 398-99. See also Stone, supra note 1, at 294 (noting that a perfect implementation of actuarial fairness would be the "antithesis of insurance" because each individual would be better off self insuring to avoid paying an insurer)

20. Stone, supra note 1, at 292-93.

21. Id.

22. Id. at 294 .

23. Id. at $288-89$

24. Id. at 288 .

25. Len M. Nichols et AL., Urban Institute, TAX-Preferred Medical Savings

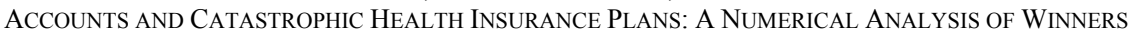
AND LOSERS 11-12 (1996), available at http://www.urban.org/UploadedPDF/winlose.pdf; Timothy S. Jost, Private or Public Approaches to Insuring the Uninsured: Lessons from International Experience with Private Insurance, 76 N.Y.U. L. REV. 419, 433 (2001); GAIL SHEARER, CONSUMERS Union, The Health CARE Divide: Unfair Financial Burdens 5 (2000), http://www.consumersunion.org/pdf/divide.pdf. 
of seeking to protect against the risk of large medical bills. ${ }^{26}$ The pooling of risk, a fundamental characteristic of insurance, functions as a mechanism for shared savings. ${ }^{27}$ The tension between solidarity and actuarial fairness appears full blown, however, as soon as we recognize that pooling entails the sharing of losses as well as the sharing of risks, for then we immediately ask whose losses we share. A disciple of actuarial fairness responds that a particular insured should share the losses only of those who share a similar risk profile. A solidarity partisan responds that all members of a community, however defined, ${ }^{28}$ should share in the community's losses. ${ }^{29}$

As one might expect, other scholars also have noted this tension between a community solidarity conception of health insurance and an individualistic focus, and they have used a variety of terms to describe the competing conceptions. ${ }^{30}$ Scholars commonly recognize this tension

26. Jost, supra note 25 , at 433 .

27. The Health Care Study Group, Report: Understanding the Choices in Health Care Reform, 19 J. Health Pol., Pol'y \& L. 499, 519 (1994). Cf. Brian J. Glenn, Risk, Insurance, and the Changing Nature of Mutual Obligation, 28 LAW \& SOC. INQUIRY 295, 300 (2003) (observing that "the risk-spreading function of insurance plays two roles, one prior to a loss (granting peace of mind) and one after (distributing the costs amongst all the policyholders)").

28. For purposes of discussing private health-insurance premiums, the community could be defined broadly as all of an insurer's subscribers, or it could be defined somewhat more narrowly as those subscribers in a particular geographic area or in a particular industry. The term "community rating" is used to describe a premium pricing scheme in which each insured is charged an identical premium (with perhaps some limited variations). For a description of state laws requiring community rating, see infra Part IV. Of course, under a single-payer health-care scheme, the community is defined even more broadly to include all residents of a polity covered by the single payer.

29. Cf. SHEARER, supra note 25 , at ii (rejecting policy initiatives that would "split the healthy from the sick" and calling for measures "insuring the sick with the healthy").

30. See, e.g., John V. Jacobi, The Ends of Health Insurance, 30 U.C. DAVIS L. REV. 311, 313 (1997) (contrasting social pooling and individual responsibility visions of health insurance). Rand Rosenblatt contrasts a "modestly egalitarian social contract" model of health law with a market competition model of health law. Rand Rosenblatt, The Four Ages of Health Law, 14 HEALTH MATRIX 156, 167 (2004). He notes, however, that proposals by leading academic proponents of a market model of health law include some form of cross-subsidization and guaranteed issue so that high-risk individuals have access to health insurance. Id. at 178-81. Scholars also have noted that other nations display a more consistent commitment to the ideal of social solidarity in health insurance than does the United States. See, e.g., Jacobi, supra, at 314 (attributing America's lessthan-firm commitment to a social solidarity ideal to Americans' being "imbued with rugged individualism and a preference for voluntary action"); Jost, supra note 25, at 434 ("In most nations, the ideal of social solidarity also plays a significant role."); Stone, supra note 1, at 289-90 (asserting that American society has only a "weak and wavering commitment" to the view that sickness is a condition that triggers mutual aid). For examples of the variety of terms used to describe these competing conceptions, see ROBERT H. JERRY II, UNDERSTANDING INSURANCE LAW 136-37 (3d ed. 2002) (contrasting the "grouping perspective" which would permit the use of gender-based classifications, with the "individual perspective," which rejects such a classification as unfair and noting the related issue of what type of subsidization in insurance is fair); Sharona Hoffman, Unmanaged Care: Towards Moral Fairness in Health Care Coverage, 78 IND. L.J. 659, 662 (2003) 
as underlying many policy debates regarding health-care systems reforms. ${ }^{31}$ They also highlight that the tension is based not simply on differing pragmatic assessments of the most effective way of accomplishing a particular goal such as lowering health-care costs or increasing the number of people covered by health insurance. Instead, many commentators appreciate that the conflicting visions pose fundamental moral and philosophical questions regarding desert and entitlement, misfortune and injustice. ${ }^{32}$

From the foregoing it might appear that the struggle for the soul of health insurance accurately could be simplified to choosing between "all for one, and one for all" and "every man for himself" as the slogan governing health insurance policy. A number of scholars, however, have noted that in reality the contrast between social solidarity and individualism is less stark. For even if an individual seeks to obtain health insurance for the purely selfish purpose of protecting herself against the possibility of overwhelming medical costs, by purchasing insurance she enters into a community of risk sharers and thereby produces a public benefit. ${ }^{33}$ And although we might assume that proponents of market-based approaches to health insurance policy would align themselves with an actuarial-fairness vision, a number of scholars employing economic theory have pointed out that imperfections in the

(contrasting actuarial fairness with a "moral fairness" standard, which "take[s] into account values of just distribution"); Leah Wortham, Insurance Classification: Too Important to be Left to the Actuaries, 19 U. MICH. J.L. REFORM 349, 359 (1985) (contrasting "traditional fair discrimination and antidiscrimination" approaches); Jill Gaulding, Note, Race, Sex, and Genetic Discrimination in Insurance: What's Fair?, 80 CORNELL L. REV. 1646, 1647 (1995) (contrasting the "efficient discrimination" and "antidiscrimination" perspectives).

31. For the most part, commentators have described policy questions regarding the structure of the health insurance market or regarding health-care financing reform more broadly in these terms, see, for example, Jacobi, supra note 30 , but the tension also has been noted in other contexts. See William M. Sage, Judicial Opinions Involving Health Insurance Coverage: Trompe L'Oeil or Window on the World?, 31 IND. L. REV. 49, 51 (1998) (suggesting that tensions about the nature of health insurance are revealed in coverage litigation); $c f$. Sara Rosenbaum \& Brian Kamoie, Managed Care and Public Health: Conflict and Collaboration, 30 J.L. MED. \& ETHICS 191, 191 (2002) (suggesting a similar tension between managed care's grafting of insurance risk avoidance principles into medical practice and fundamental precepts of public health).

32. See NichOLS ET AL., supra note 25, at 12 ("[O]pposing views about the 'optimal' health insurance market reflect philosophical differences in approach to health system reform."); Hellman, supra note 19, at 397-403 (analyzing the moral bases for differing views about risk rating).

33. See Roberta M. Berry, The Human Genome Project and the End of Insurance, 7 U. FLA. J.L. \& PUB. POL'Y 205, 227-31 (1996) ("Insurance allows self-interested individuals [to manage their own risk] only if they help others manage risk through the cooperative undertaking of insurance."); see also Glenn, supra note 27, at 304 ("By tracing out the way that insurance spreads responsibility, we see... [that i]nsurance builds communities of interest, whether we realize it or not."). 
health insurance market ${ }^{34}$ may create a need for subsidies between lowand high-risk individuals and justify limitations on insurers' pursuit of actuarial fairness to increase market efficiency. ${ }^{35}$ So even many who assert the power of market economies to maximize social welfare have suggested that some regulatory measures consistent with-if not inspired by - a solidarity vision of health insurance may be necessary to improve market efficiency. ${ }^{36}$ Notwithstanding some blurring of the stark contrast the competing visions offer, they continue to point in opposite directions on many questions, including health insurers' discriminatory riskclassification practices, to which we now turn.

\section{LAWS PROHIBITING DISCRIMINATION IN HEALTH INSURANCE}

\section{A. Risk Classification as Discrimination}

Before examining various laws proscribing health-insurance discrimination, this Section will suggest the diversity of forms that discrimination by health insurers can take. Of course, the most straightforward example is an insurer's refusal to issue a policy to an individual based on a particular trait. Such a discriminatory refusal to cover is also clearly inconsistent with social solidarity, for it excludes that person from the pooling of risks and losses that insurance coverage provides. But a brief examination of risk-classification mechanisms commonly employed by health insurers reveals how discrimination, in the neutral sense of the word, inheres in numerous other insurance practices. $^{37}$

34. For an excellent explanation of inefficiencies in the market for health insurance, see Katherine Swartz, Justifying Government as the Backstop in Health Insurance Markets, 2 YALE J. HEALTH POL'Y L. \& ETHICS 89 (2001). Swartz asserts that the primary imperfection in the market is information asymmetry that leads to inefficient risk-screening practices by insurers seeking to avoid adverse selection. Id. at 94, 98. See also Thomas L. Greaney, How Many Libertarians Does It Take to Fix the Health Care System?, 96 MicH. L. REv. 1825, 1836 (1998) (characterizing the health-care market as "beset with problems of inadequate information and imperfect agency").

35. See Greaney, supra note 34 , at 1846 (stating that "controlling risk segmentation is at the heart of market reform efforts designed to improve efficiency"); Swartz, supra note 34, at 99-103 (noting the inefficiencies of the health insurance market and how the government could address them).

36. A notable exception is Richard Epstein, who argues in his book that American society should avoid positive rights to health care, including regulation mandating cross subsidies. Richard A. Epstein, Mortal Peril: Our inalienable Right to Health Care? (1997). Reviewers, however, have criticized Epstein for basing his policy prescription on a commitment to libertarianism and for failing to pay close attention to recognized imperfections in the health-care market. See, e.g., Greaney, supra note 34, at 1826-29 (claiming that Epstein "pays no attention to the subtleties and imperfections of the [health-care] market").

37. Cf. JERRY, supra note 30 , at 136 (noting that, from one perspective, "insurance is inherently 
Private health insurers engage in risk-classification practices as part of their competitive strategies for capturing profitable segments of the health insurance market while avoiding unprofitable segments. ${ }^{38}$ Rather than segmenting the market by product and competing based on product price and quality, however, health insurers tend to segment the market by customer-competing in their efforts to sell policies to those customers considered likely to be profitable and to avoid customers who can be predicted to be unprofitable. ${ }^{39}$ To this end, health insurers seek to obtain from prospective insureds information that the insurers deem predictive of future health costs and to use that information in a variety of ways to try to avoid, or at least classify, risk.

Many risk-classification practices employed by insurers fit easily into a rubric of disparate-treatment discrimination-where the insurer somehow treats $A$ differently from $B$ based on a trait of $A$; for example, the fact that $A$ is female. ${ }^{40}$ Certainly, if an insurer decides to issue a particular insurance policy to $B$ but not to $A$ because $A$ is female, the insurer has discriminated in underwriting. ${ }^{41}$ Or perhaps the insurer does not flatly turn $A$ away, but instead charges $A$ a higher premium than $B$ for the same policy. In that instance, the insurer has discriminated in its rating, or pricing, practices. ${ }^{42}$ In the alternative, assume that the insurer agrees to cover both $A$ and $B$ for the same price, but decides to exclude certain benefits only from $A$ 's coverage or to impose a longer preexisting condition exclusion on $A$ than on $B$. Again, the insurer is discriminating against $A$, this time in making coverage decisions.

'discriminating' because the purpose of insurance is to divide a group of potential insureds into smaller categories and price each group according to its risk").

38. For a lucid and accessible description of health insurance markets and how health insurers use risk-classification mechanisms to compete, see Swartz, supra note 34, at 95-97. See also Gaulding, supra note 30, at 1651-53 (describing the role of adverse selection and competition among insurers in promoting risk classification).

39. As Kenneth Abraham notes regarding the insurance industry generally, "[i]nsurers often can capture more protection dollars by classifying because through classification they can offer lowrisk individuals lower prices.” KENNETH S. ABRAHAM, DiSTRIBUTING RISK: INSURANCE, LEGAL THEORY AND PUBLIC POLICY 67 (1986).

40. For a description of risk-classification practices, see Gaulding, supra note 30, at 1651-52. $C f$. Wortham, supra note 30, at 404 ("The selection competition feature probably causes people to most immediately make the analogy of insurance . . . classifications to civil rights laws.").

41. The insurance industry defines underwriting generally as the " process by which an insurer determines whether or not and on what basis it will accept an application for insurance."' Karen A. Clifford \& Russel P. Iuculano, AIDS \& Insurance: The Rationale for AIDS-Related Testing, 100 Harv. L. REV. 1806, 1807-08 (1987) (quoting HeAlth Ins. Ass'N OF AM., A COURSE IN GrouP LIFE \& HEALTH INS. pt. A, at 379 (1985)).

42. "Classification refers to treating an individual as a member of a class based on an individual trait such as gender, residential zip code, driving record, history of cancer, and so forth. . . Rating is the process of transforming classifications into prices for insurance." Wortham, supra note 30 , at 354 n. 19. 
Through these decisions, ${ }^{43}$ the insurer segments its market based on the relative risk that the insurer believes $A$ and $B$ pose. Segmentation occurs when the insurer decides who gets to participate in the pooling of risks, the price that different customers must pay to enter the pool, and what risks each customer can transfer to the pool. Health insurers' use of various types of risk classifications in making underwriting, coverage, and rating decisions has generated significant policy discussion and academic analysis regarding these practices' legitimacy.

But an insurer's attempt to limit its exposure to risk may also produce another form of discrimination. In contrast to disparatetreatment discrimination, disparate-impact discrimination exists not in singling out a person for different treatment based on a protected trait, but in applying a facially neutral practice or policy that disproportionately and adversely impacts a group of people sharing the protected characteristic. ${ }^{44}$ For example, let us imagine that a health insurer sells the same policy to $A$ and $B$ for the same price, but the policy excludes coverage for breast cancer (while providing coverage for all other cancers). The insurer is treating $A$ and $B$ identically in the coverage provided, but the exclusion of breast cancer undoubtedly would have a disproportionate adverse effect on women. Aside from coverage determinations, insurance marketing strategies or administrative policies may also have a disparate impact on a particular group, ${ }^{45}$ as may an insurer's reliance on a nonprotected personal trait of an insured. ${ }^{46}$ Thus, like disparate-treatment discrimination, the less easily recognized impact

43. The cases discussed all involve instances of overt, identifiable discrimination. Brian Glenn, in discussing discrimination against certain groups within the insurance industry more generally, points out that disparate-treatment discrimination also can take more subtle forms, such as an agent who fails to return certain customers' phone calls, offers higher prices and weaker policies to members of certain groups, or is slower in handling claims submitted by members of certain groups. Brian J. Glenn, The Shifting Rhetoric of Insurance Denial, 34 L. \& SoC'Y REV. 779, 779-80 (2000).

44. See Griggs v. Duke Power Co., 401 U.S. 424, 431 (1971) (noting that the Civil Rights Act "proscribes not only overt discrimination but also practices that are fair in form, but discriminatory in operation"). In the employment context, the disparate impact from an employer's practice is only actionable if not justified by business necessity. Id.

45. In employment discrimination law, the disparate impact felt is typically that members of a protected group have a higher rate of exclusion from the workplace or a lower rate of advancement within the workplace. In the health insurance setting, the disparate impact felt by a particular group might take the forms of higher levels of uninsurance, higher levels of inadequate coverage, or lower rates of successful claims. For example, an insurer who passes out enrollment applications at a health club may be likely to reach a disproportionately small number of persons with serious health conditions, and applications sent to an insurer who advertises primarily in homemaking magazines may include a disproportionately low number of male applicants. An indemnity insurer that requires that all claim forms be submitted in English may disproportionately affect the ability of subscribers of Mexican origin to receive benefits.

46. See Wortham, supra note 30, at 365-66 (noting that automobile and property insurers' use of residential zip code may have a disparate impact on racial minorities). 
discrimination potentially may be found in various health insurer practices.

Having suggested that discrimination of some sort lies at the heart of health insurers' risk-classification practices, ${ }^{47} \mathrm{I}$ hasten to note that most Americans are not subjected to these practices when they obtain insurance coverage. Most Americans under the age of sixty-five receive health insurance coverage from their employers, and for several reasons insurers do not engage in risk-classification practices for large employer groups. ${ }^{48}$ The smaller the group for which coverage is purchased, however, the more likely a health insurer is to employ risk-classification devices, so that small employers seeking to purchase coverage are more likely to encounter the use of underwriting, coverage, and pricing mechanisms. ${ }^{49}$ By all accounts, risk-classification practices are de rigeur in the market for individual health insurance policies, at least where permitted by law. Thus, health insurers' discriminatory practices are concentrated highly in the individual market, with some infiltration in the small-group market. Although the number of persons who obtain coverage through the individual market is relatively small, the stakes are typically high, for purchasers in the individual market may have no other coverage option. Moreover, the continuing erosion of employersponsored health coverage seems likely to cause the ranks of prospective purchasers in the individual market to swell. Accordingly, the number of purchasers subject to discriminatory practices by insurers probably will increase in the short run.

To this point, I have used "discrimination" in its neutral sense of drawing distinctions and have not focused on the legitimacy or legality of any particular basis for discrimination. The sections that follow undertake the task of cataloging the various bases for health-insurance discrimination that the law has proscribed. The treatment of each type of legally regulated discrimination is necessarily circumscribed, for this Part's remaining purpose is not to provide comprehensive analysis of all

47. The courts certainly are aware of this point as well. See, e.g., Thompson v. IDS Life Ins. Co., 549 P.2d 510, 512 (Or. 1976) (en banc) (stating that "insurance, to some extent, always involves discrimination").

48. See Swartz, supra note 34, at 94-95 (explaining why insurers in the large-group market are less concerned about adverse selection).

49. The small-group market generally is defined as groups having two to fifty members. See, e.g., NYS Health Maint. Org. Conference v. Curiale, 64 F.3d 794, 800 (2d Cir. 1995) (noting that regulation 146 of the Official Compilation of Codes, Rules \& Regulations of the State of New York defines a small group as having three to fifty members). The frequency with which insurers underwrite coverage in the small-group market is not entirely clear. See Clifford \& Iuculano, supra note 41, at 1809 n.17 (explaining why insurers may employ risk-classification practices with respect to small groups). 
such prohibitions, but instead to suggest their number, variety, and inconsistency of approach and rationale. What should emerge from this cataloging is a recognition that society has branded as illegitimate the discrimination embodied in some insurance practices, but not others, without any distinguishable overarching justification for doing so.

\section{B. Laws Prohibiting or Regulating Discrimination in Health Insurance}

In cataloging the various legal proscriptions of health-insurance discrimination, identifying several key items will enable comparisons. First, and most salient, what is the individual trait placed off limits as a basis for risk classification? Second, what types of discrimination are prohibited? Does the law broadly prohibit both disparate-impact and disparate-treatment discrimination by health insurers, or does it more narrowly proscribe only the latter? Third, whose actions are constrained? Does the law apply directly to health insurance issuers, to employers providing health insurance coverage, or both? And finally, what rationale justifies the legislative choice to limit insurers' use of risk-classification mechanisms and thus their freedom to pursue profit in the marketplace?

\section{Race Discrimination}

Race is the trait that receives the strongest protection against use in health insurance risk classification. Both federal and state laws forbid its use as a mechanism for segregating risk. The strong prohibitions against racial risk classification, however, do not simply reflect a judgment that race is never an actuarially valid predictor of future costs. While commentators have noted that the shorter average life expectancy for black Americans, as compared to white Americans, carries some actuarial significance for both life insurance and annuities, ${ }^{50}$ less noted is the possibility that African Americans' generally lower health status and

50. E.g., Robert H. Jerry II \& Kyle B. Mansfield, Justifying Unisex Insurance: Another Perspective, 34 AM. U. L. REV. 329, 352 (1985). 
higher disease burden ${ }^{51}$ could justify using race as a risk classifier in health insurance.

Notwithstanding its potential actuarial relevance, race is deemed an illegitimate classifier under the insurance regulation laws of most states. Some states achieve this result through laws specifically directed at outlawing race-based classifications ${ }^{52}$ others subsume the use of race within their definitions of insurance unfair trade practices. ${ }^{53}$ By their terms, however, state laws apply only to the use of race to treat persons differently; they have not generally been extended to prohibit risk classifications that have a racially disparate impact. ${ }^{54}$

When an individual receives health insurance as a benefit of employment, federal law also prohibits racial classifications. The antidiscrimination mandate of Title VII of the 1964 Civil Rights $\mathrm{Act}^{55}$ extends to discrimination in employer-sponsored benefit plans such as health insurance coverage. ${ }^{56}$ Moreover, Title VII has been interpreted to prohibit not only different treatment based on race, but also disparateimpact discrimination. ${ }^{57}$ Thus, at least in theory, an insurance risk classifier that has an unjustified disparate impact on a racial group is illegal under Title VII. ${ }^{58}$ Beyond the employment context, federal civil

51. See Vernellia R. Randall, Racial Discrimination in Health Care in the United States as a Violation of the International Convention on the Elimination of All Forms of Racial Discrimination, 14 U. Fla. J. LAW \& PUB. POL'Y 45, 51 (2002) (giving several examples of racial disparities in health status and disease incidence, including the figure that African Americans have a seventy percent higher rate of diabetes than white Americans); Lynette Clemetson, Links Between Prison and AIDS Affecting Blacks Inside and Out, N.Y. TIMES, Aug. 6, 2004, at A1 (reporting that more than half of all new cases of HIV nationwide are among African Americans and that AfricanAmerican women make up seventy-two percent of new cases among women).

52. E.g., MiCH. COMP. LAWS $\S 500.2082$ (2002).

53. E.g., MONT. CODE ANN. § 33-18-210 (2003); Gaulding, supra note 30, at 1659-60.

54. Some states, however, effectively have proscribed one form of potential disparate-impact race discrimination by explicitly prohibiting insurers from using the presence of sickle cell trait-a genetic trait found predominantly among African Americans - as a basis for underwriting or risk rating. Hellman, supra note 19, at 381-82.

55. 42 U.S.C. $§ 2000 \mathrm{e}-2(\mathrm{a})(1)$ (2000) ("It shall be an unlawful employment practice for an employer... to discriminate against any individual with respect to his compensation, terms, conditions, or privileges of employment, because of such individual's race, color, religion, sex, or national origin ....").

56. Newport News Shipbuilding \& Dry Dock Co. v. EEOC, 462 U.S. 669, 682 (1983).

57. See Civil Rights Act of 1991, Pub. L. No. 102-166, § 3(3), 105 Stat. 1071, 1071 (1991) (amending Title VII to provide statutory authority for disparate-impact suits); Griggs v. Duke Power Co., 401 U.S. 424 (1971) (recognizing disparate-impact claim).

58. See EEOC Compliance Manual, Chapter 3: Employee Benefits (Oct. 3, 2000), http://www.eeoc.gov/policy/docs/benefits.html [hereinafter Compliance Manual] ("Disparate impact analysis ... applies equally to the employer's provision of health benefits."); $c f$. EEOC v. J.C. Penney Co., 843 F.2d 249, 251 (6th Cir. 1988) (discussing legal uncertainty as to whether disparateimpact theory can be used in claim based on section 703(a)(1) of Title VII); Novak v. Nationwide Mut. Ins. Co., 599 N.W.2d 546, 554 (Mich. Ct. App. 1999) (noting split of authority on question of 
rights laws may limit insurers' use of race as a classifier, even in the absence of state action. ${ }^{59}$

What explains the law's consistently strong protection against the use of race in underwriting, coverage, and rating decisions? The answer may lie partly in that race is less valuable to insurers in predicting future medical expenses than are other traits such as sex, age, disability, or medical history - all of which, as we will see, receive more limited protection. Nonetheless, data regarding the greater disease burdens borne by some racial groups might-from the perspective of actuarial fairness - support insurers' reliance on race in classifying risks. Perhaps we should understand prohibitions on racial classifications less as a judgment of actuarial irrelevance than as a reflection of societal unwillingness to allow a divisive use of race in the context of insurance. In this sense, the social solidarity stance discernible in laws prohibiting racial classifications may be better understood as a particularized manifestation of the more general societal judgment regarding the illegitimacy or repugnance of using race in determining access to societal benefits. $^{60}$

\section{Sex Discrimination}

In contrast to the general consensus that insurers should not use race in classifying risks, controversy has marked attempts to prohibit sexbased classifications $^{61}$ and protections against sex discrimination in

whether insurance redlining is prohibited as a form of disparate-impact discrimination under the federal Fair Housing Act).

59. See 42 U.S.C. $§ 1981$ (2000) (guaranteeing to all persons a right equal to that enjoyed by white citizens to make and enforce contracts); 42 U.S.C. § 1982 (2000) (guaranteeing to all citizens a right equal to that enjoyed by white citizens to purchase real and personal property); Wortham, supra note 30, at 362-63 (discussing application of these laws to race or color classification in insurance); $c f$. Thompson v. Metro. Life Ins. Co., 216 F.R.D. 55, 59-61 (S.D.N.Y. 2003) (approving proposed settlement in class action brought by non-Caucasian policyholders alleging that life insurer violated 42 U.S.C. $\S \S 1981$ and 1982 by selling them policies that cost more and provided fewer benefits than policies sold to Caucasians).

60. See JeRrY, supra note 30, at 136 (asserting that notwithstanding black Americans' shorter life expectancy, "because our society views racial discrimination with repugnance, no one contends that black Americans should pay more for life insurance or receive a premium reduction for annuities").

61. See Sharona Hoffman, AIDS Caps, Contraceptive Coverage, and the Law: An Analysis of the Federal Anti-Discrimination Statutes' Applicability to Health Insurance, 23 CARDOZO L. REV. 1315,1349 (2002) (stating that sex-based classifications "remain a vigorously disputed practice"). Forceful debates occurred in legislative, judicial, and academic arenas in the 1970s and 1980s regarding the extent to which sex discrimination should be prohibited in employer benefit plans and insurance. For references to the scholarly debates, see Wortham, supra note 30, at 356-57 nn.3132 . 
insurance remain more limited. The objections raised to prohibitions on sex-based insurance classifications are not surprising, for sex's actuarial relevance in evaluating risks of various types is greater than that of race. In a number of settings, sex provides insurers with an inexpensive method of classifying risks; ${ }^{62}$ in the health insurance setting, relying on sex as a classifier leads to younger women being charged higher premiums than men because of the risk of medical costs associated with pregnancy and childbirth. ${ }^{63}$ Today, the protection against insurance sex discrimination varies between the state and federal levels and the employment and nonemployment contexts.

On the state level, insurance laws largely permit the use of sex as a risk classifier, at least for purposes of rate calculation. ${ }^{64}$ Despite some proposals to require "unisex" insurance rating, ${ }^{65}$ most states have declined to eliminate the practice of calculating sex-based premiums. ${ }^{66}$ Given the permissiveness of most states' laws and the actuarial value of sex as a classifier, it is not surprising that many health insurers discriminate against women by charging them higher premiums than men. ${ }^{67}$

This permissiveness evaporates, however, when the setting shifts to employer-sponsored health insurance coverage, for sex is one of Title VII's prohibited bases for discrimination. As with race, therefore, an employer who sponsors group health coverage for its employees cannot discriminate based on sex in that coverage. In addition, the Pregnancy Discrimination Act (PDA), ${ }^{68}$ which Congress passed in 1978 to amend

62. See JERRY, supra note 30, at 133-34 (pointing out relevance to life insurance, annuities, health and disability insurance, and automobile insurance and stating, "[i]n these settings, gender is a low-cost way to differentiate risks").

63. Id. at 134. See also Diane Levick, ConnectiCare Joining Gender Trend-Health Insurer, Following Anthem and UnitedHealth, Plans to Charge More for Most Women, HARTFORD Courant, Apr. 22, 2004, at E1.

64. Few states restrict sex classification regarding rating. Furthermore, while a number of states restrict the ability of insurers to deny or limit coverage on the basis of sex, see Wortham, supra note 30 , at 366 , only Montana prohibits all sex-based classifications by insurers. MONT. CODE ANN. § 49-2-309 (2003).

65. See, e.g., Jerry \& Mansfield, supra note 50, at 359-67 (discussing justifications for unisex insurance); $c f$. Anne C. Cicero, Strategies for the Elimination of Sex Discrimination in Private Insurance, 20 HARV. C.R.-C.L. L. REV. 211, 264 (1985) (discussing Montana's model of unisex legislation); Wortham, supra note 30, at 368 (arguing that the use of sex should be prohibited in insurance classifications, notwithstanding its statistical association with loss).

66. Wortham, supra note 30 , at 366.

67. See Levick, supra note 63 (reporting that ConnectiCare attributed its decision to switch to gender rating for small employers in part because of the adverse selection that occurred as a result of other companies using gender rating: a disproportionate share of employers with more women than men (i.e., high-cost employers) chose ConnectiCare).

68. Pub. L. No. 95-555, 92 Stat. 2076 (1978). 
Title VII, makes explicit that discrimination based on "pregnancy, childbirth, or related medical conditions" is a form of sex

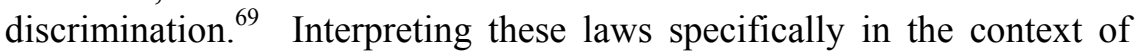
employee benefit plans, the Supreme Court has held that employers cannot provide fringe benefits that discriminate either by charging members of one sex more for equivalent coverage ${ }^{70}$ or by providing members of one sex lesser benefits for the same contribution. ${ }^{71}$

Moreover, in Newport News Shipbuilding \& Dry Dock Co. v. $E E O C{ }^{72}$ the Court indicated that even if an employer provided male and female employees with the same health insurance plan for the same contribution, the employer discriminated if the coverage provided was less comprehensive for members of one sex. ${ }^{73}$ Implicit in the Court's reasoning are two points consistent with a strong stance against sexbased inequality in employee benefits. First, the Court accepted the plaintiffs' invitation to consider the content, or terms, of the coverage provided rather than simply examining whether all employees received the same policy for the same price. ${ }^{74}$ Second, in establishing relative comprehensiveness as the touchstone for judging policy terms, the Court effectively incorporated an assessment of impacts into its analysis. ${ }^{75}$ An

\section{42 U.S.C. $\S 2000 \mathrm{e}(\mathrm{k})(2000)$.}

70. L.A. Dep't of Water \& Power v. Manhart, 435 U.S. 702, 711 (1978) (holding that requiring female employees to make bigger contributions than males to employer's pension plan violated Title VII).

71. Arizona Governing Comm. v. Norris, 463 U.S. 1073, 1084-86 (1983) (holding that retirement plan that paid men a higher monthly benefit than women violated Title VII). As Robert Jerry puts it: "Under the logic of [Manhart and Norris], it is a violation of Title VII for an employer to provide its employees any kind of insurance fringe benefit... unless identical benefits are provided to both men and women and unless contributions, if any, are the same for both genders." JERRY, supra note 30 , at 135.

72. 462 U.S. 669 (1983).

73. See id. at 676 ("Under the proper test petitioner's plan is unlawful, because the protection it affords to married male employees is less comprehensive than the protection it affords to married female employees."). The employer in Newport News provided hospitalization and medical-surgical coverage for employees and their spouses. Prior to the passage of the PDA, the plan contained a limitation (not applicable to any other hospital admission) on the coverage of hospitalizations for pregnancy. Presumably in response to the PDA, the employer amended its health plan in 1979 to remove that limitation from the coverage provided to employees; it retained the limitation, however, in the coverage provided to the wives of male employees. Id. at 671-73. Accordingly, the plaintiffs in Newport News argued that the plan discriminated against married male employees by providing them with a less comprehensive level of spousal coverage than was provided to married female employees. Id. at 674 .

74. Id. at $683-85$.

75. See id. The Newport News Court did not explicitly adopt a disparate-impact mode of analysis. The opinion can be read as applying a disparate-treatment approach to discrimination for it identified the plan's exclusion of spousal hospital maternity benefits as providing male employees' spouses with more limited coverage than female employees' spouses (who never went to the hospital to have a baby). Because the plan itself contained a distinction based on pregnancy-related benefits, 
inquiry directed to the comprehensiveness of coverage is not confined to asking whether male and female employees receive the same policy with identical terms; it instead compares how thoroughly that policy actually covers male and female enrollees' medical expenses. ${ }^{76}$

Questions about the sex-relative comprehensiveness of coverage have arisen recently in relation to employers' exclusion of prescription contraceptive coverage from their health plans. In Erickson v. Bartell Drug Co. ${ }^{77}$ a federal court found that such an exclusion violated Title VII because it failed to meet the "special or increased healthcare needs associated with a woman's unique sex-based characteristics ... to the same extent, and on the same terms, as other healthcare needs." ${ }^{, 78}$ Erickson expands on the reasoning in Newport News to conclude that an employer offering a health benefit plan is obligated to make certain both that it does not incorporate sex-based distinctions into its terms and that it "provides equally comprehensive coverage for both sexes."79 In other words, a policy may violate Title VII by providing less inclusive coverage of women's health needs, even if its terms make no reference to sex-based characteristics such as pregnancy or childbirth. ${ }^{80}$

the policy was discriminatory on its face in light of the PDA. See id. at 684 ("The 1978 Act makes clear that it is discriminatory to treat pregnancy-related conditions less favorably than other medical conditions."). The Court employed a two-step analysis that enabled it to conclude that "discrimination against female spouses in the provision of fringe benefits is also discrimination against male employees." Id.

76. Cf. Hoffman, supra note 61, at 1350-51 (asserting that Supreme Court cases require a plaintiff to "make a direct comparison between the benefits received by men and women and show that in some respect the insurance coverage available to one gender is inferior to that available to the other sex" to prove a Title VII violation).

77. 141 F. Supp. 2d 1266 (W.D. Wash. 2001).

78. Id. at 1271 .

79. Id. at 1272 .

80. The court granted summary judgment to Erickson on her disparate-treatment claim because "prescription contraceptives are used only by women." Id. As a result, the court found it unnecessary to consider Erickson's disparate-impact claim. Id. at 1277. Some commentators, however, have suggested that the claim would better be analyzed as a disparate-impact claim that looks at the burden imposed disproportionately on women, in terms of both the financial costs of prescription contraceptives and the numerous burdens of unwanted pregnancy. The disparate impact characterization would allow the legal finding of discrimination to survive the eventual introduction of male prescription contraceptives into the market. See Lee Korland, Sex Discrimination or a Hard Pill for Employers to Swallow: Examining the Denial of Contraceptive Benefits in the Wake of Erickson v. Bartell Drug Co., 53 CASE W. ReS. L. REv. 531, 552-54 (2002); Sylvia A. Law, Sex Discrimination and Insurance for Contraception, 73 WASH. L. REV. 363, 374-75 (1998).

The reasoning successfully used by the plaintiff in Erickson has not been successful in suits alleging a violation of Title VII in the failure of an employer's plan to cover treatments or procedures responding to infertility. See, e.g., Saks v. Franklin Covey Co., 316 F.3d 337, 348-49 (2d Cir. 2003); Krauel v. Iowa Methodist Med. Ctr., 95 F.3d 674, 680-81 (8th Cir. 1996). 
If one accepts Erickson's reasoning ${ }^{81}$ it becomes evident that Title VII requires an employer offering health insurance coverage to be concerned not only with the equality of treatment of male and female employees, but also (to some degree) with the equality of outcome-as measured by comprehensiveness of coverage. Accordingly, it seems that a woman who receives health insurance coverage from her employer receives strong protection against varied forms of sex discrimination under federal employment law. By contrast, a woman who obtains her own coverage (even if she does so with funds contributed by her employer for that purpose), receives little or no protection under state insurance law. ${ }^{82}$ The explanation for this inconsistent treatment is not clear, but the inconsistency suggests that as a society we are more concerned about sex-based inequality in employment than we are about pursuing a social solidarity vision of insurance more broadly.

\section{Disability Discrimination}

At first glance, the Americans with Disabilities Act (ADA) appears to be a promising source of protection against health-insurance discrimination for people with disabilities. Congress passed the ADA in an effort to eliminate discrimination against persons with disabilities ${ }^{83}$ across a broad swath of American society. Regulatory and judicial

81. The parties to Erickson eventually settled following the district court's decision. See Bartell Class-Action Settlement OK'd-Agreement on Contraceptive Coverage, SEATtLe PostINTELLIGENCER, Mar. 5, 2003, at B5. Thus, there has been no appellate review of the case. The court's decision is, however, consistent with the EEOC's approach to the question. In 2000, the EEOC ruled that an employer's exclusion of prescription contraceptives from a health plan that otherwise comprehensively covered pharmaceuticals was a violation of Title VII. EEOC, Decision on Coverage of Contraception (Dec. 14, 2000), http://www.eeoc.gov/policy/docs/decisioncontraception.html. The commentators have been divided in their assessment of Erickson. Compare Julia Bruzina, Erickson v. Bartell: The "Common Sense" Approach to Employer-Based Insurance for Women, 47 ST. LOUIS U. L.J. 463, 504-16 (2003) (supporting outcome), and Korland, supra note 80, at 544-49 (same), with E. Renee Backmeyer, Lack of Insurance Coverage for Prescription Contraception by an Otherwise Comprehensive Plan as a Violation of Title VII as Amended by the Pregnancy Discrimination Act-Stretching the Statute Too Far, 37 IND. L. REV. 437, 446-66 (2004) (criticizing Erickson), and James A. Ryan, Contraceptives and Employer Health Prescription Plans: An Examination of Erickson v. Bartell Drug Co., 11 GeO. MASON L. Rev. 215, 232-41 (2002) (same). Cf. Hoffman, supra note 61, at 1351 (questioning the soundness of Erickson's analysis).

82. Hellman, supra note 19, at 384 ("The individual insurance market, where most underwriting and risk rating takes place, is untouched by [Title VII]."); JERRY, supra note 30, at 135 (" $[\mathrm{T}]$ he employer can give the employee a sum of money, and the employee can use the money to purchase an insurance policy whose price or benefits are calculated according to gender-distinct tables.").

83. 42 U.S.C. § 12101(b)(1) (2000). 
interpretations of the $\mathrm{ADA}$, however, permit insurers to use disability as a risk classifier, demanding at most consistency with actuarial fairness. ${ }^{84}$

Like Title VII, the ADA extends its prohibition of disability discrimination to employer-provided fringe benefits. ${ }^{85}$ The question of what actions should be deemed to be prohibited "discrimination" remains substantially murkier in the context of disability discrimination than in race or sex discrimination. Without attempting to describe the numerous divisions among courts and commentators on this issue, ${ }^{86} \mathrm{I}$ briefly will describe the position that the EEOC's Compliance Manual ${ }^{87}$ takes on the ADA's application to employer-provided health insurance. That position represents what is probably the broadest plausible understanding of the ADA's application, but even it describes substantially circumscribed protection. ${ }^{88}$ Moreover, many courts have rejected the EEOC's positions and construed the ADA even more weakly. ${ }^{89}$

The EEOC asserts that if an employer provides benefits to employees with disabilities that are not equal to the benefits received by other employees, the employer may be liable for violating the ADA if any inequality in benefits is based on disability. ${ }^{90}$ In the Compliance Manual, the EEOC interprets "equality" of benefits broadly and finds unequal benefits if a health plan's terms contain a disability-based distinction, even if the plan is provided to disabled and nondisabled employees alike. $^{91}$ In this sense, the EEOC's position seems akin to the Supreme Court's comprehensiveness of coverage test for sex

84. See infra text accompanying notes 94-100.

85. 42 U.S.C. $\S 12112$ (b)(2) (2000).

86. For discussions of the application of the ADA to employer-provided health insurance coverage, see generally Melissa Cole, Beyond Sex Discrimination: Why Employers Discriminate Against Women with Disabilities When Their Employee Health Plans Exclude Contraceptives from Prescription Coverage, 43 ARIZ. L. REV. 501 (2001); Hoffman, supra note 61; Jacobi, supra note 30; H. Miriam Farber, Note, Subterfuge: Do Coverage Limitations and Exclusions in EmployerProvided Health Care Plans Violate the Americans with Disabilities Act?, 69 N.Y.U. L. REV. 850 (1994). The insurance issue most frequently litigated under Title I has involved not health insurance, but the differential in length of benefits provided for physical disabilities and for mental disabilities in employer-provided, long-term disability insurance coverage. The current weight of the authority on this question holds that such a distinction in the benefits provided does not violate the ADA, on the reasoning either that the ADA was not intended to protect against discrimination between persons with differing disabilities and/or that the distinction falls within the insurance safe harbor described infra text accompanying notes 100-02. See, e.g., Weyer v. Twentieth Century Fox Film Corp., 198 F.3d 1104, 1115-17 (9th Cir. 2000); Leonard F. v. Isr. Disc. Bank, 199 F.3d 99, 102-03 (2d Cir. 1999).

87. Compliance Manual, supra note 58, at ch. 3 .

88. Id.

89. See, e.g., Weyer, 198 F.3d at 1115-17; Leonard F., 199 F.3d at 102-03.

90. Compliance Manual, supra note 58, at ch. 2.

91. Id. at ch. 3 . 
discrimination in health insurance. $^{92}$ Just as a limitation on maternity benefits constitutes sex discrimination even if all employees receive the same policy, a limitation on coverage for HIV/AIDS constitutes disability discrimination even if all employees receive the same policy. ${ }^{93}$

The congruity of treatment with sex discrimination ends there, however, on at least two counts. First, the EEOC takes the position that the ADA, unlike Title VII, does not prohibit disparate-impact discrimination in fringe benefits. ${ }^{94}$ Second, and of more fundamental concern for this Article, Title V of the ADA includes a safe harbor provision $^{95}$ for insurance that, even as construed by the EEOC, reflects a distinct tilt toward an actuarial fairness approach to insurance. Section 501(c) contains the safe harbor, which excludes from ADA coverage certain actions by insurers and employers sponsoring employee health plans. ${ }^{96}$ According to the EEOC's interpretation of the notoriously ambiguous section 501(c) ${ }^{97}$ a disability-based distinction in coverage that produces unequal benefits violates the ADA unless the employer can show that the challenged provision is not a subterfuge to evade the purposes of the ADA. ${ }^{98}$ One of several ways that the EEOC suggests an employer can make this showing is to demonstrate that "the disabilitybased disparate treatment is justified by legitimate actuarial data, or by actual or reasonably anticipated experience, and that conditions with comparable actuarial data and/or experience are treated the same way." 99 In effect, the EEOC reads section 501(c) as creating a safe harbor for insurance classifications based on disability, as long as they are actuarially supported. ${ }^{100}$ The thinness of this protection stands in marked

92. See supra text accompanying note 73; cf. Jacobi, supra note 30, at 353 n.167 ("Without section 501(c), the ADA would bar employee classifications for purposes of benefits plans on the basis of disability similar to Title VII's prohibition of classification by sex.").

93. See Compliance Manual, supra note 58, at ch. 2 (giving example of AIDS cap).

94. The current version of the Compliance Manual states as follows: "A health-related distinction that is not disability-based, and that is applied equally to all employees, does not violate the ADA." Id. at ch. 3. In a regulatory precursor to this section of the Compliance Manual, the EEOC dropped a footnote to an identical sentence and stated explicitly in the footnote that disparateimpact theory was not available in the context of employer-provided health insurance. EEOC's Interim Enforcement Guidance on the Application of the ADA, at n.2 (Sept. 9, 1993), reprinted in Ruth ColKer, The LAW of Disability Discrimination 469 (1995). See also Hoffman, supra note 61, at 1324-26 (asserting that disparate-impact analysis cannot be used in the context of insurance coverage).

95. 42 U.S.C. $\$ 12201(\mathrm{c})(2000)$.

96. Id.

97. One judge characterized $\S 501$ (c) as "totally ambiguous on its face." Parker v. Metro. Life Ins. Co., 99 F.3d 181, 190 (6th Cir. 1996), rev'd en banc, 121 F.3d 1006 (6th Cir. 1997).

98. Compliance Manual, supra note 58, at ch. 4.

99. Id.

100. Id. For discussions of the scope of $\S 501(\mathrm{c})$ that reach this same general conclusion, see 
contrast to the substantial protection provided by Title VII's prohibition of race- and sex-based distinctions in employer-provided coverage regardless of any actuarial justification. ${ }^{101}$ And even the EEOC's thin protection surpasses that found by the numerous courts that have read the safe harbor effectively to shield any insurance practice that was not adapted for the purpose of evading the ADA. ${ }^{102}$

In one sense, however, the ADA would seem to provide broader protection against health-insurance discrimination than does Title VII, for the ADA applies to health insurers as well as to employers. Title III of the ADA prohibits discrimination by public accommodations, a category that includes insurance offices, ${ }^{103}$ but courts have been quite stingy in applying the public accommodations provisions to health-insurance discrimination. Most appellate courts that have considered the question have found that Title III's prohibition does not apply to the contents of insurance policies, so that insurers remain free to use disability in establishing policy limitations, even if they have no actuarial justification for doing so. ${ }^{104}$ While a number of courts view Title III as at least potentially constraining an insurer's decisions regarding whether to issue a policy to a person with a disability and at what price, ${ }^{105}$ insurance companies' use of disability as a risk classifier in underwriting and pricing decisions is largely immunized under section 501(c). Some courts have interpreted the statute even more restrictively, finding that Title III demands only physical accessibility of insurance offices. $^{106}$

Cole, supra note 86, at 534 (“Section 501(c) represents Congress' reasoned solution to the problem of prohibiting discrimination on the basis of disability when such a prohibition would make insurance underwriting impossible."); Hoffman, supra note 61, at 1341-44 (stating that section 501(c) "allows employers to retain discriminatory insurance terms if they can prove a basis for them in sound actuarial principles").

101. See supra text accompanying notes $81-82$.

102. E.g., Weyer v. Twentieth Century Fox Film Corp., 198 F.3d 1104 (9th Cir. 2000); Leonard F. v. Isr. Disc. Bank, 199 F.3d 99 (2d Cir. 1999).

103. 42 U.S.C. $§ 12181(7)(F)(2000)$.

104. For example, in Doe v. Mutual of Omaha Ins. Co., 179 F.3d 557 (7th Cir. 1999), the Seventh Circuit rejected the plaintiff's claim that Mutual of Omaha's imposition of a cap on coverage that applied only to the treatment of HIV/AIDS violated the ADA. The court based its rejection on its conclusion that Congress did not intend Title III to apply to the contents of insurance policies. Id. at 560-63. Thus, the court held that the plaintiff's claim should be dismissed even though Mutual of Omaha conceded that it had no actuarial justification for its AIDS cap. Id. at 558, 562. See also McNeil v. Time Ins. Co., 205 F.3d 179, 187-88 (5th Cir. 2000) (reaching same result).

105. See, e.g., Pallozzi v. Allstate Life Ins. Co., 198 F.3d 28, 33 (2d Cir. 2000) (stating that Title III prohibits a disability-based refusal to sell merchandise by public accommodations); Doe, 179 F.3d at 559 (stating that an insurance company generally cannot refuse to sell insurance to a person with AIDS)

106. E.g., Weyer, 198 F.3d at 1115; Ford v. Schering-Plough Corp., 145 F.3d 601, 612-13 (3rd 
Thus, despite the ADA's self-proclaimed purpose of providing "a clear and comprehensive national mandate for the elimination of discrimination against individuals with disabilities," 107 the statute as interpreted accepts, rather than eliminates, actuarially justified discrimination in health insurance. ${ }^{108}$ Congress's inclusion of the insurance safe harbor reflected a conscious decision not to disrupt traditional underwriting practices by insurers. Whereas Congress elevated equality concerns over deference to the insurance industry in Title VII, it largely caved to industry concerns regarding federal intrusion into common risk-classification practices. As a consequence, people with disabilities are protected from health-insurance discrimination only if it is irrational or intentionally discriminatory, and they may not receive even that protection if they purchase their health insurance directly from an insurer rather than receiving it as an employment benefit.

\section{Age Discrimination}

As in the cases of race, sex, and disability, the Age Discrimination in Employment Act (ADEA) ${ }^{109}$ announces a federal mandate against discrimination in the terms or conditions of employment or in employee compensation or privileges. ${ }^{110}$ But much as the ADA provides only meager protection against disability-based health-insurance discrimination, so too the ADEA's protection against age discrimination in health benefits is significantly more attenuated than that provided by Title VII. While courts have interpreted Title VII to prohibit both treating employees differently based on race or sex and failing to provide

Cir. 1998). This position seems particularly difficult to justify. Can a restaurant comply with Title III by making its facility completely accessible, but then refuse to serve meals to persons with disabilities or charge them higher prices for the meals? The position also is unnecessary to the purpose of protecting insurers from having to make major changes to their underwriting practices, for the insurance safe harbor accomplishes that purpose.

107. 42 U.S.C. $§ 12101(b)(1)(2000)$.

108. This constricted meaning of discrimination applicable to the health insurance context stands in marked contrast to the expanded definition that the ADA gives to "discrimination" in other contexts. See, e.g., 42 U.S.C. $\S 12112($ b)(5)(A) (2000) (stating that in the employment context "discrimination" includes a failure to make reasonable accommodations to the limitations of an individual with a disability); Olmstead v. L.C. ex rel Zimring, 527 U.S. 581, 600 (1999) (recognizing that under the ADA "unjustified institutional isolation of persons with disabilities is a form of discrimination"). By including $\S 501$ (c) in the ADA, Congress singled out insurance as subject to a far more limited understanding of discrimination, albeit an understanding consistent with that used in state unfair trade practice laws. See supra Part III.A.

109. The ADEA is codified at 29 U.S.C. $\$ \S 621-34$ (2000).

110. 29 U.S.C. $\S 623(a)(1)(2000)$. 
equally comprehensive coverage to both sexes, the ADEA explicitly allows employers to provide older workers with lesser benefits than younger workers. ${ }^{111}$

Under an exemption from the ADEA's antidiscrimination mandate that Congress enacted in $1990,{ }^{112}$ an employer that provides lesser benefits to older workers under the terms of a bona fide benefit plan will not violate the Act if the older workers' benefits cost the employer as much as the younger workers' benefits. ${ }^{113}$ Courts and commentators have described this exemption as creating an "equal benefit or equal cost" test that applies generally to employee benefit plans. ${ }^{114}$ This exemption effectively acknowledges the higher cost of providing health coverage or other insurance for older employees and tolerates employer decisions to scale back accordingly on the coverage provided to older employees ${ }^{115}$ - even though an analogous decision to scale back on women's health benefits in light of their higher cost would certainly be found illegal and intolerable. Thus, the "equal benefit or equal cost" approach to assessing the legality of health coverage under the ADEA can be understood as reflecting a congressional step away from a social solidarity approach to employer-provided health coverage and a step toward an actuarial fairness approach. Significantly, however, the EEOC has signaled recently its intent to eliminate even the limited protection provided by the "equal cost" prong of the test, at least with respect to employer-provided health coverage for Medicare-eligible retirees. ${ }^{116}$

111. Cf. Hoffman, supra note 61, at 1356 (stating that the ADEA "does not comprehensively regulate the contents of health insurance plans and does not require that individuals in different age categories be offered benefits that are substantively equivalent").

112. The Older Workers Benefit Protection Act legislatively overruled the Supreme Court's decision in Public Employees Retirement System of Ohio v. Betts, 492 U.S. 158 (1989), and amended the ADEA to make clear Congress's intent that the ADEA's purpose was to "prohibit discrimination against older workers in all employee benefits except when age-based reductions in employee benefit plans are justified by significant cost considerations." Pub. L. No. 101-433, § 101, 104 Stat. 978, 978 (1990).

113. 29 U.S.C. $\S 623(f)(2)(B)(i)(2000)$.

114. The "equal benefit or equal cost" test does not apply to early retirement incentive programs, which only have to be voluntary and in accord with the ADEA's relevant purposes. 29 U.S.C. § 623(f)(2)(B)(ii).

115. See Auerbach v. Bd. of Educ., 136 F.3d 104, 110 (2d Cir. 1998) ("Realizing that the costs of providing certain employee benefits increases with age, Congress decided that employers need not provide 'exactly the same benefits' to older employees as they do for younger ones, when to do so would result in excessive benefit costs that would discourage employers from hiring older workers in the first place.").

116. Tying the employee benefits available to an individual's eligibility for Medicare implicates the ADEA because it is an exact proxy for age-Medicare eligibility is automatic for persons who turn sixty-five (at least for those who have paid social security taxes for a sufficient period of time). Cf. Gutchen v. Bd. of Governors, 148 F. Supp. 2d 151, 158 (D.R.I. 2001) (noting that Medicare eligibility is "inextricably tied to the retiree's age"). 
A decision by the Third Circuit in 2000 applying the "equal benefit or equal cost" test to an employer's coordination of retiree health plans with Medicare coverage was the genesis of the EEOC's eventual regulatory retreat from any sort of protection against discriminatory treatment for this subset of older persons. In Erie County Retirees Ass'n v. County of Erie, ${ }^{117}$ the court held that the test applied not only to benefits provided to active workers, but also to benefits provided to retirees. Under this holding an employer who decides to reduce or eliminate health benefits for retirees once they are eligible for Medicare coverage would violate the ADEA, unless it could show either that it spent as much on benefits for the older, Medicare-eligible retirees or that the older retirees' benefits were equal to benefits received by younger retirees. $^{118}$

The EEOC initially responded to the Erie County decision by adopting the court's reasoning as its national enforcement policy, but less than a year later, an outcry by labor unions, employers, and benefits experts led the EEOC to reconsider its position. ${ }^{119}$ The concern expressed was that because employers were not legally required to provide any retiree health benefits, the prospect of ADEA litigation over the adequacy of benefits provided to Medicare-eligible retirees might prompt employers to drop retiree plans altogether. ${ }^{120}$ In April 2004, the EEOC approved a proposed final rule creating complete exemption from the ADEA's antidiscrimination rule for the practice of coordinating employer-sponsored benefits with eligibility for Medicare. ${ }^{121}$ This decision to exempt the benefits provided to Medicare-eligible retirees from any ADEA scrutiny drew immediate fire from retiree advocacy

117. 220 F.3d 193, 216 (3rd Cir. 2000).

118. The court noted that, in assessing the benefits to which the older retirees were entitled, the government-paid coverage (Medicare) and the employer-provided coverage should be considered together. Id. at 216. Ultimately, the Third Circuit concluded that the plaintiffs had stated a claim of an ADEA violation, reversed the district court's entry of summary judgment for the county, and remanded the case for further proceedings regarding whether the county could satisfy the "equal benefit or equal cost" standard. Id. at 217 .

119. See, e.g., Christopher E. Condeluci, Comment, Winning the Battle, but Losing the War: Purported Age Discrimination May Discourage Employers from Providing Retiree Medical Benefits, 35 J. MARSHALl L. REV. 709, 714, 716 (2002).

120. See generally id. (arguing that Erie County would result in the elimination of retiree medical plans).

121. Age Discrimination in Employment Act; Retiree Health Benefits, 68 Fed. Reg. 41542 (proposed July 14, 2003) (to be codified at 29 C.F.R. pts. 1625, 1627). The EEOC approved the rule for circulation to other federal agencies and the Office of Management and Budget (OMB), but the rule will not become final until approved by OMB and published in the Federal Register. The U.S. Equal Employment Opportunity Commission, http://www.eeoc.gov/policy/regs/retiree_benefits/ retiree_benefits.html (last visited Oct. 27, 2005). See also Robert Pear, Agency to Allow Insurance Cuts for the Retired, N.Y. TIMES, Apr. 23, 2004, at A1 (reporting on the EEOC's action). 
groups, and as the 2004 presidential campaign intensified, the EEOC temporarily shelved the regulation. ${ }^{122}$ Following the election, the Commission renewed its pursuit of the exemption, only to have its proposed rule struck down as a violation of the ADEA in a challenge brought by the AARP. ${ }^{123}$

This course of events illustrates how a demand for fairness in insurance coverage - even in the weak sense of actuarial fairness-is subject to being overridden by competing political concerns. As noted, Congress's enactment of the "equal benefit or equal cost" test reflects the adoption of an actuarial fairness approach to older employees' claims of health-insurance discrimination. ${ }^{124}$ But the EEOC's proposal to exempt from ADEA coverage employers' attempts to coordinate a retiree health plan with Medicare coverage signals the agency's willingness to abandon fairness entirely in hopes of encouraging employers to maintain their retiree plans. Thus, the goal of nondiscrimination or fairness for older persons in employer-sponsored health coverage appears simply as one goal to be balanced against others.

Ironically, the reason that maintaining retiree health plans is so important is that they often provide the only viable coverage option for younger retirees, who- because state laws do not typically proscribe age discrimination by insurers - may be unable to afford individual coverage once they retire and are no longer covered by employee plans. Thus, the question for retirees may be whether they prefer to remain in the frying pan of retiree health plans exempt from ADEA coverage or to jump into the fire of the individual health insurance market.

122. Employee Benefits: EEOC Proposal on Health Benefits Unlikely to Survive Due to AARP Opposition, BNA's HeAlth CARE DAILY REPORT, July 30, 2004, http://pubs.bna.com/ip/BNA /hce.nsf/is/a0a9f0w4n4.

123. AARP v. EEOC, No. 05-CV-509, 2005 WL 723991, at *6 (E.D. Pa. Mar. 30, 2005). The EEOC has indicated its intent to appeal the district court's ruling to the Third Circuit Court of Appeals. Press Release, The U.S. Equal Employment Opportunity Comm'n, EEOC Seeks to Appeal Court Order on Retiree Health Benefits Rule (Mar. 30, 2005), available at http://eeoc.gov/press/330-05.html.

124. The idea that equality of employer contribution is an acceptable alternative to equality of benefit received is not exactly the same as the vision of actuarial fairness described earlier in this Article, which focused primarily on the insurer's perception of fairness regarding the amount that insureds should be charged in relation to their actuarially predicted future health costs. Instead, the equal cost prong addresses fairness from the perspective of an employer, in light of insurers' actuarially based charges for health insurance. 


\section{Genetic Discrimination}

In contrast to race, sex, disability, and age discrimination, where the federal government has played the leading role in addressing health-insurance discrimination (albeit indirectly by prohibiting employment discrimination), the states have to date outstripped the federal government in protecting individuals from insurers' discriminatory use of genetic information. These state laws are of relatively recent advent, prompted by advances in genetic science that permit individual testing to determine the presence of a growing number of genetic markers associated with an elevated risk of developing conditions ranging from breast cancer, to diabetes, to Alzheimer's disease. ${ }^{125}$ These genetic advances, while widely acclaimed for their potential to prevent, detect, and treat disease in the future, ${ }^{126}$ have simultaneously provoked fears that insurers and employers will seek to obtain and use genetic information about individuals. ${ }^{1}$

Beginning in the 1990s, most state legislatures responded to these fears. ${ }^{128}$ Legislation broadly regulating health insurers' use of genetic information for risk-classification purposes ${ }^{129}$ has been described as evolving from a first wave of laws that barred insurers from considering the results of particular genetic tests, to more recent laws that forbid insurers' consideration of information about a person's genetic characteristics, regardless of the information's source. ${ }^{130}$ By prohibiting a variety of risk-classification uses and defining broadly the genetic information protected, these newer laws clearly reject an actuarial fairness approach to health insurance - at least with respect to this

125. See Colin S. Diver \& Jane Maslow Cohen, Genophobia: What is Wrong with Genetic Discrimination?, 149 U. PA. L. REV. 1439, 1442-44 (2001) (stating that the prospect of genetic testing has led to apprehension, which has generated legislation).

126. Id. at 1441.

127. Id. at 1444 .

128. According to Deborah Hellman, as of 2003, forty-six states had enacted laws prohibiting genetic discrimination in insurance. Deborah Hellman, What Makes Genetic Discrimination Exceptional?, 29 AM. J.L. \& MED. 77, 77 n.2 (2003). Some state legislatures passed earlier laws that kept insurers from considering the presence of particular recessive genetic traits that were irrelevant to the individual carrier's health risks. As John Jacobi points out, these laws harmonized with "the general rule requiring actuarial justification" for classifications. John V. Jacobi, Genetic Discrimination in a Time of False Hopes, 30 FLA. ST. U. L. REV. 363, 374 (2003).

129. In addition to passing anti-discrimination laws preventing the use of genetic information, some states have passed laws establishing privacy rules to protect the confidentiality of genetic information and keep it out of the hands of possible discriminators. Jacobi, supra note 128, at 367.

130. Id. at 374-75. 
particular type of risk-predictive information. ${ }^{131}$ As a result, at least some individuals ${ }^{132}$ in some states receive strong protection against having their genetic information used against them by health insurers.

By contrast, existing federal law provides far less protection against genetic discrimination in health insurance. Initially, the EEOC and some commentators thought the ADA could be read to prohibit discrimination based on an asymptomatic genetic condition, ${ }^{133}$ but subsequent judicial interpretations of the ADA have narrowed considerably the range of conditions qualifying as disabilities. ${ }^{134}$ Accordingly, it seems highly unlikely that a court would apply the ADA to a health insurer's reliance on an individual's genetic information. HIPAA, which is discussed in Part IV.C, provides some protection by prohibiting group health plans from excluding an individual from a group plan or charging him higher premiums for coverage based on "genetic conditions." protection for group plan members, however, current federal law does not regulate the ability of health insurers to use genetic information for risk-classification purposes. ${ }^{136}$

131. See, e.g., CONN. GEN. StAT. § 38a-816(19) (2000) (defining as an unfair practice an insurer's use of genetic information to refuse to insure; to limit the amount, extent, or kind of coverage available; or to charge a different rate for the same coverage). As Deborah Hellman points out, however, because so many illnesses increasingly are understood as being influenced by genetics, laws employing these broader definitions of the "genetic information" that insurers cannot use "seemingly prohibit[] almost all forms of discrimination on the basis of health, except perhaps illness or disability caused by accident." Hellman, supra note 128 , at 80 .

132. This qualification is necessary for at least two reasons. First, some state genetic discrimination laws apply only to group insurers, not to issuers in the individual market. Hellman, supra note 128, at 77 n.2. Second, even in those states that have passed legislation regulating the nongroup market, the protection falls far short of being complete because the Employment Retirement Income Security Act (ERISA) prevents state insurance laws from being applied to selfinsured employer benefit plans. See Eric Mills Holmes, Solving the Insurance/Genetic Fair/Unfair Discrimination Dilemma in Light of the Human Genome Project, 85 KY. L.J. 503, 594-97 (1996-97) (noting this effect of ERISA's deemer clause).

133. See 2 U.S. Equal Employment OpPoRtunity COMm'N, COMPLiance MANuAl, Order 915.002, at 902-45 (1995) (interpreting the ADA to prohibit genetic discrimination); Paul Steven Miller, Is There a Pink Slip in My Genes? Genetic Discrimination in the Workplace, 3 J. HEALTH CARE L. \& POL'Y 225, 230 (2000).

134. Moreover, as discussed above, even if an unmanifested genetic condition were deemed a disability under the ADA, that law's protection against insurance discrimination has been read quite narrowly. See supra Part III.B.3.

135. 42 U.S.C. § $300 \mathrm{gg}-1$ (2000). HIPAA also provides that an unexpressed genetic condition cannot be treated as a pre-existing condition by a group health plan. 42 U.S.C. $\S 300 \operatorname{gg}(\mathrm{b})(1)(\mathrm{B})$ (2000).

136. In October 2003, the Senate unanimously passed the Genetic Information Nondiscrimination Act of 2003, which would have broadly barred insurance companies from using genetic information about an individual to grant or deny health coverage or to adjust premiums. Laurie McGinley, Senate Passes Bill Barring Genetic Discrimination, WALl St. J., Oct. 15, 2003, at D11. It unanimously passed a similar measure in February 2005. Faun H. Johnson, Senate Overwhelmingly Passes Genetic Bias Bill; Rep. Boehner Promises 'Another Look, ' HeAlth CARE 
Whether health insurers should be forbidden to use an individual's genetic information in a discriminatory fashion is a question that has generated copious scholarship. ${ }^{137}$ Central to the debate is the justifiability of "genetic exceptionalism." To wit, what justifies prohibiting health insurers from considering genetic characteristics, when they are permitted to use other types of health information in classifying risks? ${ }^{138}$ What is it about genetic information that justifies the exceptional legal protection it receives? ${ }^{139}$

While some commentators reject genetic exceptionalism as unjustifiable, ${ }^{140}$ others suggest plausible reasons for the exceptional treatment. ${ }^{141}$ Professor Deborah Hellman, for example, notes that legislation prohibiting insurers' use of genetic information may be necessary to enable genetic science to make good on its promises of health benefits to individuals and society more broadly. ${ }^{142}$ Individuals who fear genetic discrimination may be less likely both to seek genetic testing that might offer them some health benefits and to participate in medical research that entails testing. ${ }^{143}$ Professor John Jacobi, while recognizing that persons with unfavorable genetic traits may not deserve protection from insurance discrimination any more than persons with other types of health problems, nonetheless views genetic discrimination laws as a desirable step toward broader social solidarity reforms of health insurance. $^{144}$

These justifications for laws prohibiting genetic discrimination are notably and essentially instrumental. Rather than invoking the "civil

DAILY REP., Feb. 18, 2005, http://pubs.bna.com/ip/BNA/hce.nsf/is/a0b0k8r3h5. Notwithstanding broad support for the measure in the Senate and an expression of support from President George W. Bush, the House refused to take up the measure. Julie Rovner, Johnson Says Genetic Discrimination Bill Unlikely to Move, CONG. DAILY, July 22, 2004.

137. In addition to the sources cited in this Section, see the sources listed in Hellman, supra note 128 , at 78 nn.5-7.

138. See id. at 78 ("[T]he question that dominates current literature is whether genetic discrimination is meaningfully different from discrimination on the basis of general health status.").

139. Id.

140. E.g., Diver \& Cohen, supra note 125, at 1445.

141. Hellman, supra note 128 , at 83 .

142. Id. at 92-94. Hellman emphasizes, however, that the strength of this justification depends on empirical questions that are as yet unanswered. Id. at 94 . She also suggests that genetic exceptionalism may be justified because "the social meaning of treating people differently on the basis of their genetic make-up is different from the social meaning of discrimination on the basis of health or illness." Id. at 79. She catalogs and rejects, however, several other proffered rationalizations for exceptionalism, such as claims that genetic discrimination should be prohibited because it is irrational, because genes are beyond individuals' control, or because a small number of people are especially burdened. Id. at 84-92.

143. Id. at 92 .

144. Jacobi, supra note 128 , at 391-94. 
rights" of genetically disadvantaged persons ${ }^{145}$ or demanding some form of justice for them, ${ }^{146}$ these scholars suggest that genetic discrimination laws, with their explicit rejection of an actuarial fairness approach, ${ }^{147}$ may make sense as means to a broader purpose - whether the production of societal health benefits or health insurance reform. In this view, legal prohibitions on discrimination against genetically disadvantaged persons can co-exist with legal permissiveness toward discrimination against otherwise unhealthy (or likely to become unhealthy) persons, not because of any analytically satisfying distinction between the two groups of individuals, but because of other policy concerns.

\section{Discrimination Against Victims of Domestic Violence}

In the same period when state legislatures were passing laws prohibiting health insurers' discriminatory use of genetic information, insurers' discrimination against victims of domestic abuse also was prompting legislative responses. ${ }^{148}$ Unlike genetic discrimination laws, however, which resulted from public fears of the potential uses of emerging genetic information, laws regulating the use of domestic abuse information reflected public disapproval of evidence of insurers' actual use of information about an insured's or applicant's experience of domestic violence in making underwriting decisions. ${ }^{149}$ From the insurance industry's perspective, information that an individual has experienced domestic abuse is simply information that - like information about an individual's medical history, age, occupation, and sex-helps an insurer predict the individual's likelihood of making future medical claims, so the insurer can hew to the principle of actuarial fairness in deciding whether and at what price to provide the individual with

145. See Diver \& Cohen, supra note 125 , at 1473 (finding the analogy between racial discrimination and genetic discrimination unconvincing); Pauline T. Kim, Genetic Discrimination, Genetic Privacy: Rethinking Employee Protections for a Brave New Workplace, 96 Nw. U. L. REV. 1497, 1500-01 (2002) (arguing that "the analogy between genetic discrimination, and race and sex discrimination, is fundamentally flawed" and that the problem of genetic discrimination in employment should properly be understood as threatening an individual's privacy rights).

146. Indeed, Deborah Hellman makes the point that genetic discrimination laws are arguably unjust because their health-promoting benefits are not applied evenhandedly. Hellman, supra note 128 , at 99.

147. See Jacobi, supra note 128 , at 375 (asserting that state genetic discrimination laws "demonstrate a legislative determination to shift the meaning of non-discrimination from a principle requiring equal treatment absent an actuarial showing of difference to one requiring equal treatment notwithstanding actuarial difference").

148. Sheri A. Mullikin, A Cost Analysis Approach to Determining the Reasonableness of Using Domestic Violence as an Insurance Classification, 25 J. LEGIS. 195, 210 (1999).

149. See id. at 216-19 (giving reasons why use of domestic violence evidence is criticized). 
coverage. ${ }^{150}$ The industry account, however, was not compelling enough to persuade the public and legislators that insurers should have free rein in using domestic abuse information to (as it was sometimes put) victimize an individual a second time, and during the 1990s a majority of states passed laws regulating that use. ${ }^{151}$

The states' legislative responses, though, are quite diverse ${ }^{152}$ and thus fail to reflect any consistent understanding as to when or why the use of domestic violence information in the underwriting process is illegitimate. They do, however, usefully illustrate the variety of legislative views of what fairness in health insurance entails. ${ }^{153}$ Some state laws merely instruct insurers not to deny or limit coverage "solely because" of a person's status as a domestic violence victim. ${ }^{154}$ This bare prohibition, however, permits an insurer to consider a person's victim status as long as it also relies on other, actuarially relevant information that may be related to abuse - such as a history of emergency room visits or the lingering physical or mental effects of abuse. ${ }^{155}$ These laws reject discrimination based purely on a person's status, but condone application of general underwriting standards to information about conditions or injuries ancillary to that status. ${ }^{156}$ Laws that more generally prohibit any underwriting use of an "abuse victim" classification are only slightly stronger; although they prevent insurers from singling out victims of abuse for special treatment, they do not protect abuse victims-whether identified as such or not - from the possibility that a history of claims or existing injuries will affect their ability to obtain affordable coverage. ${ }^{157}$ In short, both of these types of laws effectively prohibit insurers from treating domestic violence victims differently from other persons, while simultaneously embracing a vision of actuarial fairness. Insurers cannot

150. As one commentator wrote on the Web site of the Competitive Enterprise Institute, "it is extremely disingenuous to suggest insurers are practicing unfair discrimination when they respond to the higher loss costs associated with domestic violence by raising rates or denying coverage. That is, after all, how insurers treat all high-risk insureds." Robert Detlefsen, Abusing Discrimination, MONTHLY PlaneT, Aug. 1, 1997, http://www.cei.org/gencon/005,01239.cfm.

151. Since 1994, forty-one states have adopted some kind of legislative limits on insurance discrimination against victims of domestic violence. WOMEN'S LAW PROJECT \& PENNSYLVANIA

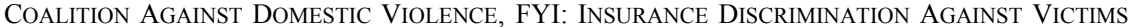
OF DOMESTIC VIOLENCE (2002), available at www.pcadv.org (follow "Publications" hyperlink; then follow "Insurance FYI" hyperlink).

152. Hellman, supra note 19 , at 404.

153. See id. at 404-10 (analyzing the legislation).

154. Id. at 404.

155. Id.; N.Y. INS. LAW. $§ 2612$ (d) (McKinney 2000).

156. See Hellman, supra note 19, at 405 (citing statute allowing for this underwriting).

157. See id. ("[U]sing medical histories alone may serve the insurer's goals almost as well as using the prohibited abuse victim classification."). 
deny coverage or increase premiums because of abuse-victim status, but they remain free to engage in underwriting based on health status or medical history.

By contrast, some states have enacted laws that more broadly limit insurers' ability to underwrite coverage in ways that have a discriminatory impact on abuse victims, such as predicting future claims based on medical records of repeated emergency room visits for abuserelated injuries. ${ }^{158}$ These laws effectively take the stance that, even if it is acceptable generally to consider an individual's medical history in predicting future claims, it is unacceptable to underwrite based on a history of abuse-related injuries. ${ }^{159}$ Such laws therefore tend toward a social solidarity view ${ }^{160}$ of health insurance for victims of domestic violence.

Of course, as with genetic discrimination laws, legislation that specially protects abuse victims against insurers' pursuit of actuarial fairness poses the question of how to justify insulating this group from generally applied risk-classification practices. In other words, how is the prohibited underwriting classification of "abuse victim" analytically distinguishable from the permissible classification of "person with diabetes"? Justifications advanced for the distinctive treatment of abuse victims are diverse. One justification typically advanced is instrumental: abuse victims should be encouraged to report their abuse and seek medical and other support services, and allowing insurers to use information gathered through reporting and the provision of services to deny coverage for abuse victims will discourage those desired activities. ${ }^{161}$ Beyond the purely instrumental justification, however, is the argument that domestic violence against women presents a civil rights issue, and therefore insurance discrimination against abuse victims

158. See id. at 406 (describing how some laws prevent insurers from substituting one predictor for another).

159. See, e.g., W. VA. CODE $\S 33-4-20(\mathrm{~d})(2)$ (2003) (allowing underwriting on the basis of a preexisting condition, provided that "the fact that an individual is, has been, or may be the victim of abuse may not be considered a physical or mental condition").

160. These laws do not fully embody a social solidarity view, however, unless they also prohibit an insurer from either refusing to cover an existing abuse-related condition under a pre-existing condition clause or exclusionary waiver or charging the insured a higher premium based on the condition.

161. See Ellen J. Morrison, Note, Insurance Discrimination Against Battered Women: Proposed Legislative Protections, 72 IND. L.J. 259, 286 (1996) ("Insurance discrimination discourages battered women from seeking necessary medical treatment and legal intervention, deters them from filing insurance claims, and constructs one more economic barrier that prevents victims from leaving abusive environments."). 
implicates gender equality. ${ }^{162}$ Finally, Professor Deborah Hellman suggests a moral justification for the distinction:

The state has a clear and uncontroversial obligation to provide crime protection and to do so on a fair basis .... The suspicion that an illegitimate tolerance toward domestic violence has affected the amount of protection afforded domestic abuse victims, and consequently, the degree of safety they enjoy, means that the state has likely failed to provide the required crime protection fairly. As a result, the community should share the cost the abuse victim faces by virtue of the fact that she is a poor insurance risk. ${ }^{163}$

In this view a social solidarity approach is justified for abuse victims because society itself bears some responsibility for their high-risk status. $^{164}$

In sum, no single understanding has emerged regarding either when or why insurers' use of domestic abuse information in classifying risks is illegitimate. Notwithstanding this lack of consensus, the variety of both legislative restrictions on that use and the justifications offered for the restrictions well illustrate the tensions between an actuarial fairness vision of health insurance and a social solidarity vision, as well as the challenges in justifying the extension of a social solidarity approach to some, but not all, members of a community.

\section{Discrimination Against Persons with Mental Illness}

Legislation prohibiting health insurers from limiting coverage for mental health-care services presents yet one more instance in which legislators have intruded on insurers' freedom, but this instance has a different look and feel. ${ }^{165}$ Unlike the laws discussed previously, mental health parity legislation does not on its face follow an antidiscrimination

162. See id. at 285-86 (relying on congressional enactment of the Violence Against Women Act of 1994); see also Hellman, supra note 19, at 383 (pointing out that gender equality justification is significantly weakened by the fact that states typically permit health insurers to use sex in rating risks).

163. Hellman, supra note 19 , at 410.

164. Id. at 411. Although much of Hellman's discussion assumes the justifiability of risk rating generally, she also acknowledges that the "strong outcry" against the use of abuse information in underwriting may suggest a more fundamental concern about the fairness of risk classification generally. $I d$. at 359. In that case, she supports legislative prohibitions against the use of abuse information "as an important first step toward a fairer system of health insurance pricing." Id.

165. See John V. Jacobi, Parity and Difference: The Value of Parity Legislation for the Seriously Mentally Ill, 29 AM. J.L. \& MED. 185 (2003) (describing state and federal mental health parity legislation). 
model. Instead, rather than prohibiting health insurers from taking an individual's mental health condition into account in deciding whether to issue or how to price a policy, mental health parity laws govern the benefits that health insurers are required to include in their policies. For example, the federal Mental Health Parity Act of $1996^{166}$ provides that employer-sponsored plans governed by the Act cannot include annual or lifetime limits on coverage of mental health services that are more restricted than parallel limits on physical health coverage. ${ }^{167}$ More aggressively, some states have enacted parity laws compelling health insurers to cover mental health services as generously in all regards as physical health services. ${ }^{168}$

In sum, mental health parity legislation focuses on the content and terms of insurers' generally provided coverage packages rather than focusing on who receives or is denied coverage. The purpose of the focus on content, however, is to assure persons with mental illness or disability that health insurance will cover their health needs as fully as it covers the health needs of persons with only physical ailments. In this way, parity legislation echoes the Supreme Court's conclusion in Newport News that insurance policies discriminate based on sex if they fail to cover the medical needs of men and women equally comprehensively. ${ }^{169}$ So understood, mental health parity laws explicitly forbid disparate-impact discrimination (or at least specified types of disparate-impact discrimination) against persons with mental illness, without addressing disparate-treatment discrimination.

What has motivated legislatures to pass mental health parity laws? In part these laws seek to correct traditional imbalances in insurance coverage of mental and physical health treatments - imbalances that today are understood to embody both misconceptions of the nature of mental illness and deep-seated prejudices against persons with mental illness. ${ }^{170}$ In this sense, parity legislation stands in line with state and

166. Pub. L. No. 104-204, 110 Stat. 2944 (1996) (codified at 29 U.S.C. $§ 1185$ a (2000) and 42 U.S.C. § $300 \mathrm{gg}-5(2000))$.

167. Id. Because its obligations are quite limited (most fundamentally, the Act does not require employers to provide mental health coverage) and subject to separate exemptions for employers with fifty or fewer employees and for employers whose health costs increase by one percent or more as a result of compliance, commentators have doubted the legislation's actual impact on coverage for persons with mental illness. See Patrick J. Kennedy, Why We Must End Insurance Discrimination Against Mental Health Care, 41 HARV. J. ON LEGIS. 363, 366 (2004) (characterizing the law's impact as slight); see also Jacobi, supra note 165, at 192 (describing the law as "very mild").

168. See Jacobi, supra note 165 , at 190-91 (describing state parity legislation).

169. See supra text accompanying note 73 .

170. See Kennedy, supra note 167 , at 364 (stating that millions hide mental disease for "fear of prejudice"); see also Brian D. Shannon, Paving the Path to Parity in Health Insurance Coverage for 
federal civil rights laws that forbid discrimination against members of historically disadvantaged groups. ${ }^{171}$ This civil rights justification, however, dovetails with government interests in ensuring that persons with mental health needs have access to needed care and thereby avoid the social and economic costs of untreated mental illness. ${ }^{172}$ Accordingly, these laws seek simultaneously to combat inequality and inadequacy in health insurance coverage.

\section{What to Make of All These Laws}

Undertaking to place all the foregoing laws into some harmonious and analytically coherent framework is likely a futile effort, and one that is certainly beyond the scope of this Article. Nonetheless this Part's descriptions prompt several observations germane to my project of considering whether government should intervene when health insurance coverage discriminates - in treatment or effect-against unhealthy people. First, the variety of laws prohibiting discrimination in health insurance demonstrates that insurer freedom to pursue actuarial fairness is not sacrosanct. The laws described in this Part confirm lawmakers' willingness to place an assortment of constraints on insurers' and employers' autonomy; they also display a remarkable lack of consistency in how they do so. The various antidiscrimination laws examined supply differing levels and types of protection, depending on the trait at issue. Some protect only against different treatment; others extend to disparateimpact discrimination. Demands for actuarial fairness by insurers and employers, as well as political expediency, significantly limit the laws' protections in some cases (for example, disability and age discrimination), but not in others.

More importantly, no single justification motivates each of the antidiscrimination laws described in this Part. Civil rights and social equality concerns certainly inspire some of the protections, but in other instances (for example, laws forbidding discrimination based on genetic or domestic violence information), instrumental goals regarding the

Mental Illness: New Law or Merely Good Intentions?, 68 U. Colo. L. ReV. 63, 66-69 (1997) (discussing insurance discrimination for people with mental illnesses, based partially on prejudice and stigma).

171. See Kennedy, supra note 167 , at 364 (referring to a "civil rights struggle remaining to be fought"); see also Deborah Stone, Beyond Moral Hazard: Insurance as Moral Opportunity, 6 ConN. INS. L.J. 11, 40 (1999) (noting how advocates for improved mental health coverage "successfully invoked equality to improve coverage").

172. See Kennedy, supra note 167 , at 370-72 (stating that costs to society of mental illness are staggering); see also Jacobi, supra note 165, at 189-90 (discussing public costs of uninsured). 
advancement of tangential social concerns appear to play significant roles. Moreover, underlying a number of the laws is the recognition of the vital importance of health insurance to ensuring that individuals who need medical care have adequate access to it. In sum, no single model exists for laws regulating discrimination in health insurance, and therefore an advocate for limiting discrimination against the unhealthy in health insurance may choose among varying rationales for the limits sought. The next Part examines the limited extent to which such protections have already been enacted.

\section{LAWS ADDRESSING HEALTH-STATUS DisCRIMINATION}

The previous Part demonstrates that federal and state lawmakers have encroached on the ability of health insurance providers to discriminate on a variety of bases. Notably absent from that Part's catalog of proscribed bases for discrimination, however, is health status. Admittedly, some forms of prohibited discrimination are closely related to an individual's current health status - disability discrimination, genetic discrimination, and discrimination against victims of domestic violence certainly fall into this category. Further, the Mental Health Parity Act, by prohibiting differential coverage limits for physical and mental health care, provides some protection directly to persons with mental illness. Nonetheless, the laws discussed so far do not instruct insurers or employers providing health coverage that they cannot make decisions regarding the issuance, terms, or pricing of insurance coverage based on an individual's current or past health status. None of these laws forbids an insurance provider from taking into account that an individual has high cholesterol, has received treatment for depression, or has been diagnosed with cancer. ${ }^{173}$

173. The exception, of course, is if an individual's health condition rises to the level of a disability so that the protections of the Americans with Disabilities Act apply. A person qualifies as an "individual with a disability" if she can show that she either (1) has a "physical or mental impairment that substantially limits one or more major life activities," (2) has a "record of" such an impairment, or (3) is "regarded as having such an impairment." 42 U.S.C. $§ 12102$ (2000). Although this definition is potentially expansive, the courts-led by the United States Supreme Court-have construed the definition narrowly. See, e.g., Murphy v. United Parcel Serv., Inc., 527 U.S. 516, 523 (1999) (finding that an employee with high blood pressure was not disabled under the ADA). Consequently, the legal thresholds for an individual to prove either that whatever health impairment she suffers "substantially limits" her performance of a "major life activity" or that she is "regarded as" having such an impairment are today higher than the proponents and drafters of the Act expected them to be. See Chai R. Feldblum, Definition of Disability under Federal AntiDiscrimination Law: What Happened? Why? What Can We Do About It?, 21 BerKeleY J. EMP. \& LAB. L. 91, 93 (2000). 
This Part takes up the task of examining the extent to which existing law constrains the ability of insurance providers to rely on health-status information. To put it more bluntly: does the law prohibit health insurers from discriminating against the unhealthy? Admittedly, posing this question often provokes an incredulous response: isn't that exactly what health insurers do all the time? Indeed, when an insurer classifies an individual or small group on the basis of risk, medical information about the prospective insured is typically central to the classification process. One might wonder whether any valid predictive basis for risk classification exists if an insurer cannot classify risks of future medical expenses based on an applicant's past or existing health conditions. While some other bases for predicting future medical expenses might remain, a complete ban on using individuals' health-status information would significantly limit insurers' capacity for accurate risk prediction.

Rather than debate whether that outcome would represent an advance or setback in health insurance policy, this Part adopts the more discrete and concrete purpose of briefly examining the current legal landscape for limits on this type of discrimination. For starters, neither the states nor Congress has taken up a "no discrimination against the unhealthy" banner, and state laws regulating insurance have even been interpreted as compelling such discrimination. At the same time, though, federal law regulating group health coverage and a number of state laws regulating health insurance premiums function to limit insurance providers' ability to engage in some forms of health-status discrimination.

\section{A. State Laws Prohibiting "Unfair Discrimination" in Health Insurance}

Because the states are primarily responsible for regulating insurance, it makes sense to look first to state law for any prohibitions on healthstatus discrimination. As discussed previously, a number of states have laws prohibiting or limiting insurers' use of particular types of information in classifying risks, and some of this off-limits information - such as genetic information or information about domestic violence-may in fact be linked to an individual's health status. Notwithstanding these specific prohibitions, states do not have laws that generally preclude health insurers from using health status as a risk classifier. Indeed, the most relevant state laws dealing with health-insurance discrimination generally have been interpreted by some courts as requiring health-status discrimination.

All states have passed some form of unfair trade practices legislation applicable to health insurance, and among the unfair trade practices that health insurers are forbidden to engage in is "unfair discrimination." 
These statutes are based, to varying degrees, on the model Unfair Trade Practices Act (UTPA) $)^{174}$ promulgated by the National Association of Insurance Commissioners, which bans health insurers from "unfair discrimination between individuals of the same class and of essentially the same hazard." 175 Without further explication, this language simply re-presents the central question at the "struggle for the soul of health insurance." To wit, is it "fair" for each insured to pay a premium that reflects as closely as possible his own predicted costs of medical care (the actuarial fairness view), ${ }^{176}$ or is it "fair" for risks to be pooled broadly so that persons who are poor risks are not required to carry their burdens alone (the social solidarity view)?

Although commentators and regulators adopted varying stances on what discrimination is "unfair" under these state laws, the resolution of the debate in the late 1980s regarding insurers' use of HIV-testing results suggests that, at least with respect to health-status classifications, ${ }^{177}$ an actuarial fairness understanding has become dominant. The debate arose in the mid-1980s, when several states passed laws or regulations restricting insurers' efforts to determine insurance applicants' HIV status. ${ }^{178}$ By restricting insurers' ability to classify risks based on an individual's HIV status, the laws functioned to prevent discrimination based on a particular medical condition. Predictably, the insurance industry argued forcefully that the HIV-testing laws misapprehended the basic tenets of insurance underwriting and would unfairly force uninfected persons to shoulder the considerable costs of covering persons with HIV and AIDS. ${ }^{179}$ In challenges to regulations banning HIV testing, courts accepted these arguments regarding the meaning of fair

174. Model Unfair Trade Practices Act (Nat'l Ass'n of Ins. Comm'rs 2001).

175. Id. $\S 4(\mathrm{G})(2)$.

176. This view is espoused by Clifford \& Iuculano, supra note 41, at 1811 ("[U]nder [UTPA] insurers have a positive duty to separate insureds with identifiable, serious health risks from the pool of insureds without those risks.").

177. By contrast, as discussed supra note 53 and accompanying text, some states reached the conclusion that the use of racial classifiers were prohibited as a form of unfair discrimination. Although race may be a weaker predictor of future losses than health-status information, commentators have pointed out that the differing life expectancies between black persons and white persons provide racial classifications with some actuarial basis. See Jerry \& Mansfield, supra note 50 , at 352 .

178. See JERRY, supra note 30, at 145-47 (describing concerns about the potential for breaches of confidentiality and the potential for covert discrimination against homosexual men as prompting these bans).

179. Clifford \& Iuculano, supra note 41, at 1811 (suggesting that a failure of insurers to assess the AIDS risk of prospective insureds would represent "a forced subsidy from the healthy to the less healthy"). These commentators also argue that laws restricting insurers' ability to require HIV testing "substantially impede the insurance industry's ability to assess risk, thereby undercutting the industry's financial stability and compromising its ability to pay future claims." Id. at 1815. 
discrimination and struck down the regulations as exceeding the regulators' statutory authority. ${ }^{180}$ Thus, few today would argue that state unfair discrimination laws protect unhealthy individuals from riskclassification practices that conform to actuarial fairness.

\section{B. State Laws Regulating Health Insurance Premiums}

Although state insurance unfair trade practice acts have been interpreted to incorporate an actuarial fairness standard, the passage of state laws reforming the small-group and individual health insurance markets beginning in the early 1990s significantly infringed upon insurers' ability to discriminate against unhealthy persons based on health status. ${ }^{181}$ Legislators concerned about rising levels of uninsurance and evidence of market failure in the small-group and individual insurance markets undertook these reforms in an attempt to make private health insurance more available and affordable. ${ }^{182}$ Thus, these reforms can be understood as efforts to "shore up" the weakest aspects of the private health insurance market and stave off calls for more comprehensive reform. ${ }^{183}$

180. E.g., Health Ins. Ass'n of Am. v. Corcoran, 551 N.Y.S.2d 615, 622-23 (N.Y. App. Div. 1990), aff'd, 565 N.E.2d 1264 (N.Y. 1990); Life Ins. Ass'n of Mass. v. Comm'r of Ins., 530 N.E.2d 168, 173 (Mass. 1988). In addition, on the legislative front, most of the statutory bans were subsequently repealed.

181. A clarification is called for here. To the extent that small-group market reforms implemented community rating or other reforms for small-group policies, these laws cannot be understood as protecting any particular individual against health-status discrimination. Instead, the small-group market reforms prohibit certain types of insurer discrimination between healthy and unhealthy groups. Although we cannot understand the group reforms as providing protection to any particular individual against health-status discrimination, I discuss the small-group and individual health insurance market reforms together in this section because both types of reform display a conviction that unhealthy persons (whether group members or those seeking individual coverage) should not be denied access to health insurance or have to bear the expected cost of their predicted poor health. Thus, these laws embody some level of commitment to the social solidarity view that entails a pooling of risk. For a useful compilation of state-level health insurance reforms (including both individual and small-group markets) as of August 1,2001, see a chart compiled by the National Association of Health Underwriters at http://www.nahu.org/government/resources/state_health_\%20 reforms_1101.pdf.

182. See Beth C. Fuchs, Robert WoOd JohnSON Found., EXPANDing THE INDIVIDUAL

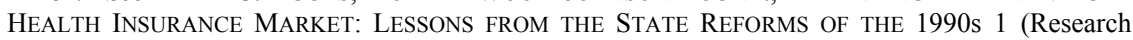
Synthesis Report No. 4, 2004), available at http://www.rwjf.org/publications/synthesis/ reports_and_briefs/pdf/n04_synthesisreport.pdf (explaining that the states "enacted laws designed to increase the availability and affordability of individual health insurance" hoping to keep the uninsured rate from growing); Jacobi, supra note 30, at 369-70 (discussing market failure as a cause of high uninsurance rates).

183. Mark A. Hall, Public Choice and Private Insurance: The Case of Small Group Market Reforms, 1998 U. ILL. L. REV. 757, 766. 
One element of these private market reforms was laws passed by a minority of states that required insurers to employ community rating in pricing their policies. Under a system of community rating, insurers charge the same premium to all insureds in a geographic location for a particular benefit package. ${ }^{184}$ Although some states enacting community-rating reforms allowed insurers to vary premiums based on demographic characteristics such as age or gender, the community-rating laws prohibited insurers' use of health information in setting premiums. In this sense, the states that passed community-rating laws outlawed discrimination against the unhealthy in the pricing of health coverage. ${ }^{185}$ These laws favor the social pooling of risk, explicitly call for good health risks to subsidize the cost of poor health risks, and, from the insured's point of view, establish a right to pay no more than the community average cost of insurance. ${ }^{186}$

Of course, as the earlier discussion of the various ways that health insurers discriminate suggests, if state legislation precludes discrimination in pricing, insurers are likely to simply shift their focus to underwriting and coverage decisions as mechanisms for segmenting the market by health status. ${ }^{187}$ Although other elements of the small-group and individual market reforms of the 1990s limited insurers' ability to engage in discriminatory underwriting or coverage practices, ${ }^{188}$ most

184. Russell Korobkin, Determining Health Care Rights from Behind a Veil of Ignorance, 1998 U. ILL. L. REV. 801, 816.

185. Most states, however, did not include community rating laws in their insurance market reforms and instead passed laws imposing "rating bands" on health insurers. See Hall, supra note 183 , at 765 (stating that adjusted community rating and rating bands are used more commonly than pure community rating for setting premiums). These laws permit insurers to use health-status factors as a basis for varying the premiums charged within particular demographic classifications, but limit the range of variation permitted. Id. Rating-band laws, therefore, permit insurers to continue to engage in health-status discrimination in pricing their products, but limit the extent of that discrimination. One might interpret these laws as reflecting the opinion that health-status discrimination in pricing health insurance policies is a legitimate practice, but that its impact on insureds should be somehow limited.

186. Jacobi, supra note 30 , at 374-75; Korobkin, supra note 184 , at 817 . Some analysts suggest that the cross subsidy required by community rating flows from the young to the old. See The Health Care Study Group, supra note 27, at 522 (explaining that the young should contribute because they will not always be young). Such a subsidy may be objected to as a regressive intergenerational transfer of wealth. Cf. Hall, supra note 183, at 769 (articulating Epstein's objection). Other commentators, however, suggest that if we adopt a lifespan approach (under which we each expect to be both young and then old), the subsidy is more appropriately understood as a subsidy by the (predicted) healthy of the (predicted) unhealthy. Korobkin, supra note 184, at 818.

187. Swartz, supra note 34, at 98 ("[I]f a state has only one or two of these regulations in place, the carriers can use other mechanisms that are not proscribed to accomplish the same objective.").

188. Laws imposing guaranteed issuance or renewal obligations on insurers can be understood as prohibiting health-status discrimination in underwriting decisions, while restrictions on pre-existing 
states failed to enact the full battery of these reforms. ${ }^{189}$ Consequently, one state might include protection from discrimination in pricing, but permit discrimination in underwriting. Ultimately, the state health insurance market reforms of the 1990s were focused on addressing market failures and provided unhealthy persons (and groups) only limited and incomplete protection against health-status discrimination. ${ }^{190}$

Aside from the failure to address the full range of insurers' discriminatory practices, state-level insurance market reforms of the 1990s provide only incomplete protection against health-status discrimination for another reason. Because the preemption provision of the Employment Retirement Income Security Act (ERISA) prevents states from applying insurance laws to self-insured employer health benefit plans, ${ }^{191}$ individuals who receive health coverage through their employer's self-insured plan receive no protection. The states' inability to control the practices of self-insured employers, along with continuing public fears about the perceived fragility of existing health insurance coverage, contributed to the enactment of a federal response to health insurers' risk-selection practices.

\section{The Health Insurance Portability and Accountability Act}

In 1996 Congress enacted the Health Insurance Portability and Accountability Act (HIPAA) to address fears that voters would lose their health insurance when they really needed it. ${ }^{192}$ Rather than attempting comprehensive health-care reform, HIPAA focused primarily on addressing the security and portability of health insurance coverage. ${ }^{193}$

condition exclusions and mandated-benefits laws can be understood as limiting discrimination in benefits covered.

189. See Swartz, supra note 34, at 98 (asserting that states' attempts to limit risk-segmenting practices "have almost always set up regulations that block the use of only one or two of these mechanisms").

190. The evidence is also mixed and inconclusive regarding the extent to which the reforms (1) accomplished their goals of increasing the affordability and availability of insurance and thereby increased rates of coverage and (2) avoided the unintended (but predicted) consequence of contributing to adverse selection in the small-group and individual market. For a synthesis of the research regarding the effects of the individual market reforms, see FUCHS, supra note 182. For a brief examination of empirical evidence regarding the effects of the small-group market reforms, see Hall, supra note 183.

191. See Metro. Life Ins. Co. v. Massachussetts, 471 U.S. 724, $732-47$ (1985) (interpreting and applying ERISA's preemption provision).

192. See Jacobi, supra note 30, at 376-77 (discussing HIPAA's “guaranteed issue/guaranteed renewal" and pre-existing conditions provisions).

193. See id. at 376 (characterizing the portability provisions as the "centerpiece" of HIPAA). HIPAA was an omnibus measure that also contained provisions addressing health-care fraud and 
To deal with these issues, HIPAA includes provisions limiting group plans' use of pre-existing condition clauses, preventing gaps in coverage when workers change jobs, and imposing guaranteed issue and guaranteed renewal obligations on insurance issuers in the small-group market. ${ }^{194}$ To further reassure insured Americans, the law also prohibits group health insurers from discriminating against individual participants on the basis of health status in establishing eligibility rules and setting premiums. ${ }^{195}$

HIPAA has been characterized as inaugurating the federal regulation of the content of private health insurance, ${ }^{196}$ and certainly the statute's nondiscrimination provisions take a significant step by protecting an unhealthy member of a group plan from being singled out for exclusion from the plan, lesser coverage, or higher premiums. The statute explicitly forbids a group health insurance provider from relying on any "health status-related factors" 197 of an individual 198 in establishing eligibility rules ${ }^{199}$ or setting individual premiums, ${ }^{200}$ and the regulations implementing HIPAA make clear that the prohibition on discriminatory eligibility rules extends to rules relating to available benefits. According to the regulations, an issuer that enrolls an individual with a medical condition, but limits the benefits available to her based on the condition, violates HIPAA's nondiscrimination provision. ${ }^{201}$ Thus, HIPAA applies

abuse, created a demonstration project for medical savings accounts, and set in motion the creation of privacy regulations.

194. Id. at 376-77. As John Jacobi points out, when combined with the nondiscrimination provisions, the effect of these provisions is to permit "all groups to obtain insurance, and for all members of groups to gain coverage without regard for their actual or expected health status." Id. at 378.

195. Id. at $377-78$.

196. See Jack A. Rovner, Federal Regulation Comes to Private Health Care Financing: The Group Health Insurance Provisions of the Health Insurance Portability and Accountability Act of 1996, 7 ANNALS HEALTH L. 183, 184 (1998) ("Federal regulation of the content of private health care financing was upon us.").

197. The Act defines these "health status-related factors" as including the following: "(A)Health status; (B)Medical condition (including both physical and mental illnesses); (C)Claims experience; (D)Receipt of health care; (E)Medical history; (F)Genetic information; (G)Evidence of insurability (including conditions arising out of acts of domestic violence); (H)Disability." 29 U.S.C. § 1182 (a)(1) (2000).

198. The Act also prohibits discrimination based on a health status-related factor of a dependent of an individual within the group. Id.

199. Id.

200. Id. $\S 1182(\mathrm{~b})$.

201. The regulations issued by the Department of Labor (DOL) provide the following illustration:

Example 5. (i) Facts. A group health plan applies a $\$ 2$ million lifetime limit on all benefits. However, the $\$ 2$ million lifetime limit is reduced to $\$ 10,000$ for any participant or beneficiary covered under the plan who has a congenital heart defect. 
a "disparate-treatment" understanding of nondiscrimination to group plans' use of health-status information; the Act generally requires that all similarly situated ${ }^{202}$ individuals within a group health insurance plan be treated identically with respect to eligibility for enrollment, benefits covered, and premiums charged.

By contrast, HIPAA expressly disavows any attempt to impose a particular benefit package or premium level on employer plans or insurers. ${ }^{203}$ As long as the benefits provided under a plan are "uniformly available to all similarly situated individuals," to provide coverage for any particular benefit." 205 Accordingly, a plan may not impose a lower lifetime coverage limit on a person with HIV than it imposes on other group members, but it may cap coverage of HIV-related expenses for all group members. ${ }^{206}$ Thus, HIPAA clearly rejects any attempt to regulate impact discrimination: as long as all similarly situated group members receive the same benefits at the same individual cost, it is irrelevant that group members with a particular health condition receive a package that fails to cover (or inadequately covers) their actual medical needs.

HIPAA's nondiscrimination provisions stand as the sole federal legislation giving individuals any protection against health-status

(ii) Conclusion. In this Example 5, the lower lifetime limit for participants and beneficiaries with a congenital heart defect violates this paragraph (b)(2)(i) because benefits under the plan are not uniformly available to all similarly situated individuals and the plan's lifetime limit on benefits does not apply uniformly to all similarly situated individuals.

29 C.F.R. $\S 2590.702(\mathrm{~b})(2)(\mathrm{i})(\mathrm{D})$ (2004).

202. The DOL regulations make clear that the determination of which group members are "similarly situated" depends on bona fide employment classifications and not health status: "a plan or issuer may treat participants as two or more distinct groups of similarly situated individuals if the distinction... is based on a bona fide employment-based classification consistent with the employer's usual business practice." Id. $\S 2590.702$ (d)(1).

203. 29 U.S.C. $§ 1182($ a)(2). See also Rovner, supra note 196, at 201 ("HIPAA permits plans and insurers to select, on a nondiscriminatory basis, the coverage and benefits they wish to offer and the premiums they want to charge.").

204. 29 C.F.R. $§ 2590.702($ b)(2)(i)(B).

205. Id. $\S 2590.702(\mathrm{~b})(2)(\mathrm{i})(\mathrm{A})$.

206. Again, the regulations provide a pertinent example:

Example 4. (i) Facts. A group health plan has a $\$ 2,000$ lifetime limit for the treatment of temporomandibular joint syndrome (TMJ). The limit is applied uniformly to all similarly situated individuals and is not directed at individual participants or beneficiaries. (ii) Conclusion. In this Example 4, the limit does not violate this paragraph (b)(2)(i) because $\$ 2,000$ of benefits for the treatment of TMJ are available uniformly to all similarly situated individuals and a plan may limit benefits covered in relation to a specific disease or condition if the limit applies uniformly to all similarly situated individuals and is not directed at individual participants or beneficiaries.

Id. $\S 2590.702(\mathrm{~b})(2)(\mathrm{i})(\mathrm{D})$. 
discrimination in health insurance. ${ }^{207}$ In some cases, the protection will be significant. For a person with an expensive health condition who obtains a job with an employer offering health benefits, HIPAA's protection is considerable. That person cannot be excluded from health insurance coverage and cannot be forced to pay more than coworkers for the same coverage. As long as that person is an employee, she is in the pool and her costs are shared across the group, ${ }^{208}$ which is consistent with a social solidarity vision of health insurance.

HIPAA's protective shield, however, is substantially limited in two distinct ways. First, although HIPAA shields an unhealthy group member from paying more for coverage, it does nothing to protect an employer from whatever premium increase an insurer might charge based on the presence of an unhealthy employee in the group. Under HIPAA, an insurer can still employ risk rating for the entire group, ${ }^{209}$ leaving the employer to figure out how to respond to the higher premium price, with one possibility being to cancel coverage altogether. ${ }^{210}$ Second, although HIPAA defends actual or prospective group members who are unhealthy from exclusion or different treatment, it does little to safeguard the interests of individuals not affiliated with an entity providing group coverage. The statute's nondiscrimination provision applies only to group plans, not to issuers in the individual market. ${ }^{211}$ Although the statute includes a "guaranteed-issue" provision granting rights to some would-be purchasers of an individual policy, ${ }^{212}$ most

207. Although ERISA contains a nondiscrimination provision, 29 U.S.C. $\$ 1140$ (2000), it has been interpreted as not preventing employers from discriminating based on participants' health conditions when they create or modify benefit plans. See McGann v. H \& H Music Co., 946 F.2d 401 (5th Cir. 1991) (holding that an employer did not unlawfully discriminate against an employee for exercising rights under an ERISA-qualified medical benefits plan simply because it substantially reduced the maximum benefits payable to any employee afflicted with AIDS within seven months of an employee's submission of an AIDS-related claim).

208. This is true whether the employer purchases health insurance for its employees from a commercial insurance carrier or HMO or self-insures its employee health benefits. The application of HIPAA to both insured and self-insured plans sets it apart from state laws regulating health insurance, because ERISA preempts the application of any state law (even one regulating insurance) to an employee benefit plan itself.

209. See Jacobi, supra note 30, at 383-84 (noting that HIPAA's market-reform provisions enforce intraplan, but not interplan, social pooling).

210. See Alexandra Marks, Healthcare Costs: Big Woe for Small Firms, CHRISTIAN SCI. MONITOR, Sept. 15, 2004, at 1 (reporting that the number of small firms providing coverage has fallen from sixty-eight percent in 2001 to sixty-three percent in 2004 and that some companies have stopped offering insurance).

211. Jacobi, supra note 30, at 383-84.

212. The guaranteed-issue provision for the individual market limits the ability of issuers in that market to refuse coverage to an applicant who has lost access to group coverage and who satisfies several other conditions. See Swartz, supra note 34, at n.17 (noting that HIPAA does not prevent issuers from engaging in risk-selection practices with respect to the "great majority" of persons 
persons seeking to purchase coverage in the individual market remain subject to any underwriting and coverage practices that comply with state law. ${ }^{213}$ This result is in harmony with HIPAA's general focus on protecting the health insurance "haves" from loss of coverage, while doing little to help the health insurance "have nots" access coverage.

Ironically, although HIPAA's nondiscrimination provision shelters unhealthy group members from discrimination in coverage or premiums, the statute may be something of a mixed blessing for those persons, for its constraints may have contributed to the recent trend toward shifting insurance risk onto individual insureds in an employee benefit plan. HIPAA's nondiscrimination provision limits how an employer can respond to premium hikes attributable (at least in part) to the presence of unhealthy group members. ${ }^{214}$ The employer cannot pursue the actuarial fairness principle by making expensive employees pay their own way (either by exclusion from the group or charging higher premiums ${ }^{215}$ ), but it can try to moderate its own health insurance cost burden by shifting some of that burden onto employees as a group. As we will see in the next Part, the rise of consumerism in health coverage reflects the choice of many employers to shift the cost of paying for care onto individual insureds.

seeking an individual health insurance policy); cf. Jacobi, supra note 30, at 376-77 (asserting that if a person meets all the statutory conditions, a carrier cannot reject the person or impose pre-existing condition limitations based on her risk of medical expenses).

213. See Jacobi, supra note 30 , at 384 (stating that both state and federal regulations are enforceable).

214. See Edmund L. Andrews, Health Care Heights: Soaring Rates Leave Little Companies in a Bind, N.Y. TIMES, Feb. 24, 2004, at G1 ("Because they are rated largely on the age and health experience ratings of their workers, businesses with a slightly older work force or a handful of employees with significant medical bills can see their rates soar 20 or 30 percent."). While felt particularly in small businesses, employees' health can also impact the premiums of larger businesses. Andrews reports that an employer with more than 300 employees faced a twenty-four percent premium increase in one year, partly attributable to a handful of employees who required expensive hospital care in the preceding years. Id. Another factor accounting for premium growth is insurers' attempts to maximize their profits. See Kaiser Family Foundation, Employer Health Benefits 2003 Annual Survey, http://www.kff.org/insurance/ehbs2003-abstract.cfm (follow "Complete Report" hyperlink) (noting that premiums increased faster than the cost of underlying claims experience).

215. Yet another way to make expensive employees pay their own way is to terminate their employment so their inclusion in the employer's group is no longer assured by HIPAA. See Joseph Pereira, Parting Shot: To Save on Health-Care Costs, Firms Fire Disabled Workers, Wall ST. J., July 14, 2003, at A1 (stating companies are firing disabled employees as health insurance costs rise). Some evidence exists that employers have begun to pursue this strategy, despite the legal risks it poses. $I d$. 


\section{DISCRIMINATION AGAINST THE UNHEALTHY IN CONSUMERIST HEALTH CARE}

\section{A. From Managed Care to Consumerism}

Significant changes have occurred in the market for health insurance products during the past half decade. Managed care grew to market dominance during the $1990 \mathrm{~s}$ and succeeded for a period of time in reining in health-care cost inflation through a variety of techniques designed to constrain the supply of unnecessary health-care services to plan enrollees. ${ }^{216}$ By the early 2000s, however, it had become clear that managed care's successes were not to be long lived. Even as one pair of commentators proclaimed managed care's dominance of U.S. health care, ${ }^{217}$ another scholar was describing managed care proponents as being "in full retreat" and suggesting the emergence of a new "consumerism" trend in health-care coverage. ${ }^{218}$

Various explanations have been offered for managed care's inability to sustain its dominance in the health benefits market. ${ }^{219}$ Undoubtedly, the "managed care backlash" by physicians and consumers played a role in defanging managed care's cost-control mechanisms, whether by prompting state legislation regulating managed care or by influencing employers' purchasing decisions (and consequently plans' product designs). ${ }^{220}$ Coincident with the waning of managed care's strength, five

216. See Robinson, supra note 12, at 1884 (characterizing managed care's use of network contracting and utilization review as efforts to limit supply).

217. R. Adams Dudley \& Harold S. Luft, Managed Care in Transition, 344 New EnG. J. Med. 1087,1087 (2001). As the title suggests, however, these authors too recognized that managed care had an uncertain future. $I d$. at 1091.

218. James C. Robinson, The End of Managed Care, 285 JAMA 2622, 2622 (2001).

219. See David Orentlicher, The Rise and Fall of Managed Care: A Predictable "Tragic Choices" Phenomenon, 47 ST. LouIS U. L.J. 411, 412 (2003) (listing the various explanations); see also Clark C. Havighurst, The Backlash Against Managed Health Care: Hard Politics Make Bad Policy, 34 IND. L. REV. 395, 397 (2001) (noting that public opinion does not favor managed care). Nonetheless, phrases such as "the death of managed care" are probably overblown, for many structures and elements characteristic of managed care remain part of the health coverage landscape, either on their own or in conjunction with newer product designs. See Debra A. Draper \& Gary Claxton, Ctr. for Studying Health Sys. Change, Managed Care Redux: Health Plans Shift Responsibilities to Consumers (March 2004), http://www.hschange.org (follow "Issue Briefs" hyperlink) (noting that in some instances managed care practices are being used in conjunction with newer products). What is remarkable is that the grouping of features known as managed care, which rapidly ascended to dominance in the health benefits marketplace, has in a similarly short period of time, lost both the vigor of its cost-containment techniques and its dominance of the marketplace. Cf. Robinson, supra note 218, at 2625 (stating that "once the consumer and physician backlash against managed care began, it quickly swirled into an unstoppable political tornado").

220. See Mark A. Hall, The Death of Managed Care: A Regulatory Autopsy, 30 J. HeAlth Pol., POL'Y \& L. 427, 431-32 (2005). 
consecutive years of double-digit increases in employers' health-care costs have been witnessed. ${ }^{221}$ This dramatic escalation left employers scrambling in their search for the next "new thing" to control costs.

Given that a chief objection to managed care was the plans' sometimes draconian limits on patients' choice of doctor, hospital, or therapy, it is hardly surprising that the latest trend in health coverage emphasizes expanded choices for consumers of health care. In the early $2000 \mathrm{~s}$, reporters, benefits managers, and health insurance industry analysts started using the phrase "consumer-driven health care" to describe the new movement. ${ }^{222}$ Lacking a single definition, the phrase has come to refer generally to health plans that give employees both greater responsibility for designing their own benefit packages and choosing their providers (often with the assistance of Web-based information tools), as well as greater financial risk for their health-care costs. $^{223}$ One version of consumer-driven plans provides employees with some form of discretionary medical spending account combined with catastrophic health coverage. While promising consumers a broader choice of providers and greater control over their medical decisions, consumer-driven plans promise employers cost savings flowing from the

221. See Vanessa Fuhrmans, Health Care Costs to Rise in 2004: Employers Expect Increase of $12 \%$, Fifth Year in a Row of Double-Digit Gains, WALL ST. J., Sept. 29, 2003, at A6 (stating that 2004 marked the fifth year of double-digit percentage increase in employers' health-care costs). Premium rates have increased even faster than average for small companies. See Andrews, supra note 214.

222. See Jon R. Gabel et al., Employers' Contradictory Views About Consumer-Driven Health Care: Results from a National Survey, HeAlth AfF. W4-210, Apr. 21, 2004, http://content. healthaffairs.org/cgi/reprint/hlthaff.w4.210v1.

223. See Robinson, supra note 12, at 1881 ("The contemporary transformation in benefit design centers around this increase in consumer cost-sharing provisions, the multiplication of benefit options offered to each consumer, and the shift from insured toward noninsured, albeit discounted, services."); Jon R. Gabel et al., Consumer-Driven Health Plans: Are They More than Talk Now?, HEALth AfF. W395, Nov. 20, 2002, http://content.healthaffairs.org/cgi/reprint/hlthaff. w2.395v1.pdf. Gabel et al. distinguish the term "consumer-driven health plan" from the term "defined contribution plan." While "consumer driven refers to health plan design," "defined contribution refers to an employer contribution strategy whereby employers set a fixed contribution for health insurance and place the employee at risk for costs beyond that point." Gabel et al., supra, at W395. As the authors point out, the two forms are not mutually exclusive, but neither does a consumer-driven health plan necessarily entail a defined-contribution strategy by the employer. Id. It is true, though, that the emergence of consumer-driven health plans can be seen as consistent with the broader trend in which employers seek to limit their future financial exposure for employee benefits by moving away from defined-benefit plans and toward defined-contribution plans. See Robinson, supra note 218, at 2623 (suggesting that the movement to defined-contibution pension plans, like consumerism in health benefits design, signals a "change from a paternalistic corporate culture to one that defines itself as supporting rather than restricting employee choice"). For an overview of defined-contribution approaches to health coverage, see American Academy of Actuaries, Understanding Defined Contribution Health Plans, ISSUE BRIEF, June 2002, available at www.actuary.org/pdf/health/dc_june02.pdf. 
combination of greater efficiency in the purchasing decisions of costconscious consumers ${ }^{224}$ and a shifting of health-care costs to employees. Notwithstanding these promises, commentators quickly recognized consumerism's potential negative consequences, particularly for persons with chronic conditions. ${ }^{225}$

Accompanying the decline of managed care and the early development of consumer-driven plans was a far more widespread move by employers sponsoring health plans to increase employees' financial obligations either by raising premium contributions or by increasing cost-sharing obligations. ${ }^{226}$ A contemporaneous development was employers' increasing reliance on "tiered" pharmacy benefits, in which the patient's cost-sharing obligation varies among different tiers of drugs. While less closely associated with consumer-driven health care, these two developments similarly shift financial risk for medical expenses to the enrollee and thereby encourage cost-conscious choices. Therefore, this Article treats consumer-driven plans, tiered benefit plans, and employer cost shifting as close allies in a consumerist movement. ${ }^{227}$ To date, increased cost sharing and tiered prescription drug benefits have been more widely implemented than plans typically designated as consumer-driven products, ${ }^{228}$ but surveys suggest that consumer-driven

224. Gabel et al. provide an apt contrast between managed care, whose temporary success in constraining employer health costs was "because a third party (or, in some cases, an at-risk physician) was placed in the role of saying no to patients," and consumer-driven health care, which represents "an effort to put patients in a position to say no to themselves. This can happen only if consumers are aware of the true cost and have a personal stake in it, and if they have enough information and confidence to make treatment decisions." Gabel et al., supra note 223, at W396.

225. Milt Freudenheim, A New Health Plan May Raise Expenses for Sickest Workers, N.Y. TiMES, Dec. 5, 2001, at A1.

226. See Gabel et al., supra note 222, at W4-211 (noting that increased employee cost sharing is occurring in both consumer-driven plans and in traditional plans like preferred-provider organizations); Sally Trude, Ctr. for Studying Health Sys. Change, Patient Cost Sharing: How Much is Too Much? (Dec. 2003), http://www.hschange.org/CONTENT/630/630.pdf (indicating that employers confronted with the higher premiums following the managed care backlash started shifting health-care costs to workers).

227. Cf. John V. Jacobi, After Managed Care: Gray Boxes, Tiers and Consumerism, 47 ST. LOUIS U. L.J. 397, 400-01 (2003) (identifying three emerging trends as the loosening of controls over patients' choices, the stratification of health insurance offerings into tiers, and employers' interest in emerging "patient-directed" plans).

228. Compare Gabel et al., supra note 223, at W404 (estimating that about 1.5 million Americans were enrolled in consumer-driven plans in November 2002), with Draper \& Claxton, supra note 219 (finding tiered pharmacy arrangements to be in extensive use). Gabel et al. classify consumer-driven plans into "three loosely defined groups." These include (1) plans that allow employees to specify the benefits and the networks that will be in their packages, but impose responsibility on the employee for any amount by which the resulting premium exceeds a fixed employer contribution; (2) "customized package" plans in which employees choose from among preset benefits and network offerings; and (3) "health reimbursement arrangements" (HRAs) in which the employee has a health spending account combined with a high deductible health plan. 
products likely will gain ground during the next several years, particularly with the creation of health savings accounts. ${ }^{229}$

This Part first describes the different vehicles by which a consumerist tide is rising in health benefits and summarizes some of the debates regarding the trend's positive and negative policy implications. The Part proceeds to examine some of the still relatively limited research into the predicted and actual effects of these changes in health coverage. Based on this research, I argue that the changes are likely to leave persons with chronic conditions and those experiencing episodes of acute illness or injury underinsured, and thus subject to many of the same health and financial consequences faced by the uninsured. In other words, the adoption of consumerist mechanisms produces an adverse disparate impact on the unhealthy and thus can be understood as discriminatory.

\section{B. Vehicles of the Consumerist Movement}

\section{Increased Cost Sharing by Employees}

Managed care's inability to continue controlling health-care costs has prompted increasing employer use of cost-sharing devices such as deductibles, copayments, and coinsurance. Historically, health insurers offering indemnity coverage employed deductibles and coinsurance requirements to reduce moral hazard by giving patients a financial stake in treatment decisions, ${ }^{230}$ but managed care systems minimized cost sharing and instead controlled the consumption of services through administrative devices or gatekeeping physicians. The new twist in twenty-first century cost sharing lies both in its acceleration and in

Gabel et al., supra note 223, at W396. As discussed below in Part V.B.3, the most recent adaptation in the HRAs' evolutionary chain is the health savings account (HSA). Because of the projected growth in the adoption of HSAs as a result of their creation in the Medicare Modernization Act, this Article will focus on HSAs in its discussions of consumer-driven health plans.

229. See, e.g., Consumer-Directed Health Plan Enrollment Expected to Grow in 2004, BNA HEALTH CARE DAILY, Mar. 15, 2004, http://pubs.bna.com/ip/BNA/hce.nsf/is/a0a8e9q5d2 (reporting survey results that thirty-two percent of large companies expect to offer a consumer-driven plan next year, as compared to twenty-one percent currently offering such coverage); Report Sees ConsumerDirected Plans Growing into Large Insurance Market Force, BNA HEALTH CARE DAILY, Aug. 19, 2003, http://pubs.bna.com/ip/BNA/hce.nsf/is/a0a7glc4m6 (reporting projection by Forrester Research that by 2010 the number of enrollees in consumer-driven plans will reach 43 million). In addition, Gabel et al. suggest that the results of such surveys may understate the prospects for the growth of consumer-driven plans, because once adopted by large employers, such plans are likely to diffuse to mid-size and smaller firms. Gabel et al., supra note 222, at W4-210.

230. See Swartz, supra note 34, at $96 \mathrm{n} .12$ (noting that increasing cost sharing can reduce moral hazard). 
employers' reliance on cost-sharing elements not only to draw employees' attention to rising health-care costs, ${ }^{231}$ but also to decrease (or, more precisely, limit the degree of increase in) the employers' premiums. Because cost sharing makes employees rather than insurers responsible for some portion of employees' medical expenses, an increase in cost sharing represents a decrease in covered benefits. Thus, during the past several years, employers have "bought down" their health insurance premiums by reducing coverage via increased cost sharing. ${ }^{232}$

These increases have involved the full range of cost-sharing mechanisms. Health plans' average annual deductibles have increased, ${ }^{233}$ as have the size of copayment obligations. Plans have begun using higher coinsurance (in which the consumer bears an indefinite obligation to pay a percentage of the charges for services received) as an alternative to higher copayments (in which the consumer's obligation is a definite amount). ${ }^{234}$ Some employers have adopted new mechanisms, such as adding separate cost-sharing obligations for inpatient hospital services. ${ }^{235}$ If employers sought to use cost sharing to make employees feel the pain of rising health-care costs, they have succeeded with a vengeance. In addition to its probable impact on employees' accessing needed medical care, ${ }^{236}$ employer plans to increase cost sharing have been bones of contention in a number of recent labor disputes, ${ }^{237}$ and increased cost sharing is one reason cited for

231. See Sally Trude \& Joy M. Grossman, Ctr. for Studying Health Sys. Change, Patient CostSharing Innovations: Promises and Pitfalls (Jan. 2004), http://www.hschange.org/ CONTENT/643/643.pdf (stating that employers' enthusiasm for increased cost sharing stems from "two main desires: to restore patient cost sharing to comparable levels before the advent of managed care or to give workers a greater financial stake in care decisions").

232. See Lydia E. Regopoulos \& Sally Trude, Ctr. for Studying Health Sys. Change, Employers Shift Rising Health Care Costs to Workers: No Long-term Solution in Sight (May 2004), http://www.hschange.org/CONTENT/677/677.pdf (discussing employers' anticipated continued use of cost-sharing strategies); see also Vanessa Fuhrmans, Shifting Burden Helps Employers Cut Health Costs, Wall ST. J., Dec. 8, 2003, at B1 (stating that in 2003 employers slowed their "runaway" health-care costs mainly by shifting costs to employees).

233. See Laura Landro, The Informed Patient: When It's Your Money, You Spend Differently, WALL ST. J., May 8, 2003, at D3 (noting single-year jump of seventy-five dollars in the average annual deductibles in preferred provider plans).

234. See Trude, supra note 226 (stating that employers have begun using both higher copayments and coinsurance); $c f$. Trude \& Grossman, supra note 231 (noting that a switch from a flat copayment to a percentage coinsurance approach will "capture patients' attention quickly").

235. Kaiser Family Foundation, supra note 214, at $\S 7$.

236. See infra Part V.D.2.

237. See Fuhrmans, supra note 232 (citing California grocery workers' strike); Barbara Martinez, Shifting Burden: With Medical Costs Climbing, Workers are Asked to Pay More, WALL St. J., June 16, 2003, at A1 (stating that cost shifting prompted strikes at General Electric, Lockheed Martin, and Hershey Foods). 
the growing number of employees choosing not to participate in employer-sponsored health plans. ${ }^{238}$

Of course, increasing cost sharing is not the sole way employers could shift health-care costs onto employees: increasing employees' contributions toward group health insurance premiums also shifts costs. $^{239}$ Employee premium contributions have also escalated significantly in the past several years, ${ }^{240}$ but research indicates employers primarily have relied on cost-sharing increases to shift costs to employees. $^{241}$ Although both mechanisms shift health costs from employers to employees, two differences significant for purposes of this Article bear noting. First, premium contribution increases shift to employees greater financial responsibility for purchasing insurance coverage; cost-sharing increases shift to employees greater responsibility for their own medical expenses. In other words, an employee who pays only an increased premium contribution has less money in his pocket, but remains as well insured as before. By contrast, an employee who faces increased cost sharing becomes partially self-insured. Cost-sharing mechanisms, by making insureds responsible for a portion of their medical costs, shift insurance risk to the employee.

A second, related difference lies in how the costs shifted by premium or cost-sharing increases are distributed among employees. Increases in premium contributions shift higher costs equally to all employees choosing a particular coverage. ${ }^{242}$ By contrast, cost-sharing increases shift costs only to those employees who consume medical services having a cost-sharing obligation. In other words, a healthy employee who needs no doctors' services or prescription drugs bears no additional costs from cost sharing, but an employee who experiences health problems and seeks medical treatment does bear additional costs. This undisputed inequality in how cost-sharing devices shift costs among employees is central to an understanding of consumerist mechanisms as discriminatory.

238. See Regopoulos \& Trude, supra note 232 (suggesting that increases in premium contributions and cost sharing probably have caused some employees to drop coverage).

239. Trude, supra note 226.

240. See Martinez, supra note 237 (citing Kaiser Family Foundation study finding that workers' average monthly premium contribution for family coverage more than tripled between 1998 and 2002).

241. Trude, supra note 226.

242. Actual premium contributions may vary depending on whether the employee signs up for single, spouse, or family coverage and, if the employer offers more than one coverage option, on which option the employee chooses. But each employee enrolling in a particular type of coverage faces the same contribution. 


\section{Tiered Plans}

Another consumerist mechanism, the tiered benefit plan, combines increased cost sharing (to shift costs to employees) with differential cost sharing (to prod subscribers toward the use of particular products). ${ }^{243}$ The term "tiered plans" refers generally to health insurance products that group providers or prescription drugs into tiers based on cost (or potentially some other criteria) and encourage subscribers to choose lower-tier products or providers by imposing higher copayment amounts on higher-tier choices. ${ }^{244}$ For example, in one tiered pharmacy plan, subscribers pay a five-dollar copay if they purchase a generic drug, a twenty-dollar copay for a brand-name drug on the plan's "preferred" list, or from thirty dollars to more than fifty dollars for nonpreferred, brandname drugs on the third tier. ${ }^{245}$ The health insurance industry has applied the tiering concept to prescription drugs, hospitals, and physicians, with varying degrees of market penetration. ${ }^{246}$ Adopting a tiered plan offers the potential for additional cost savings both by encouraging subscribers to choose lower-cost products and by giving insurers an enticement (inclusion in a lower tier) to offer providers when negotiating for discounted charges. ${ }^{247}$

During the past five years, tiered pharmacy plans have become a common feature in employer-sponsored benefits packages. ${ }^{248}$ Among

243. Jacobi, supra note 227 , at 403

244. Glen P. Mays et al., Ctr. for Studying Health Sys. Change, Tiered-Provider Networks: Patients Face Cost-Choice Trade-Offs (Nov. 2003), http://www.hschange.org/CONTENT/ 627/627.pdf.

245. Cyril T. Zaneski, Patients are Swallowing More of the Cost of Pills: Employers and Insurers Shift Rising Prices to Users, BALT. Sun, Feb. 24, 2004, at 1A (describing CareFirst BlueCross BlueShield plan). See also Cindy Parks Thomas, Incentive-Based Formularies, 349 NEW ENG. J. MED. 2186, 2187 (2003) (describing a tiered approach to drug copayments).

246. See generally Mays et al., supra note 244 (discussing hospital and physician resistance to tiered systems and technical difficulties of a tiered approach). While tiered pharmacy benefits are already widespread, the adoption of tiered hospital and physician networks has to date been far more limited, in part because the developer's decisions about how to divide providers into tiers is more complicated, and providers may offer greater resistance to the imposition of a tiered structure.

247. Id.

248. Zaneski, supra note 245 (describing an "industrywide wave" of adoptions, with sixty-three percent of employees with employer-sponsored drug coverage having tiered copay plans in 2004, up from twenty-seven percent in 2000). See also Thomas, supra note 245, at 2188 (calling the use of incentive-based formularies "standard practice"); Draper \& Claxton, supra note 219 (finding that in most of the twelve nationally representative communities visited, tiered pharmacy arrangements are in extensive use). Several reasons may have contributed to the rapid uptake of tiered pharmacy products. First, the escalation in prices for prescription drugs has been the single biggest driver in overall health-care cost inflation; therefore employers have a particularly strong incentive to try new ways of controlling these costs. See Thomas, supra note 245, at 2187. Second, because many employers provide prescription drug coverage to employees through a separate plan, employers can 
pharmacy plans, a three-tier design like that described above is the most common, though the products offered continue to evolve. Tiering copayment amounts by products provides a somewhat more refined incentive structure than a uniform increase in copayment obligations, because combining copayments with tiers encourages the consumer to think about not only whether to take money out of his pocket to consume a product, but also which product to consume. ${ }^{249}$ To the extent that they encourage consumers to choose which drug to purchase based solely on cost, without consideration of effectiveness, existing standard three-tier products remain a fairly blunt instrument. Further refinement is possible, however, if insurers can devise incentives to purchase drugs proven to be the most cost effective over time. ${ }^{250}$

\section{Health Savings Accounts}

While market forces generated both the general increase in costsharing obligations in employer-sponsored health plans and the evolution of tiered plans, federal legislation created the third embodiment of the consumerist movement that this Part examines. The Medicare Prescription Drug Improvement and Modernization Act of $2003^{251}$ (MMA) included a provision for individuals to create a health savings account (HSA), ${ }^{252}$ which is essentially a tax-favored savings account that individuals can use for medical expenses. The MMA did not conceive of HSAs out of whole cloth. Rather, the HSA is the most recent link in an evolutionary chain of consumer-directed products providing some sort of tax-favored discretionary spending account for individuals; its forebears include the flexible spending account, the health reimbursement account, and the Archer medical savings account. ${ }^{253}$ Congress's goal in the MMA

experiment with a tiered pharmacy benefit without signing onto major changes in the rest of their health coverage. Third, some level of agreement seems to exist among commentators that sorting prescription drugs into tiers is a more straightforward process than sorting hospitals or physicians.

249. Cf. Thomas, supra note 245 , at 2187 (noting that savings from tiered plans are accomplished "by both decreasing the number of medications purchased per member and increasing the proportion of lower-cost brand-name drugs and generic drugs used").

250. See generally Trude \& Grossman, supra note 231 (discussing future trends in health insurance cost sharing); see also Thomas, supra note 245, at 2188 (noting that employers and insurers are trying to "fine-tune their tiered formularies to make them 'value-based,' with copayments determined on the basis of the relative cost effectiveness of a drug").

251. Pub. L. No. 108-173, 117 Stat. 2066 (2003) (primarily amending 42 U.S.C. $§ 1395$ (2000)).

252. The MMA did so by adding section 223 to the Internal Revenue Code. 26 U.S.C.S. $\S 223$ (LexisNexis 2005).

253. For a description of each of these devices, see Nina Owcharenko, Heritage Foundation Health Savings Accounts: How to Broaden Health Coverage for Working Families, WebMemo \#481 (Apr. 16, 2004), http://www.heritage.org/Research/HealthCare/wm481.cfm. 
was to allow for the creation of a medical spending account that would be more widely available and more attractive to employers and consumers.

The introduction of HSAs raises a number of complex questions about their integration into existing health benefits schemes, ${ }^{254}$ but the HSA's basic operation is fairly straightforward. ${ }^{255}$ The MMA enables an "eligible individual" to make contributions to an HSA, which is a taxexempt account established exclusively for the purpose of paying qualified medical expenses of the individual (and potentially the individual's family). To be an eligible individual, a person must be covered by a high-deductible health plan (HDHP), but have no other health coverage. ${ }^{256}$ To qualify as an HDHP, a policy must have a deductible of at least $\$ 1000$ for individual coverage or $\$ 2000$ for family coverage, ${ }^{257}$ and must establish an annual limit on out-of-pocket medical expenses of $\$ 5000$ for individual coverage or $\$ 10,000$ for family coverage. ${ }^{258}$ The individual or her employer can contribute up to $\$ 2600$ for an individual or $\$ 5150$ for a family annually to the account on a taxfavored basis, ${ }^{259}$ but the contribution cannot exceed the HDHP's

254. See, e.g., Rev. Rul. 2004-45, 2004-22 I.R.B. 971 (discussing HSAs interaction with flexible spending arrangements and health reimbursement arrangements).

255. The I.R.S.'s Notice providing guidance on HSAs provides fuller detail for those interested and is available at I.R.S. Notice 2004-2, 2004-2 I.R.B. 269. See also Stanley D. Baum, The Advantages of Health Savings Accounts - the Code's Newest Healthcare Arrangement, 100 J. TAX'N 101, 101-11 (2004) (explaining HSAs and associated tax issues); Stephan R. Leimberg \& John J. Mcfadden, Health Savings Accounts-An Important New Tool for Estate Planners, 31 EsTATE PLANNING 194, 194 (2004) (considering advantages and disadvantages of HSAs).

256. Individuals can obtain HDHP coverage either by participating in an employer-sponsored plan that offers an HDHP or by purchasing an HDHP in the individual market. A survey of 270 companies reported by Hewitt Associates at the end of March 2004 found that, although six out of ten employers likely would offer HSAs to their employees in the near future, a much smaller number (only one-third) currently offered an HDHP. Most Firms in Survey Plan to Offer HSAs but Fewer Have the Requisite Health Plans, BNA HeAlth CARE DAILY, Apr. 5, 2004, http://pubs.bna.com/ip/BNA/hce.nsf/is/a0a8h4e4q2.

257. See 26 U.S.C.S. $\S 223$ (c)(2)(A) (LexisNexis 2005) (stating that the term "high deductible health plan" means a health plan which has an annual deductible which is not less than $\$ 1000$ for self-only coverage, and twice the dollar amount for family coverage). The law provides, however, that an HDHP is allowed to provide first-dollar coverage for preventive care services. 26 U.S.C.S. § 223(c)(2)(C).

258. See 26 U.S.C.S. $\S 223(\mathrm{c})(2)(A)$ (stating that to qualify as a high deductible health plan, the sum of the annual deductible and the other annual out-of-pocket expenses required to be paid under the plan for covered benefits cannot exceed $\$ 5000$ for self-only coverage, or twice the dollar amount for family coverage). Such out-of-pocket expenses may include amounts paid to satisfy the deductible and any cost-sharing obligations once the deductible has been satisfied. Not included are the premiums paid to purchase the HDHP.

259. A contribution made by an individual is deductible "above the line," i.e., it is not included in the individual's adjusted gross income. A contribution made by an individual's employer is not taxable income for the employee and is tax deductible by the employer. 
deductible. ${ }^{260}$ Funds in the HSA can be invested in mutual funds or other investment vehicles, and unspent amounts roll over from year to year. Moreover, the HSA is "portable"-it is the property of the eligible individual and thus follows her upon any change in employment. Once an HSA is established, distributions from the account are not taxed as long as they are used for medical expenses such as covering deductibles or copays, purchasing over-the-counter drugs, or paying for noncovered services. ${ }^{261}$

As commentators have noted (whether to their delight or chagrin), the tax advantages HSAs offer are remarkable. ${ }^{262}$ The funds an eligible individual contributes to an HSA are not taxed; the funds in an HSA can be invested and grow tax free; and distributions made from an HSA are not taxed, as long as they are used for qualified medical expenses. ${ }^{263}$ This exceptionally favorable tax treatment signals the desire of congressional backers ${ }^{264}$ to provide strong incentives for individuals to establish HSAs. The proponents of HSAs seek to stimulate their widespread establishment to dampen health-care cost inflation, ${ }^{265}$ but the

260. The maximum annual contribution is scheduled to increase annually, and under a "catchup" provision, individuals older than fifty-five can contribute more. 26 U.S.C.S. § 223(b)(3), (g).

261. Untaxed distributions cannot be used to purchase health insurance, except when the account holder is either purchasing COBRA continuation coverage or is unemployed. Distributions generally can, however, be used to pay the premiums for long-term care insurance, and Medicareeligible individuals can use distributions to pay either (1) Medicare premiums and out-of-pocket expenses relating to Medicare, or (2) any employee premium needed to maintain retiree coverage under an employer plan. 26 U.S.C.S. § 223(d)(2).

262. See Robert Greenstein \& Edwin Park, Ctr. on Budget \& Pol'y Priorities, Health Savings Accounts in Final Medicare Conference Agreement Pose Threats both to Long-term Fiscal Policy and to the Employer-Based Health Insurance System (Dec. 1 2003), http://www.cbpp.org/10-2703health.pdf (stating that "[t]o allow an account to feature both tax-deductible contributions and taxfree withdrawals is unprecedented"); see also Marla Brill, Will Health Savings Accounts Have a Market?, FinANCIAL ADVISOR, Mar. 2004, http://www.fa-mag.com/Past_issues.php?idArticle= 320\&idPastIssue $=81$ (characterizing the tax treatment of HSAs as the "equivalent of a tax home run").

263. If an individual less than sixty-five years old uses a distribution from an HSA for purposes other than a qualified medical expense, the distribution is taxed and subject to a ten-percent penalty. An individual aged sixty-five years or older who so uses a distribution must pay tax on the distribution, but is not subject to the penalty. 26 U.S.C.S. $\$ 223(\mathrm{f})(4)(\mathrm{A}),(\mathrm{C})$.

264. In a surprise to many health insurance lobbyists, the language creating HSAs was added as an amendment to the House of Representatives prescription drug bill only when it reached the House floor in the summer of 2003. Although most Democrats opposed the provision regarding HSAs, its inclusion helped rally support from conservative Republicans who were hesitant to approve a new and expensive Medicare benefit. See Jeff Dufour, Interest in HSAs Runs Rampant, but Big Sales Will Wait Until 2005, THE HILL, Mar. 4, 2004, http://www.hillnews.com/executive/ 030404_hsas.aspx ("[M]ost Democrats opposed the HSA provision. However, the provisions helped secure crucial support from some conservatives, and the legislation narrowly passed the house.").

265. Supporters of HSAs predict that they will "help[] to re-engage employees with their health care spending while giving employers the ability to make the transition from a defined benefit 
primary philosophical goal is one of individual empowerment. An analyst from the Heritage Foundation highlights the individualistic focus of consumerism in describing HSAs:

Health Savings Accounts offer Americans a new coverage option for their health care needs. They give them a new choice in coverage design, greater control of their health care spending, and the ability to own their own health care plans. These are all key features in moving America's health care system to a consumer-based system. ${ }^{266}$

Advocates for HSAs are less likely to focus on the individual risk that accompanies enhanced choice and control. First, it bears emphasis that the HSA is not itself an insurance vehicle; it does not transfer risk to an insurer or spread risk over a group. Instead, it is a mechanism designed to encourage, through tax benefits, individual savings for uninsured medical expenses. ${ }^{267}$ An HSA's tax benefits are available, however, solely to individuals who have catastrophic health-care coverage (the HDHP) and no other coverage. Thus, the necessary result (and intent) of the HSA is that consumers have less comprehensive insurance coverage than has typically been provided by employers. The decision to contribute to an HSA requires the consumer to assume the financial risks of medical expenses up to the amount of the deductible. In some cases, employers may help employees shoulder this increased risk by contributing to employee HSAs, but these contributions are not required.

From this perspective, a common thread shared by the three consumerist mechanisms described in this Part becomes visible. Each shifts to the individual greater financial responsibility for medical expenses. These are not simply cost-shifting mechanisms (for healthy individuals who consume no medical services will bear no additional costs), but are more properly understood as risk-shifting mechanisms.

system, with open-ended costs, to a defined contribution system in which health care spending can be better managed." Owcharenko, supra note 253 .

266. Id. See also John C. Goodman, Nat'l Center for Pol'y Analysis, Health Savings Accounts Will Revolutionize American Health Care (Jan. 15, 2004), http://www.ncpa.org/pub/ba/ba464/ ("The concept of HSAs is not conservative or liberal. It's an empowerment idea.").

267. Accord Robinson, supra note 12, at 1882 (stating that HSAs' design is "important as representing the evolution from collective insurance toward individual prepayment as the guiding principle of health care coverage"); Brill, supra note 262 (asserting that HSAs "are designed to help individuals save for qualified medical and retiree health expenses on a tax-favored basis"). For this reason, the Department of Labor has taken the position that while employer-sponsored HDHPs are group health plans subject to ERISA, HSAs generally will not be deemed ERISA-covered employee benefit plans. HSAs Generally Will Not Constitute Employee Welfare Benefit Plans, DOL Says, BNA HEAlth LAW REPORTER, Apr. 15, 2004, http://Pubs.bna.com/ip/BNA/hlr.nsf/is/a0a8h9r6e6. 
This shifting of risk leaves the individual less well insured against the costs of poor health or accidents. Admittedly, HSAs offer some individuals a "sweetener" in the form of tax benefits to make the assumption of greater risk more attractive. ${ }^{268}$ But all three mechanisms shift risk to the consumer in hopes that consumers who feel the impact of medical decisions in their own wallets will make wise decisions about what care to consume.

\section{Policy Implications of Consumerism in Health Coverage}

The accelerating consumerist movement raises several policy concerns that have stimulated public debate. ${ }^{269}$ The preceding paragraph hints at two areas of concern directly relevant to consumerism's potentially discriminatory effects: First, because the trend seeks to endow individuals simultaneously with greater autonomy to make health-care decisions and incentives to make those decisions in a cost-conscious fashion, some have questioned individuals' abilities to make sound, costeffective decisions regarding medical care. Second, many commentators have suggested the possibility that consumerism may harm, rather than benefit, persons with health problems (and particularly unhealthy persons who also earn low incomes). A third concern relates less directly to any impact on the unhealthy, but directly implicates the tension between social solidarity and actuarial fairness visions of health coverage. It asks what effect the consumerism trend-and specifically the development of HSAs - will have on the continued viability of employer-sponsored group health coverage. This section will briefly explicate these concerns and sketch the opposing viewpoints on each question.

\section{The Effectiveness of Consumer Decision Making}

In emphasizing individual authority to make health-care decisions, without constraints imposed by third parties, consumerism rides the wave of public sentiment against managed care. Yet proponents of consumerdriven health care do not argue for consumers to have totally unconstrained choices; instead, the consumer's financial responsibility

\footnotetext{
268. The benefit offered to employees whose employer raises cost-sharing obligations or adopts a tiered plan is far less salient, but it may exist in the employer's ability to moderate health-care costs that might otherwise lead it to drop coverage.

269. The debate has been ongoing at least since Congress included a provision authorizing a demonstration project for medical savings accounts (MSAs) in HIPAA. For a description of the debates that preceded this inclusion, see Jacobi, supra note 30, at 367 n.234.
} 
(at some level) for the choices made is a constraint that simultaneously maximizes consumer autonomy and minimizes the wasteful consumption of health care traditionally encouraged by over-generous insurance coverage. $^{270}$ The ideal of consumerism thus envisions informed individuals operating as rational consumers of health-care services and products, thereby producing an efficient allocation of health-care resources. Because of patients' traditional deference to their physicians' recommendations and managed care administrators' more recent assumption of decision-making authority, patients historically have not had enough information to enable competent decision making, ${ }^{271}$ but consumerists promote the use of Internet-based tools to educate consumers regarding treatment options and to provide information regarding the quality and cost of different providers. Ultimately, a central philosophical tenet of consumerism is the marriage of control and responsibility regarding medical decisions in the hands of the individual.

Others, however, are less sanguine about individuals' capacities to make cost-effective decisions regarding discrete medical treatment choices. $^{272}$ Commonly voiced concerns are that medical decisions are more important and complicated than most consumer decisions and that accurate consumer-friendly indicators of provider or product quality remain stubbornly in the development stage. Professor Mark Hall points out two additional ways that the distinctive nature of health care renders

270. Compare id. at 379-80 (noting his arguments supporting tax-favored MSAs), with Michael F. Cannon, Hillary's Worst Nightmare (May 9, 2004), http://www.cato.org/cgi-bin/scripts/ printtech.cgi/dailys/05-09-04.html (noting Hillary Clinton's opposition to health savings accounts).

271. $C f$. Mark A. Hall, Making Medical Spending Decisions: The Law, Ethics, and ECONOMICS OF RATIONING MECHANISMS 44 (1997) (noting that consumer ignorance might be viewed as "an artifact of the historical noncompetitiveness of the medical market").

272. See Jacobi, supra note 227, at 408 (asserting that "[c]ost-conscious consumers are notoriously poor at differentiating between unneeded and therefore dispensable treatments and those necessary to preserve life and health"); see also Dwight McNeill, Do Consumer-Directed Health Benefits Favor the Young and Healthy?, 23 HEALTH AFF., Jan.-Feb. 2004, 186, 192 (asserting that "the notion that consumers can make better judgments about their care... than their physician counterparts is not well supported"). It is important to distinguish between market enthusiasts who seek to engage individuals as rational consumers in choosing a health plan or benefit package in a market for health insurance coverage, and those who assert the importance of individuals making consumption choices in a market for health-care products and services. In the former scenario, an individual is subject to financial incentives in choosing a level of coverage; in the latter, an individual is subject to financial incentives in choosing what care to receive. Leading academic advocates of a heavier reliance on markets in allocating health-care resources have proposed the former scenario. See Rosenblatt, supra note 30, at 178-80 (describing proposals of Alain Enthoven and Clark Havighurst). The forms of consumer-driven health care discussed in this Article embody the latter scenario. Some products also falling under the umbrella of "consumer-driven health plans" emphasize consumer decision making at the benefit design level, rather than at the service purchase level. See supra note 253 for a description of such products. Consumers' abilities to make sound decisions regarding what level of coverage to purchase is less contested than their ability to make sound decisions regarding what medical care to receive. 
the efficiency of patient decision making problematic. First, because a person typically faces momentous medical decisions only infrequently and at a time of crisis, ${ }^{273}$ consumers usually do not have the opportunity to accumulate knowledge by repeatedly making a particular medical decision. ${ }^{274}$ Second, even as quality information regarding different health-care options develops, patients confronted with medical decisions likely still will rely heavily on their personal physicians' advice, which may not produce optimal (from the patients' perspectives) spending decisions. ${ }^{275}$ Hall concludes, "[f] or these reasons, it is not feasible to expect a viable consumer-driven market to develop for discrete treatment decisions." 276 Not surprisingly, proponents of consumerism respond that these concerns insult the public's intelligence and insist that empowered consumers will rise to the occasion. ${ }^{277}$ Regardless of one's level of optimism regarding patients' competency to make cost-effective medical decisions, however, this competency is indisputably a central premise of consumerism. Without it, patients' decisions may be as likely to harm as to promote their health.

\section{Consumerism's Winners and Losers}

\section{a. The Distribution of Consumerism's Costs and Burdens}

The suggestion that adoption of consumerist mechanisms might harm some patients' health throws into focus another policy implication of the consumerist trend: how will the benefits and burdens flowing from the shifting of risk from insurers to individuals be distributed? Indeed, criticism leveled at increased cost-sharing and consumer-driven health plans has included impassioned charges that these trends disadvantage persons with chronic health conditions and low-income persons. Although these charges often treat the reason for this disadvantage as

273. See McNeill, supra note 272, at 192 (noting that humans' hope for living longer and getting well "make the decision process more emotional than rational").

274. HALL, supra note 271, at 45.

275. Id. at $45-46$.

276. Id. at 46. Other commentators suggest that consumers might be better able to make rational choices about prescription drug purchases than about how to treat a life-threatening illness. Gabel et al., supra note 223 , at W406.

277. Cannon, supra note 270. Cannon, who is director of health policy studies at the Cato Institute, anticipates that HSAs will stimulate a "cultural change": "[H]ealth savings accounts breed the ... values of personal responsibility and self-reliance. Where socialized medicine requires a culture of submission, health savings accounts will accustom millions to making their own decisions." Id. 
self-evident, it is worth briefly unpacking the nature and incidence of the detriment, which on close inspection reveals multiple dimensions.

First, if we focus only on the cost-sharing aspects of consumerist mechanisms (whether across-the-board cost-sharing obligations, tiered copays, or a high deductible for catastrophic coverage), they clearly shift some portion of medical expenses incurred from the insurer to the insured. This result is desirable for an employer seeking to control premiums, and it is philosophically consistent with consumerism's reliance on informed, cost-bearing consumers as decision makers. The question, however, is not whether employees as a group should therefore be seen as "losers;" instead, I am here concerned with whether some individuals suffer more detriment than others from this shifting.

The answer, of course, is that some individuals are more disadvantaged. Because copayments and deductibles impose costs on an insured person only when care is accessed, those persons who most frequently seek care shoulder the highest financial cost. Thus, a person with a chronic condition who requires regular and ongoing care or a person who experiences a serious injury or acute illness will be disadvantaged financially; he will pay more in copayments or spend his entire deductible, while healthier persons will experience fewer out-ofpocket costs. ${ }^{278}$ Identifying disproportionate financial costs, however, does not by itself fully capture the nature of the disadvantage at stake. Of perhaps greater importance is the extent to which imposing financial costs burdens the person bearing those costs. A particular absolute level of financial costs may or may not constitute a financial burden-in the sense of affecting a person's ability to satisfy her other needs-but it is obvious that out-of-pocket medical expenses are far more likely to be burdensome for persons with low incomes. ${ }^{279}$ Thus, boosting costsharing obligations imposes disproportionate financial costs on persons with health problems, and disproportionate financial burdens on persons with lower incomes.

Two final steps in this unpacking process are in order, for the onus imposed by increased cost sharing is not wholly financial. Instead, it may also entail a health burden. The potential health burden derives from the possibility that an individual who must pay to access care may

278. See Robinson, supra note 12, at 1885 (suggesting that "the new benefit designs serve to protect healthy nonusers from chronically ill users because all users pay premiums but the chronically ill users pay much more in deductibles and coinsurance").

279. See Jacobi, supra note 227, at 404 (making the point that tiered plans "stratify" members by enabling wealthy members "to use their greater disposable incomes to see their providers of choice... [while] [t]hose of lesser means will increasingly face substantial co-payments and coinsurance that will bar them from some providers"). 
choose to delay or forgo even necessary care and may suffer negative health consequences as a result. ${ }^{280}$ Moreover, this scenario may play out even when the immediate financial cost of accessing care, viewed objectively, may not seem terribly burdensome (e.g., a fifteen-dollar copay rather than a five-dollar copay for visiting a doctor's office). Because increased cost-sharing shifts insurance risk to the insured, a person deciding whether to visit her own doctor today cannot foresee whether it is more important to save that fifteen dollars for a copay in case her daughter is sick next month. ${ }^{281}$ In economic terms, the unpredictability of health-care needs hinders a consumer's ability to make informed, rational decisions about the most valued uses of her money. It stands to reason that persons with chronic conditions - who recognize themselves as heavy, but not entirely predictable, consumersmay be more likely to forgo care for this reason than persons in generally good health. Therefore, following this line of reasoning to its conclusion, it is reasonable to anticipate that augmenting cost-sharing obligations will produce a disproportionate burden of negative health effects for both persons with lower incomes and persons with chronic conditions.

b. The Distribution of the Benefits of HSAs

The foregoing discussion helps elucidate the concern that consumerist measures entailing increased cost-sharing obligations disproportionately will harm unhealthy persons and persons with low incomes. Standing alone, however, this analysis presents only half of the benefits/burdens calculus, for we have yet to consider the substantial tax advantages that HSAs offer to some people, but not others. ${ }^{282}$ These tax advantages accrue disproportionately to persons in the highest tax brackets, on both an annual and long-term basis. ${ }^{283}$

280. See Gabel et al. supra note 223, at W406 (characterizing consumer-driven health care as a price-based rationing system that will favor high-income over low-income persons "who are more likely to delay care if they lack the resources to pay for it").

281. Cf. Jacobi, supra note 227, at 406 ("Those of lesser means may spend reluctantly, attempting to husband their spending accounts against the advent of an emergency, thereby foregoing medically appropriate care.’).

282. An increase in cost sharing or the adoption of tiered plans seems to offer little if any benefit to insureds, except that these measures may forestall the necessity of an employer's raising employee premium contributions or dropping coverage altogether.

283. Leonard E. Burman \& Linda J. Blumberg, Urban Institute, HSAs Won't Cure Medicare's Ills (Nov. 21, 2003), http://www.urban.org/url.cfm? ID=1000578 (calling HSAs “[t]oday's tax cut for rich people"). 
In a single year, the money that an eligible individual contributes to an HSA up to the statutory limit is not included in that person's taxable income. The tax savings afforded by this deduction are significant for someone in the top tax bracket, but it may produce no savings at all for someone whose income is already so low that she pays no taxes. ${ }^{284}$ An additional tax advantage flows to persons who accumulate funds in their HSAs over time, rather than draining the account each year to pay for uninsured medical expenses, because funds invested in an HSA grow tax free. Again, in general terms, this favors high-income persons whose investment returns ordinarily would be subjected to the highest rate of taxation, but more precisely it favors those who are able to accumulate funds in their account over time. That group is likely to include relatively healthy persons (who have few medical expenses for which they would take HSA distributions) and wealthy persons (who can contribute the maximum allowable to their HSAs, but pay for any medical expenses up to their deductible with non-HSA funds). For this reason, financial planners already have recognized HSAs' value as tax shelters for wealthy individuals. ${ }^{285}$ Thus, both the short- and long-term benefits of the tax preferences that HSAs offer disproportionately favor wealthy and healthy individuals.

\section{c. Responses by Proponents of Consumerism}

Commentators who look upon the consumerist trend with favor offer several responses to these distributional concerns regarding consumerism generally, and HSAs in particular. Rather than emphasizing the burdens that cost-sharing may impose, they view its financial bite as essential to giving Americans incentives to make cost-conscious (and hopefully efficient) health-care purchasing decisions and to take greater personal responsibility for the consequences of their health-related behavior. ${ }^{286}$

\footnotetext{
284. See Linda J. Blumberg, Urban Institute, Health Savings Accounts and Tax Preferences for High Deductible Policies Purchased in the Non-Group Market: Potential Impact on Employer-Based Coverage in the Small Group Market 8 (Mar. 18, 2004), http://www.urban.org/url.cfm?ID=900696. Blumberg stated,

A $\$ 5,150$ HSA contribution, the maximum permitted under the law, would generate a tax reduction of $\$ 1,802$ per year to a household in the top income tax bracket. The value of the tax benefit would be less than half as much for a moderate-income family. And it would be worth much less than that if the family could not afford to contribute very much into the account.

285. See Brill, supra note 262 (describing the ideal HSA "savers" scenario); see also Greenstein \& Park, supra note 262, at 2-3.

286. See Cannon, supra note 270 (asserting that HSAs "empower individuals to become
} 
The idea is that, if we know we will bear the financial costs of poor health, we may eat better, exercise more, stop smoking, and engage in fewer risky behaviors.

Fans of consumerism also argue that the personal control of healthcare decisions and the free choice of providers that consumerist health care offers is particularly valuable to and desired by heavy consumers of health care, such as persons with chronic conditions. ${ }^{287}$ In this view, any additional financial costs are offset by the nonfinancial benefits of heightened patient autonomy. Moreover, they note, accurately, that persons who use the most medical care may end up financially better off by establishing an HSA. The MMA requires that HDHPs have a maximum annual limit on out-of-pocket expenses, which may be lower than the limits in some more traditional coverage options. Thus, an HSA combined with an HDHP may provide superior protection against truly catastrophic costs. ${ }^{288}$

Finally, advocates assert that HSAs' tax preferences are "designed to correct a major flaw in tax law" by "giv[ing] deposits to HSAs the same tax advantages formerly granted only to [employer-paid] health insurance premiums."289 They view previous law as unfairly penalizing persons who-rather than participating in an employer's health plan or seeking to purchase their own individual coverage - simply self-insure by saving to cover their medical expenses. ${ }^{290}$ From this perspective, granting tax preferences to HSA contributions is a matter of tax equity between individuals and employers; the regressive effect of the preference is no different from that of other individual tax deductions.

stewards of their own health care dollars rather than force people to depend on their employer to spend those dollars wisely"); $c f$. Robinson, supra note 12, at 1886 ("A greater sense of personal responsibility among patients for their own health and health care will attenuate some forms of cost inflation and support the prevention and treatment of many chronic conditions.").

287. Gabel et al., supra note 223 , at W403 (noting that "[c]onsumer-driven plan executives contended that people with chronic conditions have the potential to gain the most from the increased flexibility afforded by their products").

288. Of course, given the highly skewed character of medical expenditures, this conclusion also throws into question the level of cost savings that consumer-driven plans can offer. As Gabel et al., point out: "Large deductibles will not tend to reduce utilization for persons who experience expensive episodes of care, or those with chronic diseases, because the annual deductible will be met, and stop-loss insurance coverage will provide for nearly all of the remaining costs." Id. at W402.

289. See Goodman, supra note 266 , at 1 .

290. Id. ("The result is a tax law that lavishly subsidizes third-party insurance and severely penalizes individual self-insurance."). Given the variability and unpredictability of medical expenses, it is questionable whether a rational person would ever choose to forgo insurance coverage altogether in favor of self-insuring. Accordingly, the tax benefits of HSAs are available only to an individual enrolled in a HDHP. 
Notwithstanding these responses by consumerist advocates, a strong argument remains that, when predictable distributional effects are considered, healthy and high-income persons receive a disproportionate share of the advantages flowing from the trend toward consumerism (and HSAs in particular), while unhealthy persons and low-income persons bear a disproportionate share of the disadvantages. This skewing of effects on both the benefits and burdens sides of the ledger shows that consumerist health plans are likely to create real winners and losers. In this light, the portrayal of consumerist mechanisms as producing a discriminatory disparate impact on the unhealthy becomes quite salient, as do the limits of the protection offered by existing law. While a person with a chronic condition cannot under HIPAA be excluded from her employer's health plan or be charged a higher premium to participate, if her employer adopts consumerist coverage mechanisms, she will likely bear heavier costs and burdens than will her healthier coworkers.

\section{HSAs' Impact on the Health Insurance Market}

Certainly, one might reasonably respond to the foregoing discussion by asking: if HSAs and other consumerist vehicles are such a bad deal for unhealthy persons, then why do they not just enroll in more conventional forms of coverage? In the short run, at least, that tactic may protect unhealthy persons whose employers simply add HSAs or tiered plans as additional coverage options, but the question raises the third policy concern that exists regarding HSAs. While less central to consumerism's discriminatory impact on the unhealthy (and therefore more briefly examined here), a crux of the debate regarding HSAs' creation has been their potential impact on the broader health insurance market, which brings us back to where we started, with the struggle for the soul of health insurance. ${ }^{291}$

\footnotetext{
291. John Jacobi made this point with respect to tax-favored MSAs, as follows:

The fundamental principled disagreement between proponents and opponents of MSAs concerns the ends of health insurance. If the purpose of health insurance is to make coverage available through social pooling of risk, MSAs are anathema, even if they have a limited cost-reducing effect. On the other hand, if the purpose of health insurance is to accurately assess risk in order to "fairly" charge for coverage, MSAs are appropriate financing vehicles.

Jacobi, supra note 30, at 381-82. At the time he wrote, Jacobi viewed MSAs as "outside the stream of the developing insurance system's structure," which he viewed as trending toward a social solidarity understanding of health insurance. Id. at 382 . Today, the tide has reversed, and HSAs are on the leading edge of the current consumerist wave.
} 
Critics of HSAs assert that, even if employers initially maintain other coverage options, the financial benefits that HSAs offer to healthy and wealthy persons will siphon those enrollees from conventional insurance groups, leaving group participants who are on average sicker and poorer. In response, the group insurer will raise its premiums for traditional group coverage, and a cycle of adverse selection proceeds. ${ }^{292}$ The fear is that, as premiums for conventional coverage escalate, employers and employees will eventually be unable or unwilling to bear those costs, and employers may simply eliminate conventional coverage. ${ }^{293}$ In short, the availability of HSAs - by allowing healthier persons to choose to "go it alone" without facing risks of truly catastrophic costs - may ultimately drive low-deductible coverage out of the market. ${ }^{294}$ At that point, insurers offering HDHPs would be free to engage in risk-based underwriting practices that could render even that limited coverage unaffordable or unavailable to high-risk individuals or groups. ${ }^{295}$

In sum, opponents of HSAs forecast that as healthier persons choose to self-insure for noncatastrophic costs, unhealthy persons first will face increased premiums for low-deductible coverage and eventually may lose that coverage option entirely. Thus, from this perspective, the status of HSAs as "just one option among many" is likely to be short lived, so that the distributional effects of HSAs discussed in the previous section will become entrenched and our reliance on health insurance as a mechanism for sharing and distributing risk will be sorely diminished. ${ }^{296}$

292. Swartz, supra note 34 , at 96 (noting that, while adverse selection in the form of a member of a large employer group opting out of employer-sponsored coverage entirely is uncommon, adverse selection is a concern when an employer offers a choice of plans).

293. See Greenstein \& Park, supra note 262, at 3-4; cf. Jacobi, supra note 30, at 380 (articulating this argument with respect to tax-favored MSAs).

294. SHEARER, supra note 25, at 5. As Shearer notes, this result could be avoided if some form of risk adjustment of premiums were required to eliminate any premium advantage that flows solely from the enrollment of healthier than average persons. The MMA, however, contains no mechanism for risk adjusting HDHP premiums.

295. See Gabel et al., supra note 223 , at W404 (noting that many consumer-driven plan executives "admitted to screening out employers that they judged to be high risks").

296. James Robinson captures well how the implementation of HSAs represents a significant step away from a social solidarity vision of health insurance:

The principle of collective insurance is that most enrollees will not use the benefits to which they are entitled because they are in good health, thereby leaving their premium payments to help finance the care of unhealthy enrollees with high expenditures. This "use it or lose it" logic contrasts with the "use it or save it" logic underlying the HSA benefit design. Although the HSA product retains insurance principles for catastrophic care (above the high deductible), the savings account itself reflects noninsured prepayment principles, as unspent balances are retained by healthy enrollees rather than diverted to pay for the care of others.

Robinson, supra note 12, at 1882. 
HSA proponents counter that the group insurance sky will not fall simply as a result of HSAs. First, they emphasize the benefits of flexibility and autonomy that HSAs offer to persons with chronic conditions. ${ }^{297}$ Because of these benefits, and based on reports by some vendors of health reimbursement accounts (a vehicle similar to HSAs), they suggest that people with health problems may find opening an HSA attractive. ${ }^{298}$ If healthy people and unhealthy people open HSAs at the same rate, then the dire predictions of adverse selection will not come to pass. More fundamentally, however, fans of HSAs accept the disproportionate distribution of costs to unhealthy persons as a limited ${ }^{299}$ and unobjectionable example of actuarially fair pricing.

\section{Research Findings Regarding the Effects of Consumerism}

As the foregoing description of the policy debates regarding consumerist health care suggests, many of the policy arguments rely on predictions of the real-world consequences that will follow the adoption of consumerist approaches to health coverage. But are these predictions anything more than partisan spin on the relevant questions? Because the rise of consumerist mechanisms is still recent, only limited quantitative or empirical research has been conducted regarding its actual or predictable impact. Nonetheless, several studies have been published of late that bear on the persuasiveness of the foregoing policy arguments.

In an attempt to assess the strength of this Article's claim that consumerist mechanisms are likely to produce disproportionate adverse effects on unhealthy persons, both in terms of financial costs and burdens and in terms of health burdens resulting from delayed or forgone medical care, this Part examines the findings of new (and some not so new) research. The first section describes recent research regarding the distribution of consumerism's financial costs; the second describes research relevant to the impact of increased cost-sharing on patients' access to needed medical care. ${ }^{300}$

297. See Elizabeth White, Federal Worker Unions Fight Inclusion of Health Savings Accounts in FEHBP, BNA HEALTH CARE DAILY, Feb. 23, 2004, http://pubs.bna.com/ip/BNA/hce. nsf/is/a0a8c3k9t2 (quoting the director of the Galen Institute's Center for Consumer Driven Health Care).

298. Id.

299. Under the MMA, the combination of an HDHP and an HSA limits the account holder's maximum out-of-pocket medical expenses. See supra Part V.B.3.

300. Because it relates less directly to this Article's thesis regarding the discriminatory impact of consumerism on unhealthy people, this Part does not examine research regarding the impact of consumerist mechanisms, particularly HSAs or the like, on the health insurance market. A number of analysts have projected these impacts and have predicted that the availability of tax-favored 


\section{Research Regarding the Distribution of Consumerism's Financial Costs}

Several recent studies have produced findings relevant to consumerism's distribution of financial costs and burdens. One study by Sally Trude, a scholar at the Center for Studying Health Care Change, used actuarial models to estimate the expected out-of-pocket costs for individuals covered by health plans with six different cost-sharing configurations. $^{301}$ The study reached the unsurprising finding that as cost-sharing obligations increased, so did enrollees' average annual outof-pocket expenditures. Trude emphasized, however, that focusing on average increases "masks the differences between those who use services and those who do not .... Increased patient cost sharing raises out-of[]pocket costs more for people with chronic conditions, those in poor health and people with at least one hospitalization." ${ }^{302}$ For example, under a benefit structure with moderate cost-sharing requirements, the average annual out-of-pocket amount was projected to be $\$ 236$, but persons in poor health would have out-of-pocket costs of $\$ 862$ on average, and persons with at least one hospitalization would pay $\$ 1066 .^{303}$

medical spending accounts would result in significantly higher premiums for conventional coverage. See, e.g., LEN NICHOLS ET AL., supra note 25, at 24 (concluding that the availability of MSAs for healthier individuals would leave those less healthy in traditional plans with much higher premiums and would likely crowd out comprehensive coverage from the market over time); $c f$. AMERICAN ACAdemy of ACtuaries, The Impact of Consumer-Driven Health Plans on Health Care Costs: A Closer look at Plans with HeAlth Reimbursement Accounts 9 (Jan. 2004), http://www.actuary.org/pdf/health/cdhp_jan04.pdf [hereinafter IMPACT OF CDHPS] (stating that "[t]he impact of adverse selection... can potentially worsen over time as high and low users become increasingly segmented and no longer spread costs among both groups"); SHEARER, supra note 25 , at 35 (projecting that if twenty percent of the healthiest eighty percent of employees enrolled in an MSA, the average per capita health care costs of those remaining in traditional coverage would increase by fifteen percent). These projections are premised on healthier workers' disproportionately choosing to open the spending accounts. Advocates for consumer-directed plans have relied on reports from purveyors of such plans to challenge that assertion. See Press Release, Galen Institute, Galen Institute Event Dispels Myths about Consumer Choice Care (Feb. 18, 2004), http://www.galen.org/fileuploads/Feb11_Press.pdf (stating that an executive from Definity Health reported that his company was enrolling individuals with significant risk factors). Ultimately, any reliable data regarding selection effects of HSAs will come only with the passage of time and careful research.

301. Trude, supra note 226 , at 2 .

302. Id.

303. Id. This moderate cost-sharing plan imposed a $\$ 20$ copay for physician visits, a $\$ 150$ copay for emergency department visits, and a $\$ 250$ per day inpatient hospital copay. The health-based outof-pocket differentials are even larger in benefit structures that more closely resemble HSAs. For example, Trude estimated that the average out-of-pocket costs for all persons covered by an insurance plan with a $\$ 1000$ deductible and a twenty- to thirty-percent coinsurance rate would be $\$ 763$, but that the averages for people in poor health and people with at least one hospitalization 
Recognizing that the hardship posed by a particular financial cost depends largely on a person's income, Trude went on to evaluate how often out-of-pocket spending exceeded $10 \%$ of a person's income. Although only $1 \%$ of all persons covered by a plan having no deductible and a $\$ 10$ physician copayment would experience such high out-ofpocket costs, the figure rose to $13 \%$ for all persons whose coverage required a $\$ 2500$ deductible and a coinsurance rate of $30 \%$ or higher. Moreover, at this high cost-sharing level, a majority of people in poor health or with at least one hospitalization could be expected to face outof-pocket costs over the $10 \%$ threshold. ${ }^{304}$ But for the study's assumption of a maximum out-of-pocket limit of $\$ 1500$ greater than each plan's deductible, these percentages could well have been higher. ${ }^{305}$ Based on her findings, Trude sounds a cautionary note: "As out-ofpocket costs increase... both the financial and medical consequences for seriously ill and low-income people increase."306

In a similar study, Dwight McNeill used a simulation and demographic analysis to compare out-of-pocket spending of consumers enrolled in conventional managed care plans with that of enrollees in a consumer-driven plan to test the hypothesis that such plans would favor young and healthy persons while disfavoring older and sicker persons. ${ }^{307}$ His study divided consumers into four groups - the "healthy," the "slightly sick," the "moderately sick," and the "very sick"-and generated average benefits paid by the insurer and consumer out-ofpocket expenditures for each plan. ${ }^{308}$ McNeill found that healthy enrollees saved an average of $\$ 584$ in out-of-pocket spending by

would be $\$ 1883$ and $\$ 2355$, respectively. Under an insurance plan with a $\$ 2500$ deductible and a thirty- to fifty-percent coinsurance rate, the average payments for all insureds would be $\$ 1051$, but the expenditures would rise to $\$ 2942$ and $\$ 3768$ for persons in poor health and people with at least one hospitalization. Id.

304. See id. ("Under the $\$ 2500$ deductible scenario, 22 percent of the chronically ill, 53 percent of those in poor health and 66 percent of hospitalized patients would have out-of-pocket costs exceeding 10 percent of income."). Not surprisingly, the percentage of persons bearing oppressive out-of-pocket costs increased as incomes decreased. For example, under the $\$ 2500$ deductible scenario, only $6 \%$ of persons whose income exceeded $400 \%$ of the poverty level would spend more than $10 \%$ of their income on health expenses, while $47 \%$ of persons living in poverty would do so. Id.

305. See id. ("Maximum out-of-pocket limits are set at $\$ 1500$ more than the deductible for each scenario."). In other words, according to the design of the study, persons enrolled in the $\$ 2500$ deductible plan would have their annual out-of-pocket expenditures limited to $\$ 4000$.

306. Id.

307. McNeill, supra note 272, at 186 . The consumer-driven health plan used in the study was a $\$ 1000$ health reimbursement account (HRA) with deductibles of $\$ 1500, \$ 2500$, and $\$ 3500$. The maximum out-of-pocket limit for the consumer-driven plan equaled the deductible. Id. at 187.

308. Id. at 188. McNeill included in his calculation of out-of-pocket expenses the consumer's premium contribution. Id. 
enrolling in the consumer-directed plan, as compared to the conventional plan. By contrast, people in the slightly sick and moderately sick groups lost an average of $\$ 250$ and $\$ 581$, respectively. The very sick who enrolled in a consumer-driven plan, however, would save $\$ 300$ on average. Based on this simulation of gains and losses, together with an analysis of enrollees' demographic characteristics, McNeill concluded that his results "support the hypothesis that the healthy, especially young men, are the potential winners with these plans." 309

These studies validate worries that cost-sharing increases will have a disproportionate financial impact on unhealthy persons by quantifying the projected level of that impact, and they highlight the costs imposed by high-deductible plans. Because the high-deductible plans that Trude and McNeill used do not exactly match the HDHPs that must accompany HSAs, however, neither study can be read as projecting the precise impact of HSAs. Particularly important is each study's assumption of a lower annual limit on maximum out-of-pocket expenses than the limit mandated by the MMA. ${ }^{310}$ Thus, these studies' results may under predict the extent of financial exposure for individuals who establish HSAs. On the other hand, depending on how generously employers subsidize employee coverage via HDHP and HSA contributions, the studies could also over predict the actual costs borne by employees. ${ }^{311}$ Regardless of

309. Id. at 191. See also NICHOLS ET AL., supra note 25, at 28 (concluding that younger and healthier male workers were more likely to be winners in the switch to tax-favored HSA). In a similar project, the American Academy of Actuaries examined how the adoption of employerfunded health reimbursement accounts coupled with high-deductible health plans, in contrast to an actuarially equivalent PPO, would affect hypothetical health plan participants with low, medium, and high health-care usage levels. The AAA's actuarial model found that low users would spend $\$ 360$ less out of pocket under the CDHP than under the PPO, but that medium and high users would spend $\$ 615$ and $\$ 650$ more, respectively. IMPACT OF CDHPS, supra note 300, at 3-4.

310. See McNeill, supra note 272, at 189 (choosing to use a consumer-driven product that effectively limited the amount of risk that each consumer bore to the size of the "gap" between exhaustion of the $\$ 1000$ HRA (funded by the employer) and the deductible, thus limiting out-ofpocket expenditures for medical care to \$2500); Trude, supra note 226 (including a maximum outof-pocket limit of $\$ 1500$ greater than each plan's deductible, so that the plan with the highest deductible ( $\$ 2500$ ) would have a $\$ 4000$ maximum). By contrast, the MMA allows the HDHP to set out-of-pocket limits as high as $\$ 5000$ for individual coverage (or $\$ 10,000$ for group coverage). For this reason, McNeill's result that the very sick actually saved money under a consumer-driven plan may not be replicated under HSAs.

311. For example, if an employer were to purchase HDHP coverage with a deductible of $\$ 1000$ and a low out-of-pocket limit for an employee and were also to contribute the maximum amount of $\$ 1000$ to that individual's HSA, the individual would face less financial exposure. Given the current desperation on the part of most employers to minimize their health-care costs, it seems improbable that many employers would offer such generous and costly coverage. See Press Release, Mercer Human Res. Consulting, U.S. Employers See a Role for New Health Sav. Accounts in their Benefit Programs (June 8, 2004), http://wrg.wmmercer.com/content.asp?article_id=20046474\&t=\&p=\&ar=1 (reporting that in a survey of 991 employers, thirty-nine percent indicated that, if they were to offer an HDHP with an HSA to employees, they would not contribute any money to the employees' HSA 
this imprecision, however, this research bolsters the arguments that consumerist coverage options will tend to hurt unhealthy and poor people while helping healthy and wealthy people. ${ }^{312}$

Another recent study by $\mathrm{Ha}$ Tu used survey data to examine the outof-pocket cost burdens experienced by people with chronic conditions. ${ }^{313}$ Among all privately insured persons with chronic conditions, $\mathrm{Tu}$ found that in 2003, 12\% had out-of-pocket costs exceeding $5 \%$ of their income. ${ }^{314}$ Tu's findings also confirm the greater incidence of this burden among low-income persons, $42 \%$ of whom spent more than $5 \%$ of their income on medical expenses. ${ }^{315}$ Moreover, the survey's documentation of dramatic increases between 2001 and 2003 in the percentage of insured persons with chronic conditions experiencing cost burdens suggests the profound impact of employers' escalation of costsharing obligations during that time period. ${ }^{316}$

\section{Research Regarding Cost-Sharing's Impact on Access to Needed Care}

Along with the evidence suggesting that the adoption of consumerist mechanisms distributes financial costs disproportionately to unhealthy persons, research demonstrates the impact of high out-of-pocket costs on access to medical care and, by extension, on patients' health. For example, the survey discussed immediately above also speaks to the question of how high out-of-pocket costs affect access to needed medical care. ${ }^{317}$ The survey responses showed that among privately insured

accounts and seventy-seven percent said that their contribution amount would be less than the HDHP's deductible level). In addition, neither Trude's nor McNeill's calculations accounted for any offsetting tax savings from the HSA.

312. See AMERICAN ACADEMY OF ACTUARIES, MEdiCAL SAVINGS ACCOUnts: Cost Implications AND Design Issues, Public Policy MONOGRAPH 29 (1995), http://www.actuary. $\mathrm{org} / \mathrm{pdf} /$ health/msa cost.pdf (concluding that if tax-favored MSAs were implemented, the greatest savings would accrue to individuals with only minimal health expenditures and the greatest losses would be experienced by those with substantial health expenditures, primarily pregnant women and older persons).

313. Ha T. Tu, Ctr. for Studying Health Sys. Change, Rising Health Costs, Medical Debt and Chronic Conditions (Sept. 2004), http://www.hschange.org/CONTENT/706/706.pdf. The study says that people with chronic conditions are conservatively estimated to include thirty-three percent of the working age population. Id. at 1 .

314. Id. at 2 .

315. Id.

316. See id. (finding that for all privately insured persons with chronic conditions the percentage went from $10 \%$ in 2001 to $12 \%$ in 2003 and for low-income (defined as having a family income of less than $200 \%$ of the federal poverty level) privately insured persons with chronic conditions, the percentage went from $28 \%$ in 2001 to $42 \%$ in 2003, an increase of $50 \%$ in just two years).

317. Id. at 3 . 
persons with chronic conditions, one in six reported that their family experienced difficulties in paying medical bills in the previous year, and the researcher found that the existence of large medical bills had significantly affected access to medical care. ${ }^{318}$ Chronically ill insured persons whose families had trouble paying their health-related bills were three to four times as likely as those whose families reported no billpaying difficulties to delay care, fail to fill a prescription, or simply go without needed care because of cost. ${ }^{319}$ These results are consistent with those of another recent survey of households regarding the prevalence of difficulties in paying medical bills and the impact of those difficulties, ${ }^{320}$ and together the studies suggest that fears of ever-accumulating medical debt may lead even insured people with chronic illnesses to cut back on needed medical care. ${ }^{321}$ Moreover, these fears are not idle. Recently published research found that about half of personal bankruptcies have medical causes and about one-third of those filers had health insurance at the time of filing. ${ }^{322}$

In addition to research into the prevalence and impact of medical debt, several recent studies have focused specifically on how increased copays and tiered pharmacy plans influence prescription drug usage. For example, one study relied on pharmacy claims data to model how

318. Id. at $2-3$

319. Id. at 3. Among chronically ill insured people with family-medical-bill-paying problems, $10 \%$ went without needed care, $30 \%$ delayed care, and $43 \%$ failed to fill a prescription, all because of cost. Id. Among chronically ill insured people with no family-medical-bill-paying problems, the figures were $3 \%, 8 \%$, and $9 \%$ respectively. $I d$.

320. Jessica H. May \& Peter J. Cunningham, Ctr. for Studying Health Sys. Change, Tough Trade-Offs: Medical Bills, Family Finances and Access to Care (June 2004), http://www.hschange. org/CONTENT/689/689.pdf. These researchers found that one in seven American families reported problems in paying medical bills in the previous year. $I d$. at 1 . Among insured families, more than one in ten reported medical-bill-paying problems, but the rate was significantly higher among families with members having greater health needs. Id. at 2-3. About one in four insured families that had either a member with a hospital stay or an emergency room visit or a member in fair or poor health reported bill-paying difficulties. Id. at 3 and tbl.2. But families with high out-of-pocket costs (above \$2000) were the most likely to report bill-paying troubles, with more than one in three having problems, and the researchers noted the role of rising cost-sharing obligations in producing high outof-pocket costs. Id. at 2. This survey's findings also lend weight to concerns about the impact of large medical bills on access to needed care. Among insured families alone, families reporting medical bill problems were four times as likely as families with no medical bill problems to say that a family member had experienced an unmet medical need in the previous year because of cost, with similar disparities reported regarding delaying care or failing to get needed prescription drugs. $I d$. at 2 and tbl.3.

321. Tu, supra note 313 , at 3 ("These results suggest that once families have trouble paying medical bills, concerns about accumulating more bills and further straining family finances may cause many people with chronic conditions to curtail their use of needed medical care.").

322. David U. Himmelstein et al., MarketWatch: Illness and Injury as Contributors to Bankruptcy, HEALTH AFF., Feb. 2, 2005, http://content.healthaffairs.org/cgi/content/ full/hlthaff.w5.63/DC1. 
doubling the copayment for drugs in eight widely prescribed therapeutic classes affected privately insured consumers' use of the drugs. ${ }^{323}$ Doubling the copay resulted in substantial spending reductions for all drug classes, but the reduction's extent varied among different drug classes and different types of patients. ${ }^{324}$ Overall, patients with chronic illnesses reduced their usage of medicines prescribed for those conditions somewhat less than the average reduction, but patients with diabetes were as likely as the overall population to decrease their spending. ${ }^{325}$ The concern that diabetes patients facing increased copays may suffer ill health effects from cutting back on their medications is at least partially borne out by the findings of a recent study linking cost-related underuse of medications to worse health outcomes among diabetes patients. ${ }^{326}$

Another study demonstrates that the consumption effects of higher copayments may be particularly pronounced in tiered pharmacy plans. ${ }^{327}$ It found both that while patients' use of medications for high blood pressure remained stable when copayments increased in a single-tier plan, the overall usage of those drugs declined as copayment amounts increased in multi-tier plans and that the consumption of more costly (and more effective) drugs declines as the differential between copayments for generic and brand-name drugs increased. ${ }^{328}$ In another study, researchers examined how levels of usage and spending on medications commonly used to treat three chronic conditions changed when two large employer groups implemented two different tiering structures. ${ }^{329}$ These researchers found that employees who faced a more dramatic change in prescription benefits were twice as likely as

323. Dana P. Goldman et al., Pharmacy Benefits and the Use of Drugs by the Chronically Ill, 291 JAMA 2344 (2004).

324. Id. at 2344 .

325. Id. at 2348 .

326. John D. Piette et al., Health Insurance Status, Cost-Related Medication Underuse, and Outcomes Among Diabetes Patients in Three Systems of Care, 42 MED. CARE 102, 102 (2004).

327. Sachin Kamal-Bahl \& Becky Briesacher, How do Incentive-Based Formularies Influence Drug Selections and Spending for Hypertension?, HeALTH AFF., Jan.-Feb., at 227, 227 (2004).

328. Id. at 231-32. See also Thomas S. Rector et al., Effect of Tiered Prescription Copayments on the Use of Preferred Brand Medications, 41 MED. CARE 398, 398 (2003) (finding that tiered copayments were "associated with a significant shift from nonpreferred to preferred brand medications" but noting need for further research regarding clinical effects of these changes).

329. Haiden A. Huskamp et al., The Effect of Incentive-Based Formularies on Prescription-Drug Utilization and Spending, 349 NEW ENG. J. MED. 2224, 2224 (2003). One employer made modest changes in its pharmacy benefit, switching from a two-tier plan to a three-tier plan by simply adding a third, higher copay tier without altering the copay in the two existing tiers. Id. at 2225 . The other employer made more dramatic changes by simultaneously moving from a plan with a single copay to a three-tier plan and raising its lowest copay. Id. The study examined the impact on usage of ACE inhibitors which treat hypertension and heart failure; proton pump inhibitors, which treat acid reflux disease; and statins, which are prescribed primarily to reduce cholesterol levels. Id. 
employees in a comparison group to stop using a particular class of drugs altogether. By contrast, more incremental changes to the other employer's drug benefit produced only minor effects on the likelihood that a patient would stop using a drug. ${ }^{330}$

The findings from these studies are admittedly less than conclusive regarding how increasing copayments generally or imposing differential copayments in a tiered benefit plan affects decisions by patients with chronic conditions to purchase prescription drugs. Indeed, the findings suggest that the effects of increased copayments may vary depending on the type of drug, the type of patient, and details of the benefit plan's structure. $^{331}$ Nonetheless, these studies unquestionably raise a yellow caution flag regarding the likelihood that chronically ill patients may respond to increased copayments by forgoing needed medications. The research teams themselves highlighted this concern: ${ }^{332}$ one group concluded by stressing the importance of "discourag[ing] the adoption of cost containment systems that encourage poor medication choices in the first place." ${ }^{333}$ Unfortunately, while the extant research reaches no definitive conclusions, it does reinforce concerns that significant cost incentives may often lead consumers - even those with life- and disability-threatening conditions - to disregard the venerable proverb that "an ounce of prevention is worth a pound of cure."

Other research lends further credence to the proposition that consumerism's cost-sharing burdens create the prospect of harmful health consequences for individuals - consequences that, like the financial costs themselves, are likely to be concentrated among unhealthy

330. Id. at 2227-30. The comparison group consisted of health plan enrollees not affected by changes in plan design. $I d$. at 2225.

331. See Goldman et al., supra note 323, at 2349 ("Patients do not respond indiscriminately to co-payment increases."). See also John Hsu et al., Cost-Sharing: Patient Knowledge and Effects on Seeking Emergency Department Care, 42 MED. CARE 290, 290 (2004) (finding that patients' perceptions regarding the size of their insurance copayment for emergency department visits were "strongly associated with avoidance of or delays in emergency care"); Jared T. Lurk et al., Effects of Changes in Patient Cost Sharing and Drug Sample Policies on Prescription Drug Costs and Utilization in a Safety-Net-Provider Setting, 61 AM. J. HeAlth-SYs. Pharmacy 267, 267 (2004), available at http://www.ajhp.org/cgi/reprint/61/3/267.pdf (finding that increases in the copay for prescription drugs "were associated with significant decreases in prescription drug utilization").

332. See Goldman et al., supra note 323, at 2349 ("[S]ignificant reductions in the use of antidiabetic agents or medications to treat dyslipidemia may have short- and long-term clinical consequences."); Huskamp et al., supra note 329, at 2231 ("The discontinuation of the use of medications such as statins and ACE inhibitors that are needed for the treatment of chronic illnesses raises important questions about potentially harmful effects of formulary changes and the associated changes in copayments."); Kamal-Bahl \& Briesacher, supra note 327, at 235 (concluding that their finding suggests "that people with limited personal resources might be forced to do without necessary medications or use less costly (but probably less effective) ones").

333. Kamal-Bahl \& Briesacher, supra note 327, at 235. 
persons. In the early 1970 s the RAND Corporation conducted a rigorous empirical study into the effect of different levels of health coverage ${ }^{334}$ on patients' treatment decisions and health outcomes. Among the study's numerous findings, a few are particularly relevant to this discussion. First, the researchers found that patients who faced higher cost-sharing obligations did cut back on visits to the doctor or hospital, but not in a way that differentiated between needed and unnecessary care. ${ }^{335}$ Thus, the imposition of cost sharing led to cost-conscious, but not costeffective, decisions about accessing care. By contrast, once a high costsharing patient consulted a doctor for treatment, that patient received just as much care as a patient without financial incentives. ${ }^{336}$ In other words, once care is accessed, decisions about what services to use did not appear to be cost conscious. As Professor Mark Hall summarizes, "These findings confirm that increased cost sharing will lower health care spending, but they cast considerable doubt on whether catastrophic insurance alone will result in improved cost effectiveness. Efficiency entails not just saving money but choosing wisely how to spend it." 337

Admittedly, the participants in the RAND study did not have the benefit of Internet-based decision support and information tools now becoming available. Thus, that study's findings may not accurately predict the experience of people enrolled in today's consumer-driven health plans. Nonetheless, it remains unproven whether these tools enable real patients making real spending choices to make cost-effective decisions. ${ }^{338}$ Until that case is made, the apprehension will remain strong that any immediate cost savings generated by consumerism may come at the expense of patients' health. ${ }^{339}$

334. The levels of coverage ranged from participants enrolled in "free care" plans requiring payment of five percent of the cost of treatment or less, to a catastrophic plan requiring participants to pay ninety-five percent of their costs up to an annual maximum of the lesser of $\$ 1000$ or a percentage of their income. HALL, supra note 271, at 48 (describing RAND Health Insurance Study). Although some HSA account holders may purchase (or receive from their employer) an individual HDHP with a deductible of only $\$ 1000$, some HDHPs will have higher deductibles, and the law allows them to set their annual out-of-pocket maximum expenditure as high as $\$ 5000$ (or $\$ 10,000$ for family coverage). Thus, the catastrophic plan employed in the RAND study is roughly equivalent to the most comprehensive insurance coverage available to HSA holders.

335. Id. at 49 .

336. Id.

337. Id.

338. See Robinson, supra note 218 , at 2626 ("[T]he headlong retreat of the public and private sectors from the thankless job of controlling costs is delegating to the consumer a very broad array of tasks for which many are not prepared.").

339. See HALL, supra note 271 , at 48 (reporting that RAND study found that "[u]nder some measures of health status, participants were demonstrably worse off as a result of greatly increased cost sharing, although not to a very dramatic extent" and that "these effects where [sic] more pronounced for low-income participants"). 
Indeed, survey findings confirm that patients' inability or reluctance to attain needed care may carry adverse health consequences. According to the results of a 2002 survey, among insured Americans who reported postponing medical care that they or their family needed within the previous year, thirty-six percent attributed a temporary disability (including significant pain and suffering) to the delay, while fourteen percent said it caused a long-term disability. Those with insurance who failed completely to obtain needed care were even more likely to report serious consequences. ${ }^{340}$

Finally, the large body of research on the health effects of being uninsured also sheds light on how large cost-sharing obligations are likely to affect unhealthy persons. Of course, people who have coverage through consumerist mechanisms are not in fact uninsured. But because of their heightened exposure to insurance risk for their medical needs, some people with consumerist coverage may share important characteristics with the uninsured, notably a reluctance to seek care, difficulty in accessing care, and problems in paying for care. In other words, high cost-sharing obligations may in some cases render people underinsured.

Far less scholarly and political attention has been paid to the challenges faced by the underinsured than to the problems of the uninsured. In general terms, "the underinsured" refers to persons who have some health insurance, but whose coverage is inadequate to protect them against excessive out-of-pocket costs if they experience a catastrophic level of medical need. ${ }^{341}$ The role that substantial costsharing obligations play in rendering insurance coverage inadequate is well recognized. ${ }^{342}$ As former Secretary of Health and Human Services

340. Kaiser Comm'n on Medicaid and the Uninsured, Kaiser Family Found., Fact Sheet, Underinsured in America: Is Health Coverage Adequate? (2002), available at www.kff.org/ uninsured/4060-index.cfm (follow "Fact Sheet" hyperlink).

341. Cf. Rashid Bashshur et al., Defining Underinsurance: A Conceptual Framework for Policy and Empirical Analysis, 50 MED. CARE REV. 199, 206 (asserting that underinsurance exists when out-of-pocket medical costs result in a serious financial burden or coverage limitations hinder the insured's ability to access needed care); Kaiser Comm'n on Medicaid and the Uninsured, supra note 340 ("The underinsured have health insurance but face significant cost sharing or limits on benefits that may affect its usefulness in accessing or paying for needed health services."). Although no single definition of underinsurance exists, a commonly cited approach finds that people are underinsured if their coverage exposes them to out-of-pocket expenses exceeding ten percent of their family income in the event of a catastrophic illness. See Pamela Farley Short \& Jessica S. Banthin, New Estimates of the Underinsured Younger than 65 Years, 274 JAMA 1302, 1303 (1995) (using this approach to estimate the number of underinsured).

342. See, e.g., Kevin T. Stroupe et al., Does Chronic Illness Affect the Adequacy of Health Insurance Coverage?, 25 J. HEALTH POL., POL'Y \& L. 309, 314-15 (2000) (classifying lowerincome individuals as underinsured based on deductible levels and coinsurance rates); John Dorschner, Underinsured: 29 Million of Us Don't Have Adequate Coverage, Miami HeRALD, Oct. 
Donna Shalala described the "big crisis" of the underinsured, high costsharing obligations mean that the underinsured "can't afford to use their insurance." 343

Herein lies the affinity between the uninsured and the underinsured: like the uninsured, persons who have inadequate coverage are more likely to delay obtaining needed care or even forgo it entirely, ${ }^{344}$ and a substantial body of research demonstrates that receiving too little or delayed medical care harms uninsured persons. In its report, Care Without Coverage: Too Little, Too Late, a committee of the Institute of Medicine reviewed that research and found that "the quality and length of life are distinctly different for insured and uninsured populations, with worse health status and shortened lives among uninsured adults." 345 The committee found specific evidence of harmful effects across a range of health services, including preventive services, cancer care, and care for chronic diseases. ${ }^{346}$ While confining its focus to the health effects of uninsurance, it acknowledged that being underinsured posed similar, though generally less severe, problems. ${ }^{347}$ Accordingly, to the extent that consumerism's elevated cost-sharing obligations leave unhealthy people underinsured, we have good reason to anticipate that some of those persons will suffer negative health consequences. ${ }^{348}$

Taken together, the research described in this Part lends significant force to the argument that consumerist approaches to health coverage can be expected to disproportionately affect unhealthy persons, with the ramifications including burdensome medical debt and avoidable poor

20,2003 , at $22 \mathrm{G}$ (asserting that the problem of the underinsured will worsen as employers attempt to control costs by continuing to increase deductibles and copays); Kaiser Comm'n on Medicaid and the Uninsured, supra note 340 (noting the potential for uncovered services and cost-sharing to mount up and become onerous). Other health insurance policy features that may render coverage inadequate include the following: (1) permanent pre-existing condition exclusions and lack of outof-pocket maximum limits, see Stroupe et al., supra, at 314, (2) failure to cover prescription drugs, see Claudia L. Schu et al., Lack of Prescription Coverage Among the Under 65: A Symptom of Underinsurance, COMMONWEALTH FUND ISSUE BRIEF, Feb. 2004, available at http://www.cmwf. org/usr_doc/Schur_under65.pdf, and (3) failure to cover particular expensive treatments, see Amy Dockser Marcus, Sorry, Only Half of That Surgery is Covered, WALl ST. J., Mar. 12, 2003, at D1.

343. Dorschner, supra note 342 (quoting Shalala's remarks).

344. Cf. id. (quoting researcher from the Kaiser Family Foundation as stating that "[b]asically, it's the same problem as the uninsured").

345. Comm. on the Consequences of Uninsurance, Inst. OF Med., Care Without Coverage: Too LitTle, Too LATE 7 (2002).

346. Id. at $7-13$.

347. Id. at 5. See also COMM. On the CONSEQuences of Uninsurance, Inst. Of Med., COVERAGE MATTERS: InS. AND HeAlth CARE 1 (2001).

348. The overlap between the underinsured and people enrolled in the types of benefit plans described in this Article has not been quantified, and its potential size should not be exaggerated. Certainly, without data, we cannot assume that most people enrolled in such plans are underinsured. 
health outcomes, including unnecessary hospitalizations, preventable disability, and shortened lives. ${ }^{349}$ Undoubtedly, the many questions regarding the effects of consumerism justify further careful research; the research to date is by no means definitive. Nonetheless, the existing research strongly suggests that any cost savings that consumerism generates for employers and healthy individuals will come largely at the expense of unhealthy persons. The next Part briefly examines possible bases for objecting to this discriminatory burden.

\section{CONNECTING THE DOTS ... AND MINDING THE GAPS}

This Article's fundamental focus has been to consider how the law addresses the phenomenon that, if permitted, health insurers will be least willing to provide health insurance to the people who need it the mostpeople with health problems. As explained in the previous sections, the justification for avoiding the risk of covering unhealthy people lies in an actuarial fairness vision of health insurance, which permits insurers to screen out or charge more to high-risk individuals. This vision, however, conflicts directly with a social solidarity vision of insurance, which emphasizes the social good that flows from the spreading of risk across the sick and well alike. By examining a broad range of antidiscrimination laws that constrain insurers' or employers' ability to classify risks on particular bases, Part III demonstrates that our society swears no absolute allegiance to principles of actuarial fairness. Instead, we are willing to provide groups with varying levels of protection against discrimination, but lack a consistent justification for doing so. In at least some instances, though, the law even protects groups against the discriminatory impact of particular coverage packages.

In the case of health-status discrimination, reforms enacted during the 1990s embodied social solidarity goals of increasing the ability of people with health problems to afford and maintain coverage, but these measures remained limited in scope. Moreover, laws prohibiting direct forms of health-status-based risk classification may have helped generate

349. A recent report relies on case studies to demonstrate how health insurance problems, including high cost sharing, can lead to severe medical and financial consequences for people with diabetes. Karen Pollitz et Al., Geo. Univ. Health Policy Inst. \& Am. Diabetes Ass'N,

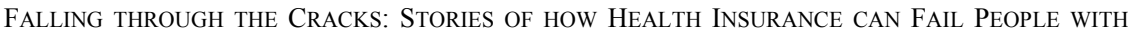
DIABETES (2005), available at http://www.healthinsuranceinfo.net/diabetes_and_health insurance.pdf. The occurrence of preventable complications has serious societal ramifications as well. In March 2005, a federal agency estimated that the United States could save almost \$2.5 billion each year by preventing diabetes-related hospitalizations. AGENCY FOR HEALTHCARE RESEARCH AND QUALITY, ECONOMIC AND HEALTH COSTS OF DIABETES (March 2005), http://www.ahrq.gov/data/hcup/highlight1/high1.htm. 
new coverage vehicles that instead discriminate against unhealthy people indirectly, by impact. Part V describes the consumerist trend in health coverage and presents evidence that the shifting of insurance risk that consumerist coverage mechanisms entail can be expected to disproportionately and negatively affect people with health problems. These effects are not limited to forcing unhealthy people to pay more money, but are likely to include stranding unhealthy people with even heavier burdens of ill health.

My central goal herein has been twofold: (1) to make the case that consumerist coverage mechanisms can be expected to mete out financial and health disadvantages in a lopsided fashion, with unhealthy people feeling the brunt of the disadvantage, and (2) to demonstrate that lawmakers have in numerous other instances been willing to intervene to protect groups of individuals from discrimination in health insurance. In other words, the Article seeks to show that a problem (the discriminatory impact of consumerist vehicles on unhealthy people) exists and can be expected to grow, and that our society has been willing to address other similar problems in the past. I recognize, however, that describing the greater burden imposed on unhealthy people as a problem depends on my own intuitions regarding fairness and that policy prescriptions need a basis far sturdier than intuition. While it is beyond the scope of this Article to explore fully the analytical foundations for objecting to this unequal burden, I will close by sketching two possible related approaches.

First, as this Article's title suggests, we might approach the plight of the unhealthy with respect to health insurance as essentially a problem of discrimination, as that term commonly is used in the context of civil rights legislation prohibiting discrimination in employment and other contexts. Indeed, we have seen that some of the existing laws regulating health-insurance discrimination are but pieces of larger efforts to end the unequal treatment of historically disadvantaged groups and extend to discriminatory impacts. On even brief reflection, however, it seems doubtful that a civil rights justification would adequately sustain policy initiatives to limit consumerism's impact.

Any civil rights law to advance the health insurance rights of "the unhealthy" would need to define precisely which persons can claim those rights, and this task alone might prove insurmountable. ${ }^{350}$ More

350. While this Article has used the term "the unhealthy" as shorthand to describe a large group of people who, for widely varying reasons, can be expected to generate large medical expenses, see supra note 9, legislation providing legal rights to members of this group would require far more definitional rigor. 
fundamentally, however, it is unclear to what extent the unhealthy have, as a group, suffered a history of discrimination by virtue of being unhealthy. Indeed, persons with chronic medical conditions (who are likely to constitute a large portion of the unhealthy) are effectively the product of modern medical advances permitting people with conditions like diabetes, hypertension, and heart disease to live for long periods with medical assistance. Nor is it clear that the unhealthy suffer substantial discrimination today in contexts other than health coverage. Of course, demonstrating a significant intersection between ill health and racial or ethnic minority status could conceivably bolster regulatory proposals to eliminate or mitigate the discriminatory impact of consumerism, but such proposals would seem to be both under and over inclusive. ${ }^{351}$ Finally, an effort to limit the disparate impact against the unhealthy that consumerist coverage vehicles produce would have to contend with the assertion that any disparate impact is justified by some sort of "actuarial necessity," akin to the "business necessity" that justifies a disparate impact in the employment setting. In sum, notwithstanding the rhetorical value of invoking the civil rights heritage, unhealthy people's current health insurance predicament does not seem at root to be a problem of existing social inequality.

Instead, concerns sparked by the growth of consumerism are more precisely concerns that its skewed allocation of benefits and burdens will create and aggravate social inequality. ${ }^{352}$ The objection is essentially that schemes imposing financial and health burdens on unhealthy persons, while offering financial benefits to healthy and wealthy persons, are inconsistent with leading theories of distributive justice. These schemes appear patently inconsistent with Rawls's "difference principle," which calls for a distribution of goods that maximizes the well-being of the most disadvantaged. ${ }^{353}$ Moreover, consumerist vehicles cannot easily be defended against charges of distributive injustice by assertions that the financial and health burdens complained of are simply the results of

351. See Hellman, supra note 128 , at 89 (making this point with respect to justifications for genetic discrimination laws). A similar attempt to highlight the overlap between the unhealthy and people with disabilities is likely to be fruitless, both because the Supreme Court's narrow interpretations of disability have shrunk that overlap and because the lower courts' narrow application of the ADA to insurance has deflated the law's significance in that context. See supra Part III.B.3.

352. Cf. Glenn, supra note 27, at 298-99 (noting the ability of insurance to create social and economic inequalities).

353. John RAWls, A Theory of Justice 75-80 (1971). See also Norman Daniels, Just HEALth CARE 46 (1985) (noting that justice requires the use of "resources to counter the natural disadvantages induced by disease"); Korobkin, supra note 184, at 802 (suggesting how Rawls would evaluate claims to a positive right to health care). 
natural endowments of poor health. Rather, they must be seen as steps away from earlier forms of health coverage - the baseline, so to speakin which individuals bore relatively little insurance risk for their medical expenses. $^{354}$

Thus, distributive justice arguments appear to provide a more fitting basis for objecting to consumerism's discriminatory impact on the unhealthy, but a number of issues with this approach remain to be resolved. Most prominently, debates about the contours and persuasiveness of distributive justice arguments remain contentious. For example, although many would agree that good health is morally arbitrary and not somehow deserved, sharp disagreement exists over the extent to which justice entitles the healthy to reap financial benefits from their undeserved good fortune. ${ }^{355}$ Furthermore, some would argue that justice permits holding individuals personally responsible for the positive and negative results of their chosen health-influencing behaviors; in other words, some among the unhealthy may deserve their ill health and its consequences. ${ }^{356}$ Finally, even if we could reach some level of agreement that the disproportionate financial and health burdens foisted on the unhealthy by consumerism are unjust, lengthy conversations about the proper remedial steps would ensue. ${ }^{357}$

\section{CONCLUSION}

As employers seek to contain their health-care costs and politicians create coverage mechanisms to promote individual empowerment, people with health problems increasingly are forced to shoulder the load of their own medical costs. The trend toward consumerism in health coverage shifts not simply costs, but also insurance risk, to individual insureds, and the results may be particularly dire for people in poor health. A growing body of research lends credibility to the contention that unhealthy people will disproportionately pay the price for consumerism, not only in dollars, but in preventable disease and

354. Cf. Orentlicher, supra note 219, at 419-20 (noting a societal choice "to allocate medical resources on the basis of wealth rather than medical need of the likelihood of receiving benefit").

355. See Hellman, supra note 19, at 400-02 (contrasting views of Rawls and Nozick)

356. Cf. Health Care Study Group, supra note 27, at 520-21 (noting this sentiment, as well as the difficulty in applying it fairly and efficiently).

357. The classic debate is whether redistributive goals are better advanced through regulation or by tax-and-transfer schemes. See Hellman, supra note 19, at 360 (noting the debate with respect to the use of domestic violence information in risk classification). For a thorough discussion of how the debate plays out in the context of genetic discrimination in insurance, see Kyle Logue \& Ronen Avraham, Redistributing Optimally: Of Tax Rules, Legal Rules, and Insurance, 56 TAX L. REV. 157 (2003). 
disability. In short, consumerist coverage vehicles discriminate against the unhealthy by impact, and existing laws protecting against healthstatus discrimination do not address impact discrimination. Although some might attempt to justify this impact by invoking the principle of actuarial fairness, a review of the various laws prohibiting discrimination in health insurance reveals our society's willingness to elevate other social values above actuarial fairness. This Article calls for more careful scrutiny of consumerism's effects and a sustained dialogue regarding the limits a just society should place on the burdens borne by unhealthy persons. 